\title{
LEONARDO SANTI
}

Estratégia reprodutiva e dinâmica populacional de Poecilochaetus australis Nonato, 1963 (Polychaeta, Spionida) em local sujeito à influência de efluentes urbanos não tratados, Baía de Guanabara, Rio de Janeiro, Brasil: Projeto Australis.

Tese apresentada ao Instituto Oceanográfico da Universidade de São Paulo, como parte dos requisitos para obtenção do título de Doutor em Ciências, área Oceanografia Biológica

Orientador: Prof. Dr. Paulo Yukio Gomes Sumida

São Paulo

2008 


\title{
Universidade de São Paulo \\ Instituto Oceanográfico
}

\begin{abstract}
Estratégia reprodutiva e dinâmica populacional de Poecilochaetus australis Nonato, 1963 (Polychaeta, Spionida) em local sujeito à influência de efluentes urbanos não tratados, Baía de Guanabara, Rio de Janeiro, Brasil: Projeto
\end{abstract} Australis.

\section{Leonardo Santi}

Tese apresentada ao Instituto Oceanográfico da Universidade de São Paulo, como parte dos requisitos para obtenção do título de Doutor em Ciências, área Oceanografia Biológica

Julgada em 1

Conceito

Conceito

Conceito

Conceito

Conceito 
"O correr da vida embrulha tudo, a vida é assim: esquenta e esfria, aperta e daí afrouxa, sossega e depois desinquieta. O que ela quer da gente é coragem"

Guimarães Rosa

"Natural history tells us unequivocally that we are foolish to look for general answers to specific questions about how organisms perform... At the organismic level the question are apt to be general and the answers specific."

Bartholomew, 1986 


\section{Agradecimentos}

À Universidade de São Paulo e ao Instituto Oceanográfico da Universidade de São Paulo pela excelente infra-estrutura, física e pessoal, disponível para a realização do presente trabalho.

Aos meu orientador Paulo Sumida por acreditar no meu projeto de pesquisa e estar sempre pronto a redimir dúvidas e auxiliar na minha pesquisa.

Aos colegas do laboratório, Angelo Bernardino, Marcos Yoshinaga, Cintia Quintana, Paula Moraes, Karin Elbers, Betina Alves e Arthur Guth pela ajuda constante na rotina do laboratório e pela motivação. Um especial agradecimento à Mariana Cussioli pela dedicação e precisão no trabalho de triagem da fauna.

À Clarice Leão, a grande Cacá, que sem pestanejar abraçou um carioca perdido em São Paulo dando dicas, idéias e conforto de amigo. Não poderia ter sido recebido por uma paulistana mais gabaritada que você. Não poderia esquecer o agregado do laboratório que por muito pouco não deixa de ser "peixólogo" e vira bentólogo. Falo do frango, Wellington Fernandes, que sempre esteve presente no bate-papo de todos os assuntos, fato importantíssimo neste período que vivemos. Valeu Frango. A Natalia Venturini pela amizade e apoio constantes.

A Universidade Santa Úrsula por facilitar o uso da estrutura da Universidade. Um especial agradecimento à pesquisadora e amiga prof ${ }^{a} \mathrm{Dr}^{\mathrm{a}}$. Elaine Figueiredo Albuquerque, pelo apoio incondicional em todas as etapas do trabalho.

Às secretária de pós-graduação Ana Paula e Silvana por serem extremamente competentes, atenciosas e prestativas na condução de suas funções que facilitou em muito o término do trabalho. Acreditem, sobra espaço para serem super-simpáticas! Obrigado também ao grande Tomazinho e ao incansável Walter Miyagi, ambos na mesma categoria.

Ao professor Edmundo Nonato que além da importância científica de suas descobertas, traz consigo a naturalidade dos grandes pesquisadores e professores: a facilidade e a felicidade em passar o conhecimento adquirido. Obrigado pela troca de idéias no laboratório.

À Cinthya Gomes Santos pelo apoio fundamental na fase final do trabalho, sem o qual seria muito mais penoso finalizar esta etapa. Obrigado. E em outra etapa anterior, agradecimento em especial à Ana Claudia Brasil por ter me incetivado a continuar apesar das dificuldades e contra-tempos. 
Aos meus parceiros de empresa (GSI Brooks) que por muitas vezes sacrificaram-se no meu lugar para que eu pudesse finalizar esta etapa da minha vida: Adriana Carvalho, Fernanda Rymer, Andrea Rocha, Anatole Trochimczuk, Maria Ester Paixão, Marcelo Barbosa, Leandro Dessoy, Leleco, João Duarte, Juliana Lira Andrade, Heitor Tozzi, Mariana Santiago, Marcus Seeliger, Mano e Carlão. Obrigado de coração, grande equipe.

Aos meus grandes amigos, Joel, Henrique Barbosa, Richard Brinn (Salim), Erik Rutledge (The Flash), André Pol, Paulinho, Chicre, Marcelo Negão, que em momento algum suspeitaram que eu pudesse desistir do desafio. Agradeço pela confiança e apoio constantes. Um agradecimento especial à minha namorada, Rosana. Ainda bem que a conheci em tempo. Seu carinho, paciência e motivação constantes fizeram da etapa final do trabalho a parte mais tranqüila de todas.

A minha família: Mammina, Dadá, Nando e Vera Lúcia, que sempre apoiaram e incentivaram a conclusão do meu trabalho.

Ao meu pai, seu André (Andrea Santi), que mesmo estando em outro plano, me traz a força de seu espírito trabalhador incentivando-me silenciosamente em momentos de fraqueza. Obrigado Babbo, você me ajudou e ainda continua presente nas etapas importantes da minha vida. 


\section{SUMÁRIO}

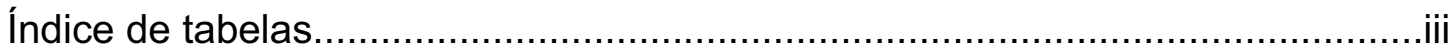

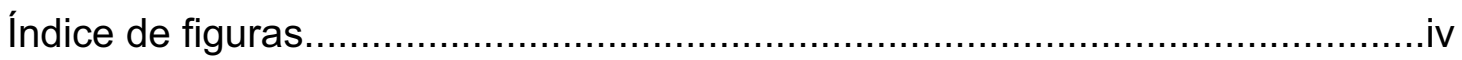

Resumo

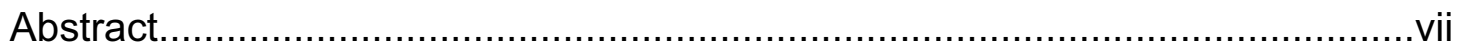

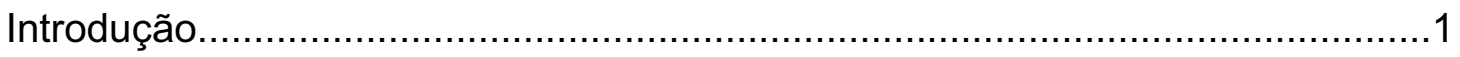

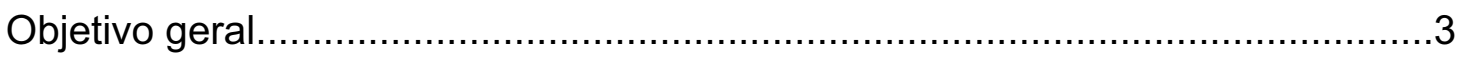

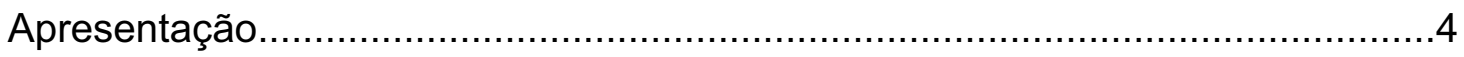

\section{CAPÍTULO 1}

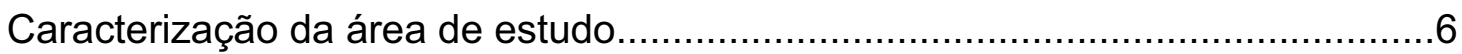

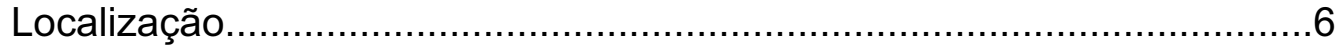

Estado ambiental da Baía de Guanabara..............................................

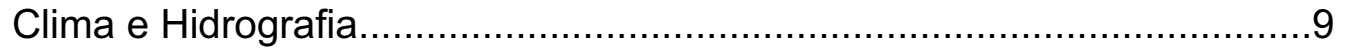

Características físicas e oceanográficas................................................10

Ponto de amostragem...........................................................................

Procedimentos de campo

Variáveis da coluna d'água.............................................................16

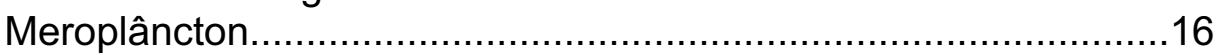

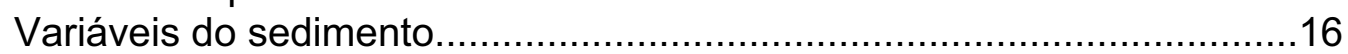

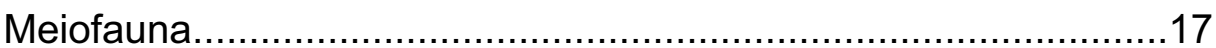

Macrofauna e Poecilochaetus.....................................................17

Análise das variáveis ambientais do sedimento............................................18

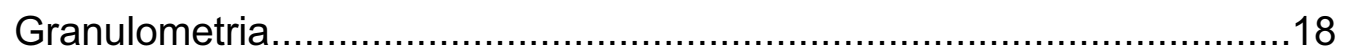

Matéria Orgânica Total (MOT).................................................18

Determinação dos pigmentos ( $\mathrm{Cl}$ a sedimentar e feopigmentos)............18

Processamento do material referente à biomassa microbiana......20

Análise estatística das variáveis ambientais.................................................21

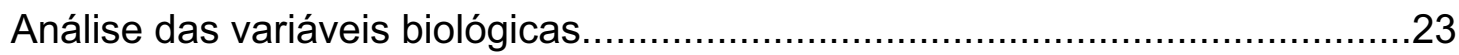

RESULTADOS

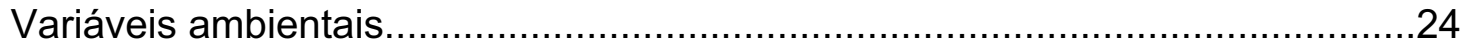

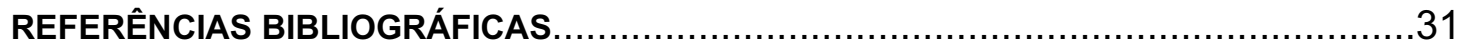




\section{CAPÍTULO 2}

Análise taxonômica do gênero Poecilochaetus e sua distribuição na costa

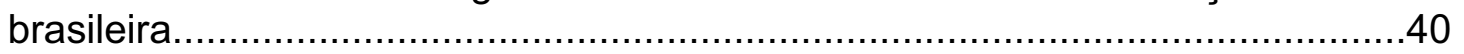

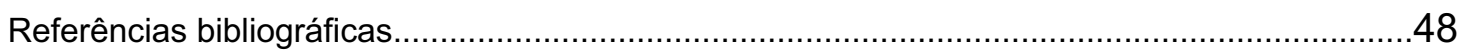

\section{CAPÍTULO 3}

Dinâmica estrutural da macroinfauna bêntica sublitoral em local sujeito à influência de efluentes urbanos não-tratados, Baía de Guanabara, Rio de Janeiro, Brasil.......................................................................................53

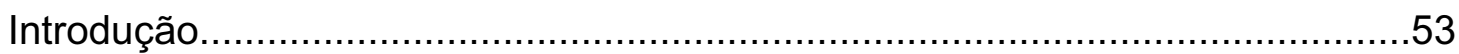

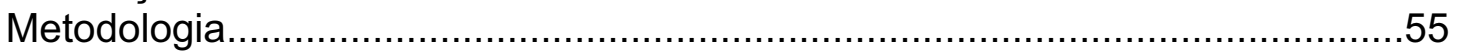

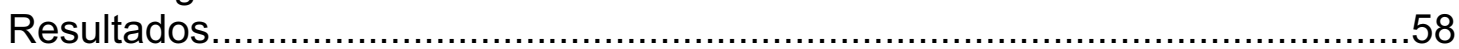

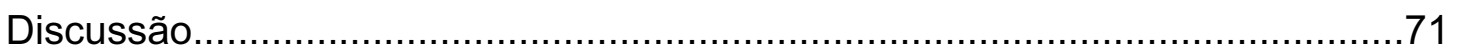

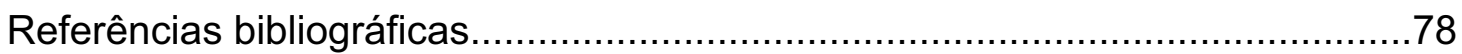

\section{CAPÍTULO 4}

Estratégia reprodutiva de uma população de Poecilochaetus australis Nonato, 1963 (Annelida, Spionida) na Baía de Guanabara, Rio de Janeiro,

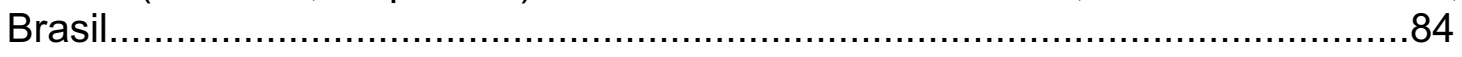

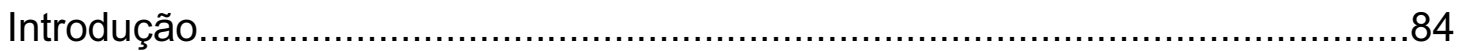

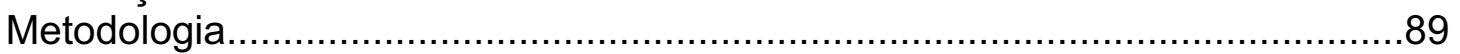

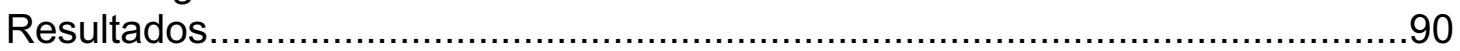

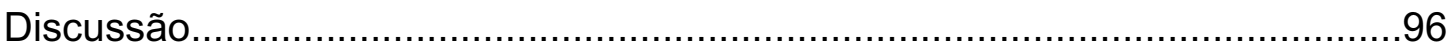

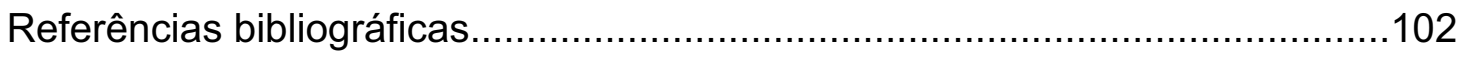

\section{CAPÍTULO 5}

Dinâmica populacional de Poecilochaetus australis Nonato, 1963 (Polychaeta Spionida) na Baía de Guanabara, Rio de Janeiro,

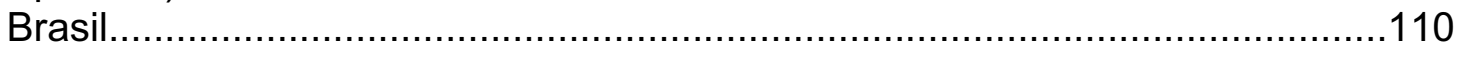

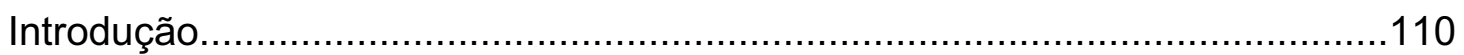

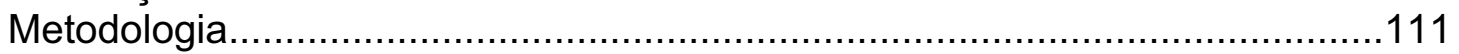

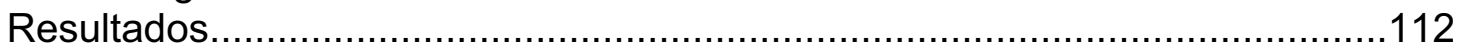

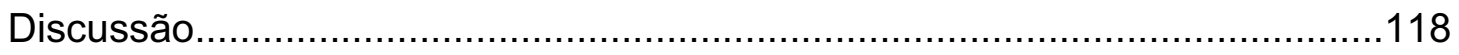

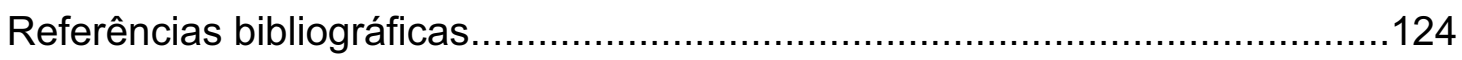

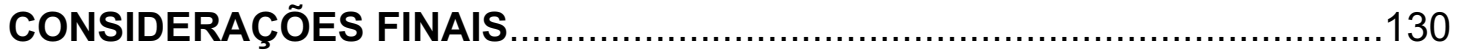




\section{Índice de tabelas}

Tabela 1.1. Variáveis ambientais da coluna d' água obtidos durante as campanhas oceanográficas realizadas até o mês de Maio de 2006

Tabela 1.2. Análise granulométrica obtida nos 12 meses de amostragem: Junho de 2005 a Maio de 2006.

Tabela 1.3. Resultados da análise ANOSIM para os fatores $A, B, C$ e $D$ (Outono, Inverno, Primavera e Verão) e a afinidade entre os resultados das amostras das variáveis ambientais obtidas em cada um dos 12 meses.

Tabela 2.1. Locais de ocorrência de Poecilochaetus australis Nonato, 1963 na costa brasileira citados na literatura.

Tabela 3.1. Táxons dominantes ( $\geq 10 \%$ de contribuição) em pelo menos 1 dos 12 meses de coleta. Os valores representados na tabela apresentam a abundância média no mês.

Tabela 3.2. Percentual de similaridade obtido através da análise SIMPER (percentuais de contribuição dos táxons) em todos os meses estudados.....

Tabela 3.3. Resultado da análise BIOENV (Biota and Environmental matching) realizada entre as matrizes ambientais e biológica (abundância da macroinfauna) utlilizando a correlação de Spearman..

Tabela 4.1. Tamanho médio dos ovócitos mensurados entre os meses amostrados. .92

Tabela 4.2. Análise de variância (ANOVA unifatorial) do tamanho dos ovócitos entre os meses coletados. Interseção entre os meses (barras horizontais) indica diferença significativa $(p<0,01)$.

Tabela 4.3. Larvas de Polychaeta e de Poecilochaetus sp. encontradas entre Junho de 2005 e Maio de 2006

Tabela 5.1. Resultados obtidos através da correlação de Spearman $\left(r_{s}\right)$ entre a abundância total e as variáveis ambientais da coluna d água e sedimento ao longo do período estudado. .114

Tabela 5.2. Classes de tamanho identificadas ao longo do ano 


\section{Índice de figuras}

Figura 1.1. Mapa da Baía de Guanabara evidenciando o ponto de amostragem do presente trabalho.

Figura 1.2: Exemplo de curva padrão utilizada para estimar a concentração de ATP nas amostras.

Figura 1.3. Concentração de Matéria Orgânica Total (MOT \%) encontrada entre Junho de 2005 e Fevereiro de 2006.

Figura 1.4. Concentrações de clorofila-a nos primeiros $10 \mathrm{~cm}$ de sedimento de Junho de 2005 a Janeiro de 2006.

Figura 1.5. Concentrações de feopigmentos nos primeiros $10 \mathrm{~cm}$ de sedimento de Junho de 2005 a Janeiro de 2006.

Figura 1.6. Baía de Guanabara. Biomassa microbiana nos sedimentos superficiais. .28

Figura 1.7 - Cluster (distância euclidiana) e mapa MDS bi-dimensional evidenciando o grau de similaridade dos resultados obtidos de todas as variáveis ambientais nos 12 meses estudo......29

Figura 2.1. Esquema dos caracteres morfológicos da família Poecilochaetidae. .44

Figura 2.2. Cerdas família Poecilochaetidae...

Figura 2.3. A, região anterior de Poecilochaetus perequensis Santos \& Mackie, 2008 evidenciando a carúncula trilobada com lobos laterais subiguais. B, região anterior de Poecilochaetus australis Nonato, 1963.

Figura 3. 1. - Percentual de contribuição dos táxons mais representativos encontrados no período estudado.

Figura 3.2. Abundância total de indivíduos da macroinfauna. .59

Figura 3.3. Abundância média de indivíduos da macroinfauna coletados ao longo dos 12 meses.

Figura 3.4. Abundância relativa dos táxons mais representativos da macroinfauna coletada ao longo do período de coleta.

Figura 3.5. Contribuição em número de indivíduos dos 13 táxons dominantes e sua distribuição ao longodo período estudado.

Figura 3.6. Curva de dominância cumulativa da macroinfauna plotando-se os 12 meses de coleta.......

Figura 3.7. Distribuição do percentual de contribuição da abundância dos 13 táxons dominantes de Junho de 2005 a maio de 2006.

Figura 3.8. Riqueza específica ao longo do período de coleta. Nota: barras verticais representam o desvio padrão. 
Figura 3.9. Diversidade específica de Shannon-Wiener (bits por indivíduo) ao longo do período de coleta

Figura 3.10. Similiaridade entre os meses de coleta levando-se em consideração os dados de abundância da macroinfauna coletadas no período estudado.

Figura 3.11. Mapa bi-dimensional MDS dos meses de coleta utilizando os dados de abundância da macroinfauna coletadas no período estudado.

Figura 3. 12. Galerias e tubos de (A, B) camarões thalassinídeos, (C) Caranguejo ocypoda, (D$\mathrm{G})$ poliquetas, $(\mathrm{H})$ ofiuróide, $(\mathrm{I})$ holotúria ápoda e $(\mathrm{J})$ e uma staphylinid.

Figura 3. 13. Diagrama representando o tubo de Poecilochaetus australis e a respectiva fauna associada dominante encontrada ao longo do período estudado.

Figura 4.1. A, aspecto macroscópico do preenchimento dos setígeros maduros por gametas masculinos; B, massa de espermatozóides vista ao microscópio óptico; C, disposição do canal nefridial com ovócitos em desenvolvimento nos parapódios medianos; D, canal nefridial com ovócitos em fase inicial de desenvolvimento; E, canal nefridial e ramificações deste canal evidenciando ovócitos bem desenvolvidos porém ainda imaturos; $\mathbf{F}$, ovócito maduro livre na cavidade celomática e ovócito imaturo ainda preso ao canal nefridial; G, ovócito maduro evidenciado as vesículas internas fechadas; $\mathbf{H}$, ovócito maduro.

Figura 4.2. Número de fêmeas maduras observadas de junho de 2005 a maio de 2006 93

Figura 4.3. Tamanho dos ovócitos encontrados durante o período amostral.....

Figura 4.4. Larva de Poecilochaetus sp. com 25 setígeros. 95

Figura 5.1. Abundância de larvas de Poecilochaetus coletadas entre Junho de 2005 e Maio de 2006.

Figura 5.2. Densidade de Poecilochaetus australis encontrada entre julho de 2005 e maio de 2006.

Figura 5.3. Fotografias digitais demonstrando as classes de tamanho de Poecilochaetus australis. Escala: $1.0 \mathrm{~mm}$. 116

Figura 5.4. Distribuição relativa dos indivíduos de Poecilochaetus australis em classes de tamanho (D 7) na Baía de Guanabara. Nota: eixo y = frequência (\%).

Figura 5.5. Padrão de recrutamento obtido através da curva de crescimento de Von Bertalanffy para Poecilochaetus australis entre junho de 2005 e maio de 2006. 


\section{Resumo}

A Baía de Guanabara é um dos ecossistemas costeiros mais impactados do mundo. Apesar da fauna sublitoral de substratos inconsolidados ser amplamente utilizada como ferramenta ao monitoramento dos impactos de efluentes urbanos, pouco se sabe sobre a biologia das espécies dominantes. Foram analisadas amostras de variáveis ambientais e biológicas da coluna d'água e do sedimento através de coletas mensais ao longo de um ano em uma estação fixa na Baía de Guanabara (ca. $12 \mathrm{~m}$ de profundidade), com objetivo de compreender a estratégia reprodutiva e a dinâmica populacional da espécie Poecilochaetus australis (Annelida: Polychaeta) em local sujeito à influência de efluentes urbanos não-tratados. Os resultados das variáveis ambientais demonstraram pequena flutuação. $O$ sedimento foi composto essencialmente por frações finas de silte e argila com grãos pobremente selecionados, altas concentrações de matéria orgânica total, clorofila-a sedimentar e intensa atividade microbiana na camada superficial. A comunidade foi composta essencialmente por organismos tubícolas e sofreu pouca variação estrutural ao longo do tempo, sendo dominada pelos poliquetas $P$. australis, Spiochaetopterus nonatoi, Aricidea suecica simplex, Prionospio steenstrupii, pelos anfípodes Tiburonella viscana e uma espécie não identificada da família Corophiidae, uma espécie de isópode da família Anthuridae, o braquiúro Pinnixa sp. e o cladócero Daphnia sp. Não foram verificadas diferenças temporais significativas entre as riquezas e as diversidades específicas. Os valores médios de riqueza e a diversidade específica ficaram entre 15 táxons e 2,77 bits por indivíduo, respectivamente. Houve investimento reprodutivo contínuo das fêmeas de $P$. australis. A menor fêmea madura $\left(0,8 \mathrm{~mm}\right.$; largura do $7^{\circ}$ setígero - D7) foi encontrada em junho de 2005. Grande parte dos indivíduos maduros concentrou-se entre 1,1 e 1,3 mm D7. Os maiores ovócitos foram encontrados no mês de dezembro de 2005 com 163 $\mu \mathrm{m}$ de diâmetro, e os menores em março de 2006 com $115 \mu \mathrm{m}$. Foram observadas diferenças significativas no grau de desenvolvimento dos ovócitos ao longo do ano com amadurecimento dos ovócitos de um mês para o seguinte. Os ovócitos tenderam a atingir seu ápice de desenvolvimento em dezembro de 2005. Não foi possível determinar sincronismo entre as fêmeas maduras. Não houve variabilidade mensal significativa da abundância de $P$. australis. O tamanho médio dos 1575 indivíduos amostrados de $P$. australis ficou em $0,71 \mathrm{~mm}$ D7 $(\mathrm{dp}=0,36)$. Foram identificadas oito classes de tamanho. O maior indivíduo foi uma fêmea com $1.5 \mathrm{~mm} \mathrm{D7}$ e os menores foram encontrados entre as larvas planctônicas com 0,15 mm D7 e nos recrutas do sedimento com $0,20 \mathrm{~mm}$ D7. Em todos os meses, as classes de tamanho inferiores $(0,20-0,55 \mathrm{~mm})$ estiveram presentes, sendo responsáveis por grande parte da densidade encontrada. O tamanho assintótico de $P$. australis ficou em $0,97 \mathrm{~mm} \mathrm{D7}$, sendo que $79,1 \%$ dos indivíduos encontraram-se neste ou abaixo deste tamanho. A constante de crescimento $\mathrm{K}$ ficou em 1,7. A taxa de mortalidade ficou em 3,12. Em grande parte do período estudado houve contribuição expressiva de recrutas na abundância de indivíduos, sem que as classes de tamanho maiores fossem excluídas. A população manteve-se estável, já que foi capaz de manter simultaneamente adultos com potencial reprodutivo e alta disponibilidade de larvas e recrutas em ambiente propício ao desenvolvimento, crescimento e reprodução. Não foi encontrado nenhum resultado que apontasse ciclo de vida do tipo oportunista.

Palavras-chave: macroinfauna sublitoral, Polychaeta, biologia reprodutiva, dinâmica populacional, enriquecimento orgânico, poluição. 


\begin{abstract}
Guanabara Bay is one of the most human impacted coastal ecosystems in the world. Despite the wide use of sublittoral soft bottom fauna on urban sewage monitoring programs, little is known about the biology of dominant species. Water column and sediment environmental and biological variables were monthly analyzed in a permanent station in Guanabara Bay (ca. $12 \mathrm{~m}$ depth) in order to understand the reproductive ecology and population dynamics of Poecilochaetus australis (Annelida: Polychaeta) in a grossly sewage impacted area. Environmental variables showed only minor fluctuations. Surface sediments were composed of poorly sorted silt and clay fractions, with high concentrations of total organic matter, chlorophyll-a and microbial biomass. The softbottom community structure showed only small, non-significant temporal variations with a large abundance of tube dwellers. Macroinfauna was dominated by the polychaetes $P$. australis, Spiochaetopterus nonatoi, Aricidea suecica simplex and Prionospio steenstrupii; the amphipods Tiburonella viscana and a non-identified species of the family Corophiidae; a species of the isopod family Anthuridae; the brachiuran Pinnixa $\mathrm{sp}$; ; and the cladoceran Daphnia sp. There were no significant temporal differences in species richness and diversity. Mean values for these two parameters were 15 taxa and 2.77 bits ind. $^{-1}$, respectively. Reproductive output was continuous in $P$. australis females. The smallest ripe female $\left(0.8 \mathrm{~mm} ; 7^{\text {th }}\right.$ setiger width $\left.-\mathrm{D} 7\right)$ was found in June 2005 . Most mature individuals measured between 1,1 and $1,3 \mathrm{~mm}$ D7. The largest oocytes were found in December 2005 measuring $163 \mu \mathrm{m}$ in diameter. The smallest ones were 115 $\mu \mathrm{m}$ and occurred in March 2006. Significant temporal differences were found in oocyte development with fully matured oocytes occurring every month. However, most oocytes were mature in December 2005. Analysis of ripe females did not show synchronous development. There were no significant differences in numerical abundance of $P$. australis. Mean D7 size was $0.71 \mathrm{~mm}(\mathrm{SD}=0,36 ; \mathrm{N}=1575)$. Eight size classes were identified, with the largest individual a female $1.5 \mathrm{~mm} \mathrm{D7}$. The smallest individuals were a planktonic larva $0.15 \mathrm{~mm} \mathrm{D7}$ and a recently settle recruit $0.20 \mathrm{~mm}$ D7. The smallest size classes $(0.20-0.55 \mathrm{~mm} \mathrm{D} 7)$ were present throughout the sampling period, responding for most of the individuals collected. $P$. australis asymptotic size was 0.97 $\mathrm{mm}$ D7, with over $79 \%$ being smaller or at this size. The growth constant $\mathrm{K}$ was 1.7 and the mortality rate 3.12. There was a large contribution of newly settled recruits on all studied months. The population was stable, showing the presence of mature adults and a high availability of larvae and recruits. There was no evidence of an opportunist type life cycle for $P$. australis.
\end{abstract}

Key-words: sublittoral macroinfauna, Polychaeta, reproductive biology, population dynamics, organic enrichment, pollution. 


\section{Introdução}

O presente trabalho teve origem durante a execução de projeto BIOPLAT (Biodiversidade e Biomassa da Plataforma Continental Brasileira), realizado na Baía de Guanabara através de coletas trimestrais entre os anos de 2000 e 2001. Os resultados encontrados evidenciaram um grande banco de poliquetas sublitorais do gênero Poecilochaetus Claparède, 1875, apresentando densidade e biomassa jamais encontrados anteriormente na costa brasileira (SANTI, 2003, 2007, 2008). Esta espécie é referida na literatura como uma espécie rara, com ocorrência fragmentada ao longo da nossa costa e animais de pequeno tamanho e biomassa corpórea. A densidade e o tamanho dos animais encontrados levantaram diversos questionamentos sobre a possível influência de elevadas cargas de compostos orgânicos provenientes dos efluentes urbanos não tratados sobre a macroinfauna bêntica e o ciclo de vida dos poliquetas sublitorais em resposta a tais estímulos. Após verificação da ocorrência da espécie ao longo da costa brasileira, foi constatado que o gênero Poecilochaetus ocorria com frequência nas enseadas de Ubatuba, litoral norte de São Paulo, porém de forma fragmentada e em em baixas densidades.

O levantamento bibliográfico revelou uma grande lacuna de informações, tanto taxonômicas como da história de vida, onde somente um trabalho datado do início do século passado (ALLEN, 1904) traz informações biológicas importantes e bem detalhadas da família Poecilochaetidae através de Poecilochaetus serpens, espécie ainda não registrada em nossa costa.

Para tentar preencher algumas destas lacunas, o presente trabalho se propôs a levantar evidências sobre a identidade taxonômica dos animais coletados na Baía de Guanabara e Ubatuba, como também entender a dinâmica populacional e o ciclo de vida dos indivíduos encontrados em altas densidades na Baía de Guanabara e compará-las com aquela encontrada no litoral norte do estado de São Paulo.

Em recente estudo realizado na Baía de Guanabara (Rio de Janeiro/RJ), a espécie Poecilochaetus australis Nonato, 1963 teve distribuição relativamente homogênea, porém com densidades extremamente elevadas nas estações de coleta localizadas nas proximidades de despejos de esgotos não 
tratados de origem doméstica (SANTI, 2008a, 2008b). Nonato (1963) descreveu esta espécie através de exemplares coletados em sedimento lodoarenoso contendo $30 \%$ em peso constituído por minerais metálicos como ferro e titânio na Enseada do Flamengo, Ubatuba, litoral norte do estado de São Paulo. No canal de Santos, maior área portuária do Brasil e uma das maiores cidades brasileiras, $P$. australis foi encontrada em altas densidades nas proximidades de locais onde havia despejo de esgotos domésticos, em sedimentos pobremente selecionados e alto teor de calcário e cálcio (TOMMASI, 1967). Tais observações sugerem que esta espécie ocupa nichos ecológicos muito estreitos e raramente utilizáveis por outras espécies, utilizando-se de estratégias biológicas que sustentam sua permanência em ambientes letais às demais espécies.

O status taxonômico desta espécie tem sido questionado, principalmente pela falta de exemplares completos. Informações importantes da morfologia da espécie são encontrados essencialmente na região posterior do animal (RIBEIRO, 2004; SANTI, 2006). Entretanto, a grande maioria das identificações dos exemplares coletados na costa brasileira deu-se através de indivíduos incompletos. Devido à fragilidade do animal e à falta de cuidado em preservar a integridade do indivíduo para estudos taxonômicos mais precisos, as informações sobre a ocorrência da espécie são questionáveis. Recentemente, duas novas espécies foram descritas para a costa brasileira (MACKIE; SANTOS, 2008), aumentando a margem de incerteza a respeito de sua distribuição.

Além da descrição detalhada biologia da espécie Poecilochaetus serpens (ALLEN, 1904), não há nenhum outro estudo sobre a biologia, história de vida, dinâmica populacional e estratégias reprodutivas das demais espécies desta família. BLAKE \& ARNOFSKY (1999) utilizaram informações sobre a biologia reprodutiva das espécies na interpretação filogenética dos Spionida, utilizando porém poucas evidências da família Poecilochaetidae. Existe portanto, carência de informação sobre a biologia desta espécie que possa auxiliar tanto aos estudos filogenéticos como ecológicos.

Muito embora estudos autoecológicos contribuam substancialmente para o entendimento do ecossistema bêntico, um exame mesmo que breve da literatura revela uma imensa lacuna sobre a estratégia reprodutiva e o 
conhecimento da dinâmica populacional de espécies de poliquetas sublitorais em substratos inconsolidados na costa brasileira.

A falta destes estudos gera uma demanda crescente para o desenvolvimento de parâmetros consistentes, que possam auxiliar na interpretação dos padrões espaço-temporais da macroinfauna sublitoral em regiões tropicais, cada vez mais sujeitas à influência de distúrbios ambientais de origem humana.

\section{Objetivo geral}

O presente estudo tem como objetivo geral contribuir para o entendimento funcional dos ecossistemas bênticos costeiros através do estudo taxonômico e ecológico, como também da estratégia reprodutiva e da dinâmica populacional de Poecilochaetus australis, presente em densidade e biomassa extremamente elevadas, em local sujeito à influência de efluentes urbanos nãotratados. 


\section{Apresentação}

Em função das diferentes abordagens, o presente trabalho foi dividido em capítulos a fim de facilitar o entendimento da problemática apresentada.

No capítulo 1 são apresentadas a caracterização da área de estudo, estratégia amostral, procedimentos de campo, metodologia de análise das variáveis ambientais e biológicas e seus respectivos resultados parciais.

No capítulo 2 são apresentadas a análise taxonômica do gênero Poecilochaetus e sua distribuição na costa brasileira, no intuito de esclarecer a ocorrência da espécie e sua identidade taxonômica, visto que trabalhos recentes apontam dúvidas a cerca das identificações de exemplares desta família ao longo da nossa costa.

- A espécie encontrada na Baía de Guanabara e na região de Ubatuba, litoral norte de São Paulo, é Poecilochaetus australis?

No capítulo 3 a "Dinâmica estrutural da macroinfauna bêntica sublitoral em local sujeito à influência de efluentes urbanos não-tratados" foi estudada ao longo do período de coleta do presente trabalho. O objetivo deste capítulo foi verificar se existe oscilação da estrutura básica da comunidade bêntica na qual $P$. australis está inserida.

- Qual a estrutura e a dinâmica temporal da macroinfauna sublitoral na qual a espécie Poecilochaetus australis se encontra na Baía de Guanabara ao longo do ano? Há estabilidade estrutural da macroinfauna?

A "Estratégia reprodutiva da espécie Poecilochaetus australis Nonato, 1963 (Polychaeta: Spionida)" é apresentada no capítulo 4, fornecendo informações sobre o ciclo de vida da espécie que evidenciam o grau de adaptação da espécie e sua manutenção no ambiente.

- Quais seriam as adaptações biológicas desta espécie que favorecem o sucesso desta população na Baía de Guanabara? Qual a estratégia reprodutiva desta população? Teria a espécie em questão adotado hábito 
reprodutivo típica de espécies oportunistas? A reprodução é contínua (politélico)?

No capítulo 5 a "Dinâmica populacional de Poecilochaetus australis Nonato, 1963 (Annelida, Spionida) na Baía de Guanabara, Rio de Janeiro, Brasil" foi estudada a fim de obter informações a respeito da manutenção desta população ao longo do ano e sua contribuição para a manutenção da comunidade sublitoral.

- Qual a dinâmica populacional de $P$. australis na Baía de Guanabara ao longo do ano? Existe algum período do ano que é visível a introdução de recrutas no ambiente? Caso positivo, quando?

Na última parte do trabalho são apresentadas as "Considerações finais" que descrevem os principais resultados obtidos, assim como propostas de estudos para esta espécie. 


\section{CAPÍTULO 1}

\section{Caracterização da área de estudo}

\section{Localização}

A Baía de Guanabara situa-se no estado do Rio de Janeiro entre as latitudes $22^{\circ} 41^{\prime} S$ e $22^{\circ} 58^{\prime} S$ e os meridianos de $043^{\circ} 02^{\prime} \mathrm{W}$ e $043^{\circ} 18^{\prime} \mathrm{W}$. A sua bacia de drenagem, denominada Bacia da Guanabara, está localizada entre as latitudes $22^{\circ} 24^{\prime} \mathrm{S}$ e $22^{\circ} 57^{\prime} \mathrm{S}$ e longitudes $042^{\circ} 33^{\prime} \mathrm{W}$ e $043^{\circ} 19^{\prime} \mathrm{W}$. Engloba toda a região metropolitana do Rio de Janeiro, incluindo total ou parcialmente os municípios do Rio de Janeiro, Niterói, São Gonçalo, Itaboraí, Rio Bonito, Cachoeiras de Macacu, Guapimirim, Magé, Petrópolis, Duque de Caxias, São João de Meriti, Nova Iguaçu, Nilópolis e Queimados (Figura 1).

Segundo o Instituto Brasileiro de Geografia e Estatística - IBGE (1991), a totalidade da população dos municípios que integram a área de influência direta e indireta da Baía de Guanabara era de 9.620.000 habitantes em 1990. Estima-se que desse total, cerca de $76 \%$ corresponda à população da Bacia contribuinte da Guanabara, ou seja, cerca de 7,3 milhões de habitantes.

\section{Estado ambiental da Baía de Guanabara}

A Baía de Guanabara é a mais proeminente baía brasileira. Apesar de sua importância histórica, econômica, cultural e científica, está entre os ecossistemas costeiros mais degradados do país.

Pouco antes da colonização européia, o quadro ambiental era completamente distinto do encontrado recentemente. A Mata Atlântica ocupava cerca de $73,91 \%$ da superfície da bacia da Baía de Guanabara a qual era sulcada por cerca de 55 rios e córregos, que a ela chegavam diretamente e por dezenas de afluentes. Os manguezais cobriam aproximadamente $257 \mathrm{~km}^{2} \mathrm{da}$ orla da Baía. No litoral da Guanabara existiam cerca de 39 lagunas costeiras. As restingas, terraços marinhos e dunas se estendiam por uma superfície de cerca de $132 \mathrm{~km}^{2}$ (2,89\% da superfície da Baía). Existiam cerca de 118 praias, além de uma série de saliências e reentrâncias do litoral, formando promontórios, pontões, enseadas, sacos, estuários e gamboas (AMADOR, 1997). 
O processo de degradação assumiu uma escala mais drástica nas últimas décadas, com o pleno desenvolvimento urbano-industrial. Percebe-se, quanto ao grau de urbanização atual, que a área em questão possui um perfil eminentemente urbano, visto que a maioria dos municípios apresenta taxa de urbanização de $100 \%$ ou bem próxima a este valor (FUNDAÇÃO GETÚLIO VARGAS, 2000). Recentemente, um levantamento dos focos de risco potencial de ameaça ambiental no estado, realizado pelas comissões de Meio Ambiente da Assembléia Legislativa e da Câmara Municipal do Rio, revelaram que existem pelo menos 35 pontos de alto risco, grande parte deles inseridos na área de influência da Bacia da Guanabara. As estações de tratamento de esgoto processam somente $15 \%$ dos efluentes fazendo com que as águas da Baía recebam rejeitos domésticos de aproximadamente 6 milhões de pessoas (KJERFVE et al., 1997). PARANHOS et al. (1995) destacaram que a poluição doméstica é considerada como o pior problema ambiental da Baía. As altas taxas de nutrientes que alcançam as suas águas resultaram em sua eutrofização (REBELLO et al., 1988; LAVRADO et al., 1991), ao passo que a captura de recursos pesqueiros sofreu um declínio de 10\%, atingindo um patamar de três décadas atrás (FEEMA, 1990), apesar do esforço de pesca ter aumentado. Aproximadamente 6.000 toneladas de lixo são geradas ao redor da Baía diariamente. Grande parte dos rejeitos da região são depositados no aterro sanitário de Gramacho, em Duque de Caxias, que sofre constantes denúncias a respeito da contaminação do lençol freático. O seu entorno imediato é ocupado por aproximadamente 6.000 industrias, além de 6.000 outras instaladas em uma área aproximada de $4.080 \mathrm{~km}^{2}$ de sua bacia de drenagem. Duas refinarias de petróleo instaladas às margens da Baía processam $17 \%$ do petróleo nacional. Uma grande indústria de beneficiamento de sardinha, localizada na cidade de Niterói, processa toneladas de pescado por ano. A intensa atividade portuária na Baía requer a dragagem contínua da área portuária para manter uma profundidade média de 17 metros.

A demanda contínua e crescente por mais espaço vem infringindo à Baía severas reduções na sua superfície. Desde o início do século XVI, mais de $10 \%$ do espelho d'água da Baía foram perdidos. As bacias fluviais vêm sendo modificadas desde o início da colonização, tendo estas intervenções se tornado mais dramáticas, no entanto, a partir do início do século $\mathrm{XX}$, quando os 
rios das pequenas bacias urbanas passaram a ser canalizados e os maiores rios da Baixada dragados e retilinizados. Como conseqüência, os antigos canais-de-maré deram lugar a canais inteiramente retilíneos. AMADOR \& KIFFMANN (1978) observaram que os canais meândricos foram encurtados em mais de três vezes, fazendo com que os cursos fluviais tivessem aumentada a capacidade de transporte de carga sólida para a Baía. Estima-se que 18 toneladas diárias de hidrocarbonetos, dos quais $85 \%$ de origem urbana, são carreados para a Baía. Grandes quantidades de sólidos em suspensão, matéria orgânica e metais pesados são despejados na Baía e acumulados no sedimento.

Em janeiro de 1975, num acidente com o navio Tarik Ibn Ziyad, a Baía foi a protagonista do segundo maior derramamento de óleo ocorrido no Brasil. Em janeiro de 2000, um acidente na refinaria de Duque de Caxias resultou no derrame de 1,3 milhão de litros de óleo nas águas da Baía causando um impacto ecológico sem precedentes na região. Quinze dias após o acidente, mais de $30 \%$ dos $90 \mathrm{~km}^{2}$ de praias e manguezais circunvizinhos estavam contaminados.

As águas da Baía de Guanabara apresentam-se extremamente eutrofizadas devido às elevadas taxas de entrada de nutrientes, na forma de amônia e fosfato, oriundos do esgoto doméstico (QUIROGA, 1999). Os altos níveis de matéria orgânica no sedimento da Baía de Guanabara estão associados ao despejo contínuo de esgoto e efluentes industriais, levando o sedimento superficial a condições subóxicas a anóxicas (SILVA et al., 2008). A concentração de amônia pode variar até dez vezes e a de fosfato cinco vezes entre as regiões interna e externa da Baía (REBELLO et al., 1988; LAVRADO et al., 1991; KJERFVE et al., 1997). Um reflexo desta eutrofização é a elevada concentração de clorofila, que excede $130 \mu \mathrm{g} \mathrm{L}^{-1}$, apresentando uma média global de $57 \mu \mathrm{g} \mathrm{L}^{-1}$ (REDUC/DTSE, 2000). Paranhos et al. (1995) constataram que a média de coliformes fecais variou de 103 a $108 \mathrm{~L}^{-1}$ entre os anos de 1980 e 1990, refletindo também o grande volume de despejo de esgotos domésticos. ANDRADE et al. (2003) encontraram valores de atividade bacteriana de até $7,35 \mu \mathrm{g} \mathrm{C} \mathrm{L} \mathrm{L}^{-1} \mathrm{~h}^{-1}$ em locais situados na parte interna e com baixa circulação de marés da Baía de Guanabara. O despejo de esgoto não tratado no Canal do Mangue da Baía de Guanabara tem favorecido o aumento da carga orgânica e 
a manutenção de coliformes totais e fecais nos sedimentos superficiais (SILVA et al., op. cit.).

\section{Clima e Hidrografia}

Em função de sua localização geográfica, o território da Bacia da Guanabara está inteiramente compreendido na área intertropical e, em decorrência, possui um clima quente e chuvoso, tipicamente tropical. Não obstante, apesar das dimensões relativamente reduzidas da Bacia da Guanabara, nela ocorrem praticamente todos os tipos climáticos brasileiros, que tenham por base a temperatura (AMADOR, 1997).

Podem ser notadas duas estações (períodos) bem definidas. Uma úmida (chuvosa), entre dezembro e abril, e outra seca, de junho a agosto (PARANHOS; MAYR, 1993; CPTEC/ INPE, 2002). Durante os meses de verão austral, fortes chuvas podem alcançar $10 \mathrm{~mm}$ em poucas horas, produzindo um intenso processo de drenagem e lixiviação continental (ALCÂNTARA; WASHINGTON, 1989).

A precipitação média observada na bacia de drenagem durante 30 anos (1961-1990) variou de $291 \mathrm{~mm} / \mathrm{mês}$ na região montanhosa a um valor mínimo de $30 \mathrm{~mm} /$ mês na estação metereológica do aterro do Flamengo nos períodos secos de inverno (KJERFVE et al., 1997).

A Bacia da Guanabara possui uma superfície aproximada de 4.080 $\mathrm{km}^{2}$, constituindo-se por 32 sub-bacias e respondendo pela drenagem de 45 rios e córregos. Destes, seis respondem por $85 \%$ da descarga dos aportes continentais (KJERFVE et al., op. cit.). Anualmente, a descarga líquida média afluente à Baia de Guanabara é da ordem de $351,48 \mathrm{~m}^{3} / \mathrm{s}$, oscilando entre o mínimo de $166,8 \mathrm{~m}^{3} / \mathrm{s}$ no mês de agosto, característico do inverno, e de 551,7 $\mathrm{m}^{3} / \mathrm{s}$ no mês de fevereiro, característico do verão (JICA, 1994). Com base na relação entre os deflúvios médios mensais e as descargas sólidas dos rios que contribuem para a Baía de Guanabara, o total anual do aporte sólido estimado à Baía é de 4.000.000 toneladas/ano (HIDROSERVICE-GEIPOT, 1974). 
Atualmente, a Baía de Guanabara apresenta uma superfície total de $384 \mathrm{~km}^{2}$, da qual $56 \mathrm{~km}^{2}$ ocupada por ilhas, totalizando um perímetro de 131 $\mathrm{km}$ e um volume médio de água de 1,87 x $109 \mathrm{~m}^{3}$. Seu limite externo é formado pelas pontas de Copacabana (posto 6) e de Itaipu, incluindo as ilhas do Pai, Mãe e Menina. A maior extensão da Baía é de 36 km (AMADOR, 1997). Na porção interna encontra-se a largura máxima, que é de 29 km; já na porção intermediária da Baía a largura é de 23 km (AMADOR, op. cit.). A menor largura corresponde a um estreitamento entre a Ponta de São João (Rio de Janeiro) e a Ponta de Santa Cruz (Niterói) com 1.650 metros (KJERFVE et al., op. cit.).

A Baía de Guanabara apresenta uma batimetria complexa. Possui uma profundidade média de 5,7 metros, podendo atingir menos de 3 metros no seu interior. O canal central é relativamente plano, estendendo-se da entrada da Baía até a linha entre o aeroporto Santos Dumont, Rio de Janeiro, e Gragoatá, em Niterói. Possui uma profundidade média de 30 metros, podendo atingir até 58 metros. Progressivamente, em direção ao interior da Baía, o canal central perde sua característica batimétrica (KJERFVE et al., 1997).

A entrada crônica de nutrientes, associada a uma boa disponibilidade de luz, favorece um estado permanente de eflorescência algal, com a biomassa clorofiliana concentrando-se na superfície, diminuindo ao longo da coluna de água (QUIROGA, 1999). A temperatura média das águas da Baía situa-se em torno de $25^{\circ} \mathrm{C}$ na superfície e $23,7^{\circ} \mathrm{C}$ junto ao fundo (PARANHOS; MAYR, 1993). Existe uma variação sazonal marcante da temperatura, com os maiores valores sendo encontrados na superfície durante o verão. Como esperado, a salinidade decresce em direção ao interior da Baía, variando de 31,8 a 21,0 na superfície e de 34,5 a 26,1 junto ao fundo (KJERFVE et al., 1997). Em relação às condições gerais da salinidade, PARANHOS; MAYR (1993) descreveram padrões sazonais na região, com a separação do verão (quente e chuvoso), com salinidades mais baixas, e do inverno (seco), com valores de salinidade superiores. Esporadicamente, nos meses de verão, podem ser encontradas as menores temperaturas e as maiores salinidades, principalmente junto ao fundo, como resultado da penetração da Água Central 
do Atlântico Sul (ACAS) no interior da Baía. Com base nos dados de salinidade e temperatura, KJERFVE et al. (1997) descreveram a Baía como uma condição bem misturada na área próxima à entrada, assumindo uma condição moderadamente estratificada à altura da Ponte Rio-Niterói, porção intermediária da Baía.

KJERFVE et al. (1997) verificaram que as concentrações de oxigênio dissolvido também sofrem flutuações temporais tanto na superfície como no fundo. A Baía de Guanabara é considerada como uma das baías mais produtivas do mundo, com valores de assimilação do carbono variando entre 800 a $3600 \mathrm{mg} \mathrm{C}$ por dia. Essa produção segue as tendências encontradas para os descritores quantitativos do fitoplâncton, ou seja, uma maior produtividade na superfície nos meses de verão (REDUC/DTSE, 2000). Entretanto, os valores médios não variam significativamente, com exceção dos locais próximos da descarga de poluição orgânica. A Baía apresenta-se bastante estratificada com relação a disponibilidade de oxigênio, podendo ser observada uma diferença de $20 \%$ a $45 \%$ da concentração de oxigênio entre a superfície e o fundo. As partes internas da Baía alcançam condições anóxicas próximas ao fundo. Em contraste, as águas superficiais apresentam-se freqüentemente supersaturadas, até mesmo em áreas altamente poluídas, refletindo as altas taxas de produção primária fitoplanctônica (REBELLO et al., 1988). Nestes locais, o consumo de oxigênio dissolvido pela oxidação da matéria orgânica excedente resulta em altos níveis da demanda bioquímica de oxigênio (LAVRADO et al., 1991).

A Baía de Guanabara pode ser classificada como um estuário dominado por marés (SCHUBEL, 1971). Neste tipo de estuário, a movimentação da água é predominantemente ocasionada pelas oscilações de maré. Na Baía de Guanabara, a maré é caracterizada como semi-diurna com desigualdade (AMADOR, 1997). A altura média é de cerca de $0,7 \mathrm{~m}$ com uma pequena amplitude de maré $(0,5$ a $1,3 \mathrm{~m})$. Os resultados obtidos pela Japan International Cooperation Agency - JICA (1994) revelaram que a duração da maré na superfície durante a enchente é de cerca de 4 horas e trinta minutos e a vazante é de cerca de oito horas; no fundo a enchente e vazante apresentaram a mesma duração, com aproximadamente 6 horas. A maior renovação das águas e as trocas com o oceano ocorrem no canal central (eixo 
Norte-Sul) devido a maior amplitude de maré (SEVRIN-REYSSAC et al., 1979). As velocidade de correntes são maiores no estreitamento da Baía, atingindo de 50 a $150 \mathrm{~cm} / \mathrm{s}$ em sua entrada. No fundo da Baía as correntes são de velocidade muito baixas (24 a $32 \mathrm{~cm} / \mathrm{s}$ ) (JICA, 1994).

O tempo de residência médio, ou seja, o período necessário para que haja renovação de $50 \%$ do volume de água da Baía de Guanabara é de 11,4 dias. A taxa de renovação é relativamente rápida e pode estar condicionado às condições relativamente boas da qualidade da água nas regiões de maior circulação. Por outro lado, nas áreas de menor circulação, como nas enseadas, o tempo de residência pode ser significativamente longo (KJERFVE et al., 1997).

De forma geral, a Baía possui águas calmas com pequenas ondulações e ventos predominantes do quadrante leste (AMADOR, 1997). Com a chegada de frentes frias, com ventos do quadrante sul/sudoeste, podem ocorrer ondulações que chegam a ter altura de 2 a 4 metros e período de 8 a 12 segundos, gerando arrebentações nas praias oceânicas e na entrada da Baía (KJERFVE et al., 1997).

A composição sedimentológica da Baía de Guanabara é caracterizada principalmente por areia, areia lamosa, lama arenosa e lama (AMADOR, 1992). Segundo o sistema classificatório de sedimentos proposto por SHEPARD (1954), estão presentes dez tipos de sedimentos, predominando areias e lamas sílticas. As areias se distribuem ao longo dos canais autodragáveis, o canal principal (AMADOR, 1997), estendendo-se da plataforma continental até a altura da ponte Rio-Niterói (KJERFVE et al., 1997). As areias ainda dominam na região oceânica da Baía e em áreas situadas junto à foz de alguns rios da baixada fluminense. A distribuição do sedimento no setor externo da Baía de Guanabara reflete diretamente as forças hidrodinâmicas. As areias da região externa são produto da ação de mecanismos litorâneos e têm sua origem principal no retrabalhamento e transporte de sedimentos pleistocênicos da plataforma continental (AMADOR, 1997). Um perfil norte - sul da profundidade efetuado entre o Forte São João e a Fortaleza Santa Cruz demonstrou que há um grande banco de areia na entrada da Baía, composta por areia média quartzosa. Esta característica pode ser observada ao longo da plataforma continental do litoral do estado do Rio de Janeiro desde a Baía de Sepetiba, ao 
sul, até a localidade de Arraial do Cabo, a noroeste. É possível observar um contraste pronunciado entre este banco de areia e o sedimento arenoso presente no canal central (KJERFVE et al.,op. cit.). AMADOR (1997) constatou que as areias do canal principal estão presentes desde a entrada da barra até as proximidades da ilha de Paquetá, e têm sua explicação na atuação de correntes concentradas de maré, que produzem o transporte dos sedimentos mais finos e a concentração residual de areias (by passing). Áreas isoladas de bancos de areia podem ser encontradas de noroeste a sudoeste da llha do Governador (AMADOR, 1992). Por outro lado, extensos depósitos de lama cobrem as partes interiores da Baía em conseqüência do transporte ativo de materiais clásticos fluviais (KJERFVE et al., 1997) associada a áreas submetidas a menor energia do sistema de circulação (AMADOR, 1997).

De acordo com BARRETO \& CUNHA (1977) são baixos os teores de carbono orgânico presentes nos sedimentos de fundo da Baía. Estes estariam relacionados a presença de carbono inorgânico, proveniente de matéria orgânica estabilizada (envelhecida) na totalidade do carbono presente. Por outro lado, de um modo geral, predominam elevados teores de nitrogênio orgânico (>0,2\%). A classe de valores mais elevados $(>0,4 \%)$ distribui-se numa faixa contínua que ocupa quase toda a área do fundo da Baía, situada no reverso das ilhas do Governador e Paquetá, estendendo-se numa faixa estreita no lado oriental até Niterói (AMADOR, 1997). Ainda segundo Barreto \& Cunha (1977), estes elevados valores de nitrogênio orgânico podem ser interpretados como provenientes de lançamentos de esgotos domésticos e despejos industriais nos rios da bacia hidrográfica.

Os metais pesados parecem não exercer uma influência negativa na biota local (REDUC/DTSE, 2000). Segundo CARVALHO \& LACERDA (1992), embora a Baía receba uma carga elevada de metais pesados, principalmente na sua porção noroeste, as concentrações encontradas em algas bênticas, crustáceos e moluscos são similares àquelas encontradas em organismos de áreas não poluídas. Isto deve-se à elevada carga orgânica, oriunda de esgotos domésticos, que é despejada diariamente à Baía, que torna o ambiente parcialmente redutor, mantendo os metais fortemente ligados ao sedimento, de forma indisponível para incorporação pela biota local. 
Os principais biótopos bênticos existentes na Baía de Guanabara são os fundos infralitorais dominados por lodos, areias e rochas, costões rochosos, praias arenosas e manguezais. No fundo da Baía, em sua parte noroeste, existe uma extensa área de manguezal constituída pela área de proteção ambiental (APA) de Guapimirim. Além disso, a Baía apresenta um complexo sistema pelágico que abriga uma variedade de espécies planctônicas e nectônicas, tanto de origem marinha como estuarina (REDUC/DTSE, 2000).

\section{Ponto de amostragem}

O ponto de amostragem utilizado no presente trabalho tomou como base os resultados obtidos por Santi (2003), que realizou o estudo da taxocenose de poliquetas da Baía de Guanabara entre 2000 e 2001. Após verificação dos resultados das densidades de Poecilochaetus australis obtidas nas 38 estações de coleta, foi planejada uma coleta-piloto nas 5 estações de coleta com as maiores densidades de Poecilochaetus. Com os resultados da coleta-piloto ocorrida em Março de 2005 foi constatado que a estação localizada sob as coordenadas $22^{\circ} 53.320^{\prime} \mathrm{S}$ e $043^{\circ}$ 09.956' W (Figura 1.1.) corroborou o estudo da taxocenose realizado por Santi (2003) quanto à presença do banco de Poecilochaetus nos arredores do canal do Mangue. Esta localidade apresentou novamente as maiores densidades de $P$. australis dentre todas as demais da Baía de Guanabara. Ficou determinado que este ponto de amostragem seria satisfatório para a realização do presente estudo. A escolha deste ponto de amostragem levou em consideração quatro características principais: 1) alta densidade de indivíduos (SANTI 2003, SANTI et al 2004, SANTI; TAVARES 2008); 2) proximidade e influência de fontes de efluentes urbanos não-tratados relatados na literatura científica (CARREIRA et al., 2004; SILVA et al., 2008); 3) facilidade de acesso através de pequena embarcação; 4) profundidade local, cerca de 12 metros, compatível para utilização de pequeno amostrador sem necessidade de utilização de guincho mecânico.

O ponto de amostragem foi composto por sedimento com frações finas (silte e argila) e areias finas. Está próximo a fontes de efluentes urbanos como o canal do Cunha e o Canal do Mangue, assim como apresenta diversidade reduzida e alta biomassa com predomínio de espécies de poliqueta com 
hábitos depositívoros. Este local foi classificado como zona intermediária de degradação ambiental, considerando parâmetros biológicos e ambientais, contendo o sedimento compostos orgânicos (ex: Coprostanol) que evidenciam forte influência de efluentes urbanos não tratados (CARREIRA, 2004). Silva et al. (2008) também demonstraram que o ponto de amostragem está sujeito a altos níveis de coliformes totais e fecais nos sedimentos superficiais, devido ao incremento de esgoto e efluentes industriais não tratados no canal do Mangue.

Como este ponto de amostragem encontra-se dentro do canal de navegação do Porto do Rio de Janeiro, foi utilizado uma pequena embarcação capaz de realizar manobras rápidas em caso de necessidade devido a entrada de embarcações de grande calado na Baía. A localização do ponto de amostragem foi feita através de um GPS portátil. Também foi feito um croqui da área com três pontos de referência em terra a fim de aumentar o grau de precisão das coletas.

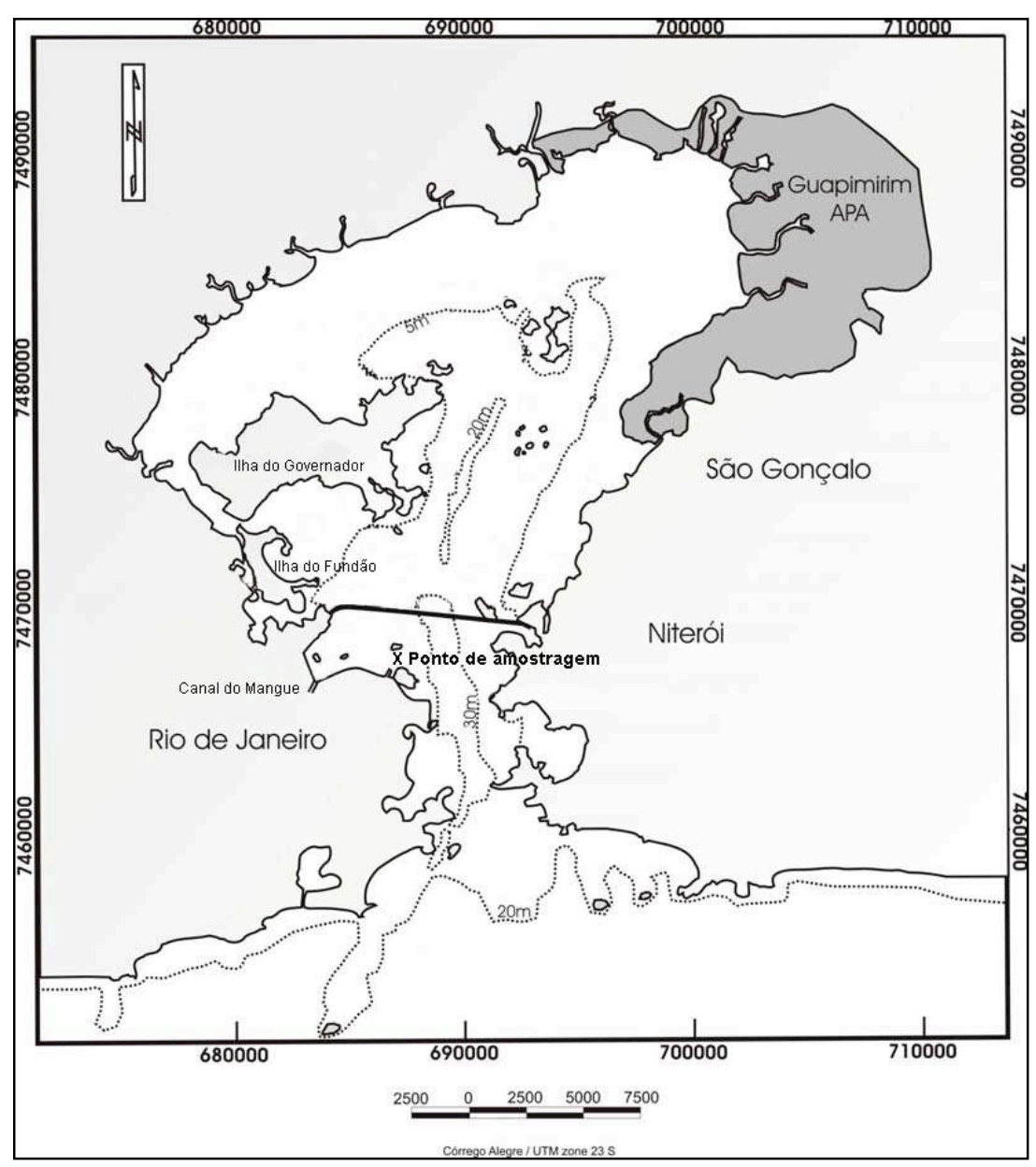

Figura 1.1. Mapa da Baía de Guanabara evidenciando o ponto de amostragem do presente trabalho. Adaptado de Silva et al., 2008. 


\section{Procedimentos de campo}

Em todos os doze meses de amostragem a mesma metodologia de coleta foi empregada para a aquisição das variáveis ambientais e biológicas. A escolha das variáveis ambientais a serem coletadas tanto na coluna d'água como no sedimento foram selecionadas a fim de caracterizar prováveis oscilações mensais do aporte orgânico durante o período de estudo e traçar possíveis relações com as variáveis biológicas observadas.

\section{Variáveis da coluna d'água}

Para a obtenção das alíquotas necessárias para as análises das variáveis da coluna d'água, salinidade, temperatura e oxigênio dissolvido, superfície e de fundo, foi utilizada uma garrafa de van Dorn. Primeiramente, foram coletadas as amostras de oxigênio dissolvido e fixadas e lavadas ao laboratório para análise através do método químico de Winkler. Os dados para obtenção da temperatura e salinidade foram obtidos in situ com auxílio de um termômetro digital acoplado ao pHmetro e um refratômetro, respectivamente. A transparência da coluna d'água foi obtida através do disco de Secchi.

\section{Meroplâncton}

O meroplâncton foi coletado através de um arrasto vertical utilizando-se uma rede com abertura de malha de malha $100 \mu \mathrm{m}$ até 1 metro da profunidade máxima do ponto de amostragem. As amostras obtidas foram fixadas em formol $4 \%$.

\section{Variáveis do sedimento}

Para a obtenção das amostras de sedimento foi utilizado um pegador de aço inox do tipo Van Veen de $0,05 \mathrm{~m}^{2}$ (volume 1,75 I) de área capaz de ser operado manualmente sem necessidade de guincho. Este equipamento mostrou-se bastante eficiente para o tipo de sedimento do local de estudo (silte argilo arenoso), visto que a amostra coletada apresentava-se em ótimo estado em quase $100 \%$ dos lançamentos.

Para a análise granulométrica e a matéria orgânica total (MOT) foram coletadas duas alíquotas de 200 gramas de sedimento para cada parâmetro, 
sendo acondicionadas em sacos plásticos devidamente etiquetados e imediatamente congeladas e mantidas neste estado até o momento da análise em laboratório. Para a determinação de pigmentos (clorofila-a sedimentar e feopigmentos), cerca de 50 gramas de sedimento foram coletados e acondicionados em potes plásticos escuros e congelados até o momento da análise. Para o processamento do material referente à biomassa microbiana (Método do ATP) foram coletados cerca de 50 gramas de sedimento, acondicionados em potes plásticos esterelizados com água mili-q e mantidos refrigerados a cerca de $4^{\circ} \mathrm{C}$ até o momento da extração do ATP no laboratório, a qual ocorreu dentro de 4 horas após a coleta.

\section{Meiofauna}

Para verificação da presença de exemplares jovens (recrutas) do gênero Poecilochaetus foram coletadas amostras de sedimento para análise da meiofauna. A coleta da meiofauna foi realizada nos lançamentos em que se notava a presença destes indivíduos no sedimento. Em cada uma destas réplicas foi inserido um tubo cilíndrico plástico de $5 \mathrm{~cm}$ de diâmetro por $15 \mathrm{~cm}$ de altura da superfície até $10 \mathrm{~cm}$ do sedimento. Esta fração do sedimento obtido foi então cuidadosamente transferida para potes plásticos previamente identificados, fixando-se a amostra com formol tamponado $4 \%$.

\section{Macrofauna e Poecilochaetus}

Para a coleta da macrofauna e de indivíduos de Poecilochaetus foram utilizadas três réplicas obtidas através do lançamento do Van Veen. Somente os lançamentos que preencheram todo o volume interno do amostrador foram utilizados. O material coletado foi transferido para sacos plásticos previamente identificados e fixados com formol tamponado 4\%. Quando exemplares intactos de Poecilochaetus eram observados houve coleta cuidadosa destes indivíduos no intuito de se preservar a integridade corporal para fins de identificação taxonômica, contagem dos setígeros, estudos morfométricos e da biologia reprodutiva. Estes indivíduos foram acondicionados separadamente em frascos plásticos, previamente etiquetados e fixados em formol $4 \%$. 


\section{Análise das variáveis ambientais do sedimento}

\section{Granulometria}

As análises granulométricas seguiram a metodologia proposta por Suguio (1973). As frações menores do que $63 \mu \mathrm{m}$ foram separadas por pipetagem, enquanto que as frações maiores foram separadas por peneiramento a seco. Foi adotada a escala de classificação do sedimento de Shepard (1954) e Folk \& Ward (1957).

\section{Matéria Orgânica Total (MOT)}

O sedimento preservado em freezer $\left(-20^{\circ} \mathrm{C}\right)$ foi submetido à secagem em estufa $\left(60^{\circ} \mathrm{C}\right.$ por 48 horas). Posteriormente, o sedimento seco ( 0,5 a $\left.2 \mathrm{~g}\right)$ foi transferido para cadinhos de porcelana e, através do método de Byers et al. (1978), a matéria orgânica total do sedimento foi determinada após calcinação em mufla $\left(495-500^{\circ} \mathrm{C}\right.$ por $\sim 2$ horas).

\section{Determinação dos pigmentos (clorofila-a sedimentar e feopigmentos)}

A clorofila-a, feopigmentos e os carotenóides foram quantificados por espectrofotometria (espectrofotômetro modelo HITACHI® U-3010) através da extração com acetona 100\% (segundo o método de Plante-Cuny, 1978). 1-3 g de sedimento contendo $10 \mathrm{~mL}$ de acetona foi ultrasonicado (Thorton T14) por $10 \mathrm{~min}$ a $100 \mathrm{~W}$. Posteriormente, as amostras foram incubadas à $-20^{\circ} \mathrm{C}$ por 18 $24 \mathrm{~h}$. Para remover partículas em suspensão, as amostras foram centrifugadas por $15 \mathrm{~m}$ à $3000 \mathrm{rpm}$. O sobrenadante foi então analisado no espectrofotômetro. Os cálculos para obtenção das concentrações de clorofilaa, feopigmentos e carotenóides do sedimento foram realizados utilizando-se as seguintes equações (LORENSEN, 1967; PARSONS et al., 1984): 
Chl a $\left(\mu g g^{-1}\right)=\frac{26,7[(C 665-C 750)-(F 665-F 750)](\text { vol.água }+ \text { vol.acetona })}{\text { peso da amostra úmida }- \text { vol.água }}$

$F e o\left(\mu g g^{-1}\right)=\frac{26,7[(1,7 C 665)-C 750](\text { vol.água }+ \text { vol.acetona })}{\text { peso da amostra úmida }- \text { vol.água }}$

$\operatorname{Car}\left(\mu g g^{-1}\right)=\frac{7,6[(A 480+(3 C 750))-1,49(A 510-(2 C 750))(\text { vol.água }+ \text { vol.acetona })]}{\text { pesodaamostraúmida }- \text { vol.deágua }}$

onde:

26,7 = taxa de correção da clorofila-a (chl-a);

1,7 = taxa de C665/F665 na ausência de feopigmentos (feo);

C665 e C750 = leitura nas densidades ópticas de 665 e 750 nm;

F665 e F750 = leitura nas densidades ópticas de 665 e 750 nm após acidificação com HCl;

7,6 = taxa de correção dos carotenóides (car);

A480 = leitura na densidade óptica de $480 \mathrm{~nm}$;

A510 = leitura na densidade óptica de $510 \mathrm{~nm}$;

3 C750 = correção de turbidez para a absorbância de 480 nm;

1,49 = taxa de correção para absorbância de $510 \mathrm{~nm}$;

2 C750 = correção de turbidez para a absorbância de $510 \mathrm{~nm}$.

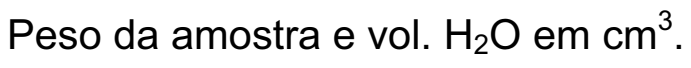

A quantificação da clorofila a é uma medida indicadora do aporte de matéria orgânica lábil e produção primária no sedimento, que recentemente se depositou e que está disponível como suprimento alimentar aos organismos do bentos (e.g. GRAF, 1989; SUN et al., 1991; BOON; DUINEVELD, 1998). Esta análise visa identificar possíveis correlações entre o aumento da densidade de Poecilochaetus e o incremento de clorofila-a depositada recentememente no sedimento. Segundo a literatura, a espécie atua como depositívora de superfície, podendo portanto, beneficiar-se do aumento da disponibilidade de 
alimento para crescimento corpóreo e otimização do esforço reprodutivo ao longo do ano.

\section{Processamento do material referente à biomassa microbiana (Método do ATP)}

A biomassa microbiana total foi estimada através da quantificação da Adenosina-5'-trifosfato particulada (P-ATP) seguindo o método descrito por Karl (1993), modificado para o estudo em sedimentos. A etapa de extração de ATP sedimentar foi realizada no laboratório de Oceanografia Química da Universidade Santa Úrsula e seguiu as seguintes etapas: após o fracionamento dos intervalos determinados, o sedimento foi homogeneizado e retirado $1 \mathrm{~mL}$ para cada uma das três réplicas, utilizando-se uma seringa. A extração do ATP intracelular foi realizada através da adição de $5 \mathrm{~mL}$ de ácido ortofosfórico $\left(\mathrm{H}_{3} \mathrm{PO}_{4}\right.$ - 0,5 M) em $1 \mathrm{~mL}$ de sedimento úmido (KARL, 1980). Após a centrifugação e adição de solução tampão Tris ( $\mathrm{pH} 7,5$; Trizma Pre-set crystals, Sigma $\left.{ }^{\circledR}\right)$, as amostras foram acondicionadas em freezer $\left(-20^{\circ} \mathrm{C}\right)$. No Laboratório de Dinâmica Bêntica (IOUSP), as amostras foram transferidas para ultrafreezer $\left(-80^{\circ} \mathrm{C}\right)$. A quantidade de ATP foi medida utilizando-se um luminômetro (Sirius ${ }^{\circledR}$, Berthold Systems $\mathrm{GmbH}$ ), através da reação com luciferina-luciferase. A degradação da luciferina é mediada pela luciferase, na presença de oxigênio, íons de magnésio e ATP, gerando fótons de luz. A quantidade de luz medida é proporcional à quantidade de ATP na amostra. A quantidade de ATP, por sua vez, tem relação direta com a quantidade de carbono orgânico da célula, originando uma medida da biomassa microbiana (C:ATP, 250:1, segundo Karl, 1980). As medidas luminosas foram comparadas com as curvas-padrão feitas para cada conjunto de amostras (Figura 1.2.). 


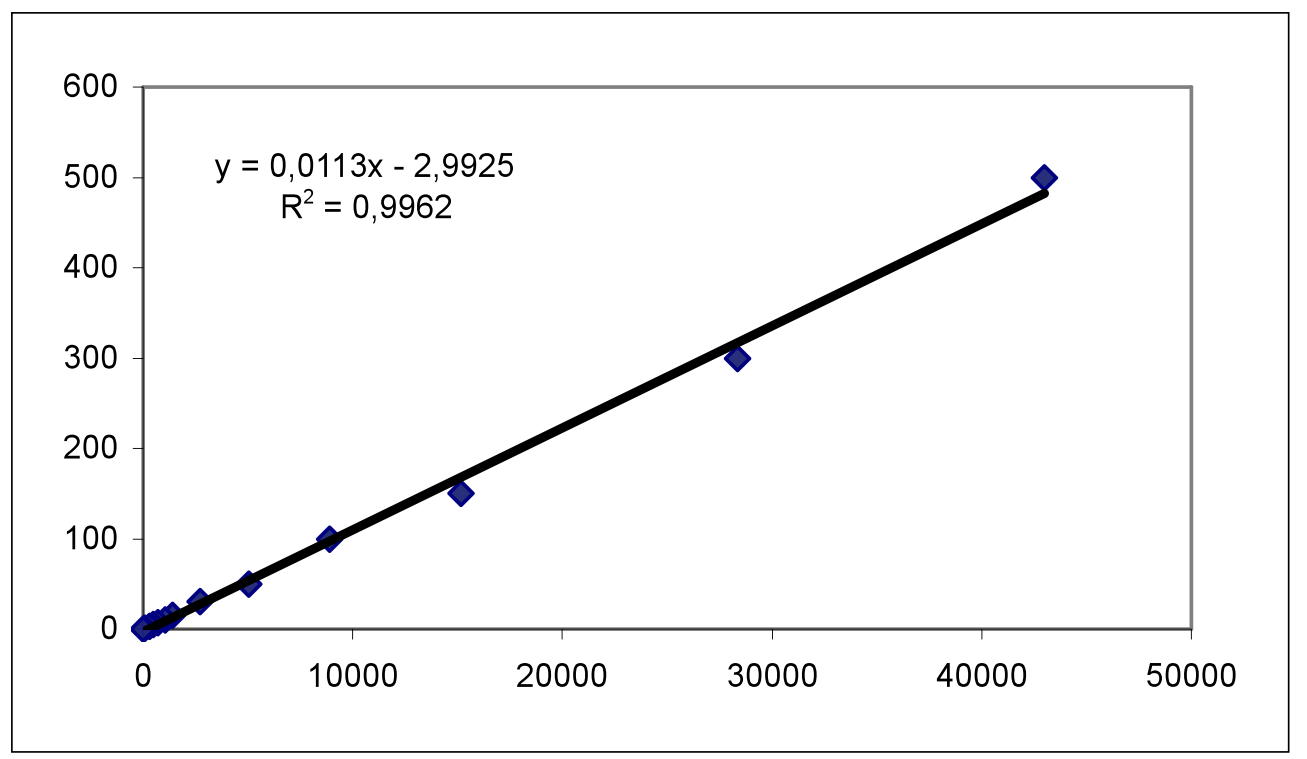

Figura 1.2. Exemplo de curva padrão utilizada para estimar a concentração de ATP nas amostras (eixo " $x$ ": unidades relativas de luz e eixo "y": concentrações de ATP (ng/mL)).

O ATP é um indicador confiável da biomassa microbiana, pois ocorre em todas as células vivas, tem uma meia-vida relativamente curta após a morte celular e autólise, e está presente em concentrações intracelulares relativamente constantes, independentes do modo nutricional (KARL, 1993). Este método, contudo, não distingue os diferentes grupos de microorganismos, obtendo uma medida da biomassa microbiana total (CRAVEN et al., 1986; NOVITSKY; KARL,1980; KARL, 1993).

\section{Analise estatística das variáveis ambientais}

A fim de se testar a similaridade entre os 12 meses de coleta, jun 2005 a maio de 2006, foram realizadas análises multivariadas utilizando-se diferentes abordagens para a interpretação dos resultados. Em um primeiro momento, todas as variáveis mensuradas da coluna d'água (superfície e fundo), transparência da água, salinidade, temperatura, oxigênio dissolvido, clorofila-a e feopigmentos (superfície), e do sedimento, sedimentologia (frações granulométricas e percentual de carbonatos), matéria orgânica total (\% MOT) e ATP foram consideradas para verificar o grau de similaridade entre os meses estudados. Posteriormente, somente as variáveis da coluna d'água obtidas junto ao fundo e novamente todas do sedimento foram analisadas a fim de 
testar a influência dos parâmetros ambientais mais diretamente relacionados com o substrato inconsolidado estudado. Em ambos os testes, as variáveis ambientais foram analisadas através de formações de agrupamentos, padronizando-se os valores obtidos entre todas as variáveis e adotando-se a ligação entre as afinidades entre os meses de coleta através da distância euclidiana. Após a construção dos dendogramas, um mapa MDS bidimensional (Multi Dimensional Scaling) foi elaborado a fim de se visualizar as distâncias entre os meses analisados e verificar mais claramente possíveis afinidades através das distâncias espaciais apresentadas entre cada um dos meses dispostos no mapa.

A afinidade entre os 12 meses de coleta também foi testada através da análise ANOSIM (Analysis of Similarities) usando 0 método de permutação/randomização na matriz de similaridade, a fim de se verificar o nível de significância das similaridades encontradas entre os grupos de estações. A afinidade entre os meses de coleta foi testada sob duas hipóteses de agrupamento a priori. A primeira hipótese considerou os meses estudados ao longo de um ano em 4 grupos de estações climatológicas (Primavera, Verão, Outono e Inverno) nomeando-se como fatores A, B, C e D para cada grupo de três meses. Espera-se no resultado hipotético que haverá agrupamento de cada três meses de coleta respectivos às estações do ano em resposta às oscilações climatológicas e oceanográficas de cada uma das 4 estações do ano.

Seguindo a mesma tendência, as 12 coletas também foram agrupadas em dois conjuntos de meses quanto ao período de precipitação atmosférica ao longo do ano, sendo considerados somente dois principais picos, um máximo (período chuvoso) composto por 6 coletas e outro mínimo (período seco), com as demais 6 amostras, sendo nomeados como fatores A e B. Espera-se haver formação de dois grupos, compostos cada um, por 6 meses de coleta relacionados aos períodos seco e chuvoso.

Os resultados destes testes foram expressos através do $R$ estatístico (Global R). O nível de significância da amostra estatística foi de 0,1\%. O número de permutações foi de 999. Para a realização destas rotinas estatísticas foi utilizado o programa PRIMER $5^{\circledR}$ (versão 5.2 .4 - 2001). 


\section{Análise das variáveis biológicas obtidas}

\section{Meroplâncton}

Foram geradas subamostras de cada um dos frascos coletados nos arrastos verticais realizados, cada uma delas contendo $100 \mathrm{ml}$ de amostra para separação das larvas de poliqueta e Poecilochaetus. Após a triagem das amostras todas estas larvas encontradas foram transferidas para frascos etiquetados e preservadas em álcool $70 \%$. As larvas de Poecilochaetus encontradas foram contabilizadas e separadas das demais para realização dos estudos taxonômicos e morfométricos (dinâmica populacional).

\section{Meiofauna}

Cada uma das 36 amostras coletadas foi triada em sua totalidade em malha de 63 um após elutriação utilizando o método de flotação com auxílio de Ludox a fim de facilitar a separação da meiofauna agregada ao sedimento.

Todo o procedimento de laboratório necessário para esta análise foi acompanhado pela Dra. Adriana Galindo, do laboratório de meiobentos da Universidade Santa Úrsula, Rio de Janeiro.

\section{Macrofauna}

Cada uma das $34^{*}$ amostras coletadas foi peneirada em malha de 500 $\mu \mathrm{m}$. As réplicas obtidas foram colocadas em baldes e posteriormente em um elutriador, o qual otimizou a obtenção de indivíduos intactos. Assim como ocorreu no campo, exemplares de Poecilochaetus observados durante o procedimento de elutriação e peneiramento foram cuidadosamente separados do restante da amostra e fixados em álcool $70 \%$.

O restante do material retido na malha foi triado por grandes grupos, sendo posteriormente, identificado até o menor nível taxonômico possível, contabilizado e acondicionado em frascos de vidro contendo álcool $70 \%$.

\footnotetext{
* Não houve coleta das réplicas 2 e 3 durante a primeira campanha oceanográfica (junho de 2005) por dificuldades com o posicionamento da embarcação no ponto de amostragem.
} 


\section{RESULTADOS}

\section{Variáveis ambientais}

\section{Hidrologia}

Os dados das variáveis ambientais da coluna d'água selecionadas e coletadas durante as campanhas oceanográficas realizadas encontram-se na Tabela 1.1.

Tabela 1.1. Variáveis ambientais da coluna d' água obtidos durante as campanhas oceanográficas realizadas até o mês de Maio de 2006. Nota: Transparência em metros, Temperatura em graus Celsius, O.D., oxigênio dissolvido em mg/L, S - superfície; F - fundo.

\begin{tabular}{|c|c|c|c|c|c|c|c|c|c|c|c|c|c|c|}
\hline \multirow{4}{*}{$\begin{array}{l}\text { Campanha } \\
\text { Mês } \\
\text { Estrato }\end{array}$} & \multicolumn{14}{|c|}{2005} \\
\hline & \multirow{2}{*}{\multicolumn{2}{|c|}{$\begin{array}{l}\text { AUST. I } \\
\text { JUNHO }\end{array}$}} & \multirow{2}{*}{\multicolumn{2}{|c|}{$\begin{array}{l}\text { AUST. II } \\
\text { JULHO }\end{array}$}} & \multirow{2}{*}{\multicolumn{2}{|c|}{$\begin{array}{l}\text { AUST. III } \\
\text { AGOSTO }\end{array}$}} & \multirow{2}{*}{\multicolumn{2}{|c|}{$\begin{array}{c}\text { AUST. IV } \\
\text { SETEMBRO }\end{array}$}} & \multirow{2}{*}{\multicolumn{2}{|c|}{$\begin{array}{l}\text { AUST. V } \\
\text { OUTUBRO }\end{array}$}} & \multirow{2}{*}{\multicolumn{2}{|c|}{$\begin{array}{c}\text { AUST. VI } \\
\text { NOVEMBRO }\end{array}$}} & \multirow{2}{*}{\multicolumn{2}{|c|}{$\begin{array}{l}\text { AUST. VII } \\
\text { DEZEMBRO }\end{array}$}} \\
\hline & & & & & & & & & & & & & & \\
\hline & $S$ & $\mathrm{~F}$ & $S$ & $\mathrm{~F}$ & $S$ & $\mathrm{~F}$ & $S$ & $F$ & $S$ & $F$ & $S$ & $\mathrm{~F}$ & $S$ & $\mathrm{~F}$ \\
\hline Transparência & 3 & * & 6 & * & 1.2 & * & 5,0 & * & 3.5 & * & 1.2 & * & 1.5 & * \\
\hline Salinidade & 36 & 39 & 35 & 37 & 32.7 & 35.5 & 33,6 & 35,4 & 33,0 & 34,2 & 33,0 & 35,0 & 29 & 34 \\
\hline Temperatura & 23.5 & 24 & 20.7 & 20.6 & 26 & 24 & 22,5 & 21,5 & 25,5 & 23,5 & 24 & 21 & 22.9 & 16.9 \\
\hline O.D. & 3.44 & 3.35 & 7.16 & 4.90 & 7.49 & 4,30 & 4,44 & 4,22 & 3,19 & 2,07 & 7,75 & 2,55 & 4.5 & 3.78 \\
\hline
\end{tabular}

\begin{tabular}{|c|c|c|c|c|c|c|c|c|c|c|}
\hline \multirow{4}{*}{$\begin{array}{l}\text { Campanha } \\
\text { Mês } \\
\text { Estrato }\end{array}$} & \multicolumn{10}{|c|}{2006} \\
\hline & \multirow{2}{*}{\multicolumn{2}{|c|}{$\begin{array}{l}\text { AUST. VIII } \\
\text { JANEIRO }\end{array}$}} & \multirow{2}{*}{\multicolumn{2}{|c|}{$\begin{array}{c}\text { AUST. IX } \\
\text { FEVEREIRO }\end{array}$}} & \multirow{2}{*}{\multicolumn{2}{|c|}{$\begin{array}{l}\text { AUST. X } \\
\text { MARÇO }\end{array}$}} & \multirow{2}{*}{\multicolumn{2}{|c|}{$\begin{array}{c}\text { AUST. XI } \\
\text { ABRIL }\end{array}$}} & \multirow{2}{*}{\multicolumn{2}{|c|}{$\begin{array}{c}\text { AUST. XII } \\
\text { MAIO }\end{array}$}} \\
\hline & & & & & & & & & & \\
\hline & $S$ & $\mathrm{~F}$ & $\mathrm{~S}$ & $\mathrm{~F}$ & $S$ & $\mathrm{~F}$ & $S$ & $\mathrm{~F}$ & $S$ & $\mathrm{~F}$ \\
\hline Transparência (m) & 1.5 & * & 1.5 & * & 1.5 & * & 1.2 & * & 5,5 & * \\
\hline Salinidade & 34 & 37 & 34 & 36 & 33 & 37 & 33 & 36 & 34 & 36 \\
\hline Temperatura & 24.9 & 15.3 & 25.6 & 22.6 & 24.6 & 21.6 & 23.7 & 23.8 & 22,6 & 21,5 \\
\hline O.D. & 5.96 & 4.39 & 4.51 & 3.66 & 6.48 & 3.95 & 6.42 & 3.55 & 4.09 & 3.64 \\
\hline
\end{tabular}

Os resultados obtidos sugerem pequena flutuação das variáveis da coluna d'água no local amostrado. As oscilações encontradas na transparência da água e na salinidade da superfície e do fundo parecem ter relação com o padrão de circulação das marés da Baía, verificado pela coincidência dos dados de menor transparência com os períodos de vazante da maré que transporta a massa d'água proveniente da parte interna da Baía. Quanto à salinidade, houve discreta estratificação da coluna d'água, com homogeneidade de dados entre os meses estudados mais acentuada junto ao fundo. Já na superfície, os menores valores e as maiores diferenças foram 
verificadas após período de chuvas com dados recolhidos durante a maré vazante, como por exemplo no período de Janeiro e Março de 2006. Nestas duas campanhas também foi verificado a influência da Água Central do Atlântico Sul (ACAS), principalmente junto ao fundo, pela estratificação da coluna d'água quanto a temperatura da água. BRAGA \& MÜLLER (1998) registraram condições sub-óxicas na região de Ubatuba, SP, durante a penetração da ACAS em subsuperfície, atribuindo estes resultados ao aumento de produtividade primária devido à entrada de nutrientes na zona fótica.

\section{Sedimentologia}

\section{Análise granulométrica}

A análise da amostras demonstrou variação discreta da textura sedimentológica do local estudado. As classificações (SHEPARD, 1954) variaram do silte argiloso ao silte arenoso com pouca contribuição de carbonatos. O diâmetro médio foi do silte muito fino ao silte médio, pobremente selecionado a muito pobremente selecionado, respectivamente (Tabela 1.2.). As evidências até então apresentadas evidenciaram pouca variabilidade temporal da textura sedimentológica do local amostrado. Este fato pode ser explicado pela baixa energia hidrodinâmica do local, condicionando predominantemente depósitos de frações finas nas camadas superficiais do sedimento, independentemente do período estudado.

Tabela 1.2. Análise granulométrica obtida nos 12 meses de amostragem: Junho de 2005 a Maio de 2006. Nota: valores contidos na tabela em percentual.

\begin{tabular}{lcccccccc}
\hline \multicolumn{1}{c}{ Campanha } & seixos & granulos & areia & silte & argila & Shepard & CaCO3 & Grau de Seleção \\
\hline \hline Aust. I (jun 2005) & 0,00 & 4,39 & 30,48 & 54,85 & 10,28 & Silte arenoso & 0,7 & muito pobremente selecionado \\
Aust. II (jul 2005) & 0,00 & 0,00 & 9,74 & 54,50 & 35,76 & Silte muito fino & 0,1 & pobremente selecionado \\
Aust. III (ago 2005) & 0,00 & 0,00 & 18,64 & 58,45 & 22,21 & Silte fino & 0,2 & pobremente selecionado \\
Aust. IV (set 2005) & 0,00 & 0,00 & 15,26 & 62,87 & 21,87 & Silte muito fino & 1 & pobremente selecionado \\
Aust. V (out 2005) & 0,00 & 0,00 & 31,25 & 38,56 & 30,18 & Silte fino & 0,9 & muito pobremente selecionado \\
Aust. VI (nov 2005) & 0,00 & 0,00 & 6,81 & 60,13 & 40,07 & Silte muito fino & 0,2 & pobremente selecionado \\
Aust. VII (dez 2005) & 0,00 & 0,00 & 10,36 & 55,32 & 45,28 & Silte muito fino & 0,6 & muito pobremente selecionado \\
Aust. VIII (jan 2006) & 0,00 & 0,00 & 6,59 & 51,26 & 49,14 & Silte fino & 0,4 & pobremente selecionado \\
Aust. IX (fev 2006) & 0,00 & 0,00 & 5,16 & 38,58 & 61,82 & Silte muito fino & 0,4 & pobremente selecionado \\
Aust. X (mar 2006) & 0,00 & 0,00 & 5,28 & 46,22 & 53,98 & Silte fino & 0,2 & pobremente selecionado \\
Aust. XI (abr 2006) & 0,00 & 0,00 & 7,20 & 51,23 & 49,27 & Silte fino & 0,5 & muito pobremente selecionado \\
Aust. XII (mai 2006) & 0,00 & 0,00 & 6,81 & 45,32 & 55,58 & Silte muito fino & 0,9 & pobremente selecionado \\
\hline
\end{tabular}




\section{Matéria Orgânica Total (MOT)}

Foram encontradas concentrações extremamente elevadas de matéria orgânica total em todas as amostras analisadas, com média de 12,88\%, típicas de ambientes hipereutrofizados. Os dois maiores valores foram observados nos meses de Janeiro e Fevereiro de 2006, com 13,23\% e 15,86\%, respectivamente (Figura 1.3.). O local amostrado demonstra estar sujeito a altas concentrações de matéria orgânica ao longo de todo o ano, com pequeno acréscimo nos períodos de verão chuvosos, seja pelo aumento da disponibilidade de nutrientes pela entrada da ACAS, seja por incremento do aporte de material orgânico de origem terreste através do runoff continental urbano.

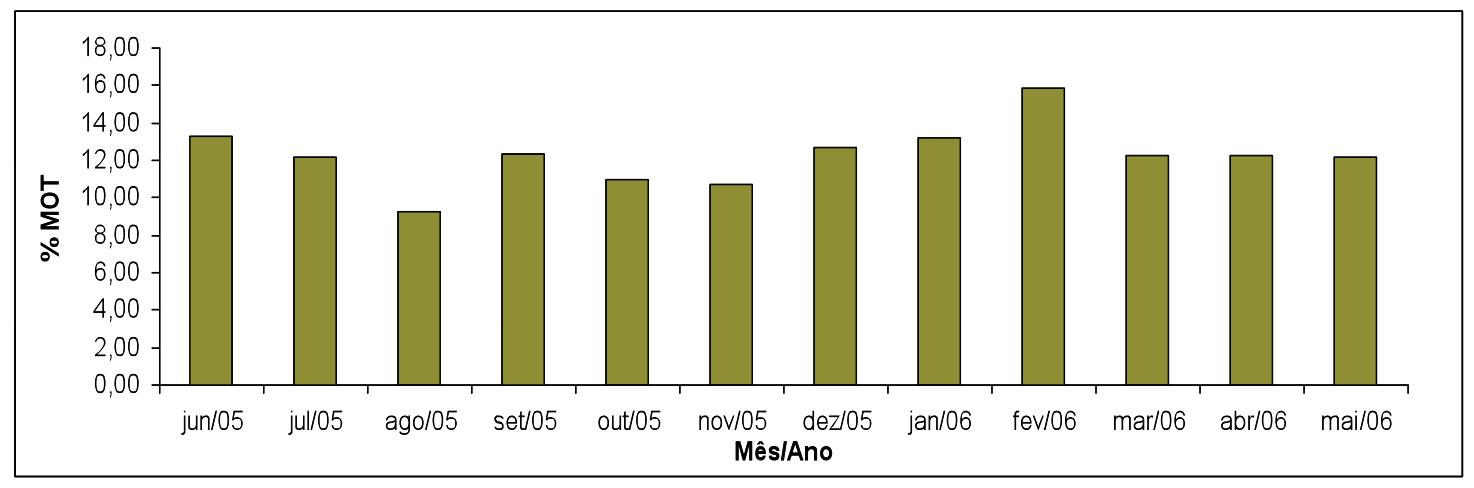

Figura 1.3. Concentração de Matéria Orgânica Total (MOT \%) encontrada entre Junho de 2005 e Fevereiro de 2006.

\section{Determinação dos pigmentos (clorofila-a sedimentar e feopigmentos)}

Os resultados encontrados nas amostras seguiu o mesmo padrão daquele encontrado para matéria orgânica, ou seja, altas concentrações e pequenas variações ao longo do período estudado. As concentrações de clorofila-a sedimentar e feopigmentos nos primeiros $10 \mathrm{~cm}$ do sedimento foram maiores nos meses de Julho de 2005 e Janeiro de 2006 (Figura 1.4. e 1.5.). Nota-se que houve acúmulo de clorofila-a na superfície do sedimento, a qual pode ser proveniente de fitodetritos oriundos da coluna de água ou de produção primária bêntica. Não foi identificado um padrão claro da resposta da 
produção primária na coluna d'água com as variáveis ambientais analisadas. Fica evidente que os dados demonstram concentrações de clorofila-a e, principalmente, de feopigmentos muito elevadas ao longo de todo período analisado, destacando a condição do ponto de amostragem sujeito à alta produtividade primária da coluna d' água e rápida degradação dos compostos orgânicos devido à intensa atividade microbiana (ver resultados do ATP abaixo), típica de estuários impactados.

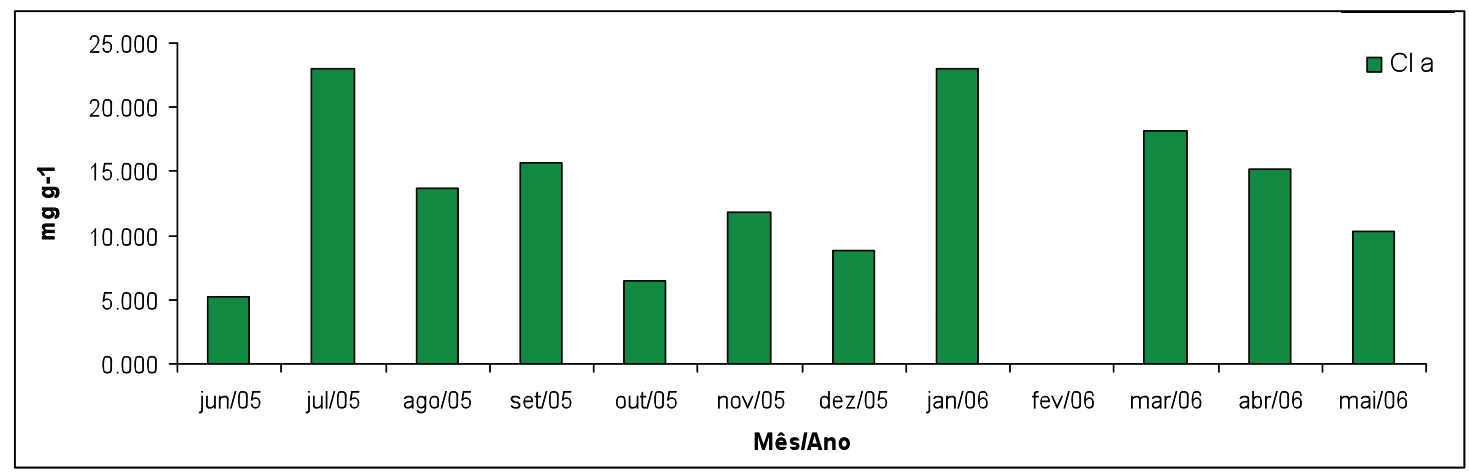

Figura 1.4. Concentrações de clorofila-a nos primeiros $10 \mathrm{~cm}$ de sedimento de Junho de 2005 a Janeiro de 2006. Linhas verticais representam o desvio padrão. Nota: o mês de fevereiro de 2006 não foi analisado.

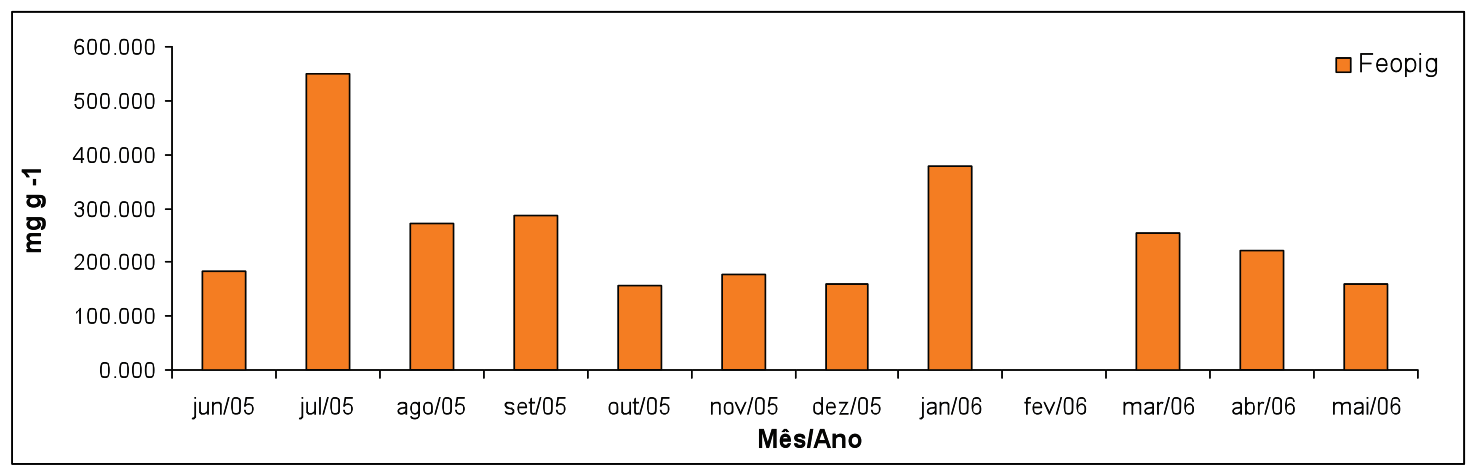

Figura 1.5. Concentrações de feopigmentos nos primeiros $10 \mathrm{~cm}$ de sedimento de Junho de 2005 a Janeiro de 2006. Linhas verticais representam o desvio padrão. Nota: o mês de fevereiro de 2006 não foi analisado. 
Processamento do material referente à biomassa microbiana (Método do ATP)

A biomassa microbiana analisada entre os meses de Junho de 2005 e Maio de 2006 também evidenciou valores elevados ao longo de todo o período estudado. Comparativamente, os inventários de biomassa microbiana apresentaram as maiores concentrações no meses de Novembro de 2005 e Janeiro de 2006 (Figura 1.6.). Os dados não evidenciaram nenhuma associação das maiores concentrações com as variáveis até agora analisadas. A alta produtividade da coluna d'água, normalmente associada à entrada da ACAS durante os meses de verão, pode estar ligada aos maiores valores de concentração de biomassa microbiana destes dois picos. Os resultados encontrados em todos os meses sugerem atividade microbiana intensa, típica de áreas eutrofizadas.

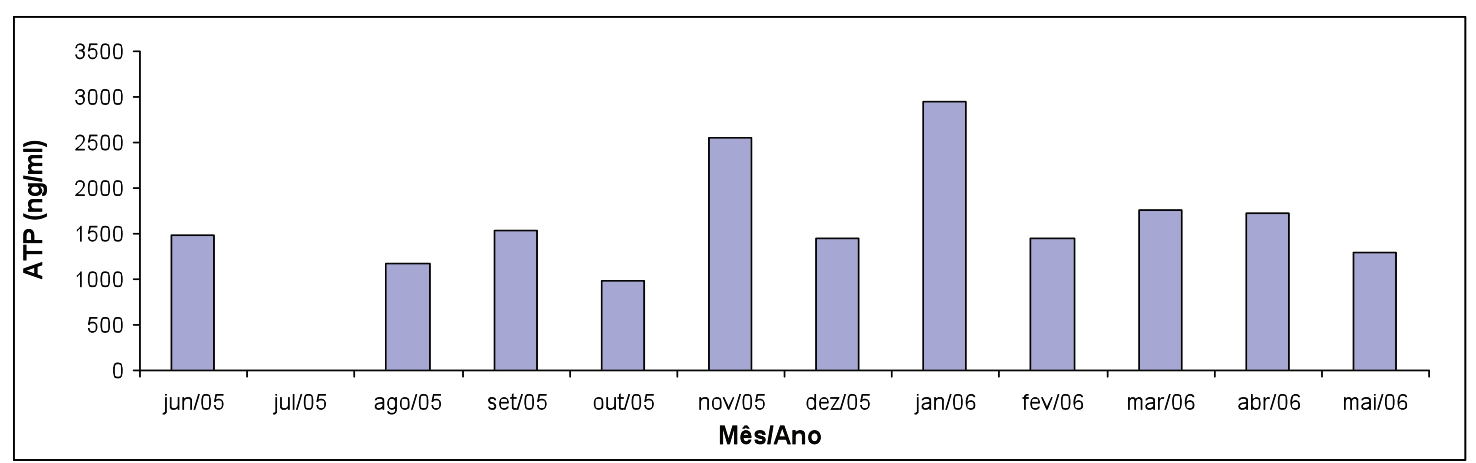

Figura 1.6. Baía de Guanabara. Biomassa microbiana nos sedimentos superficiais. Nota: a amostra de julho de 2005 não foi analisada.

\section{Análise estatística das variáveis ambientais analisadas}

Como era esperado em função da homogeneidade dos resultados encontrados não houve similaridade significativa entre os meses estudados (Figura 1.7.), considerando-se todas as variáveis ambientais, assim como no caso da segunda abordagem que utilizou somente os dados da coluna d'água junto ao fundo e todas as variáveis do sedimento. 
A análise de similaridade ANOSIM revelou não haver padrão consistente entre as variáveis ambientais analisadas e as estações do ano (Tabela 1.3.) e com os períodos mínimo (seco) e máximo (chuvoso) de precipitação atmosférica revelado pelo resultado da amostra estatística (Global $R=0,093)$.
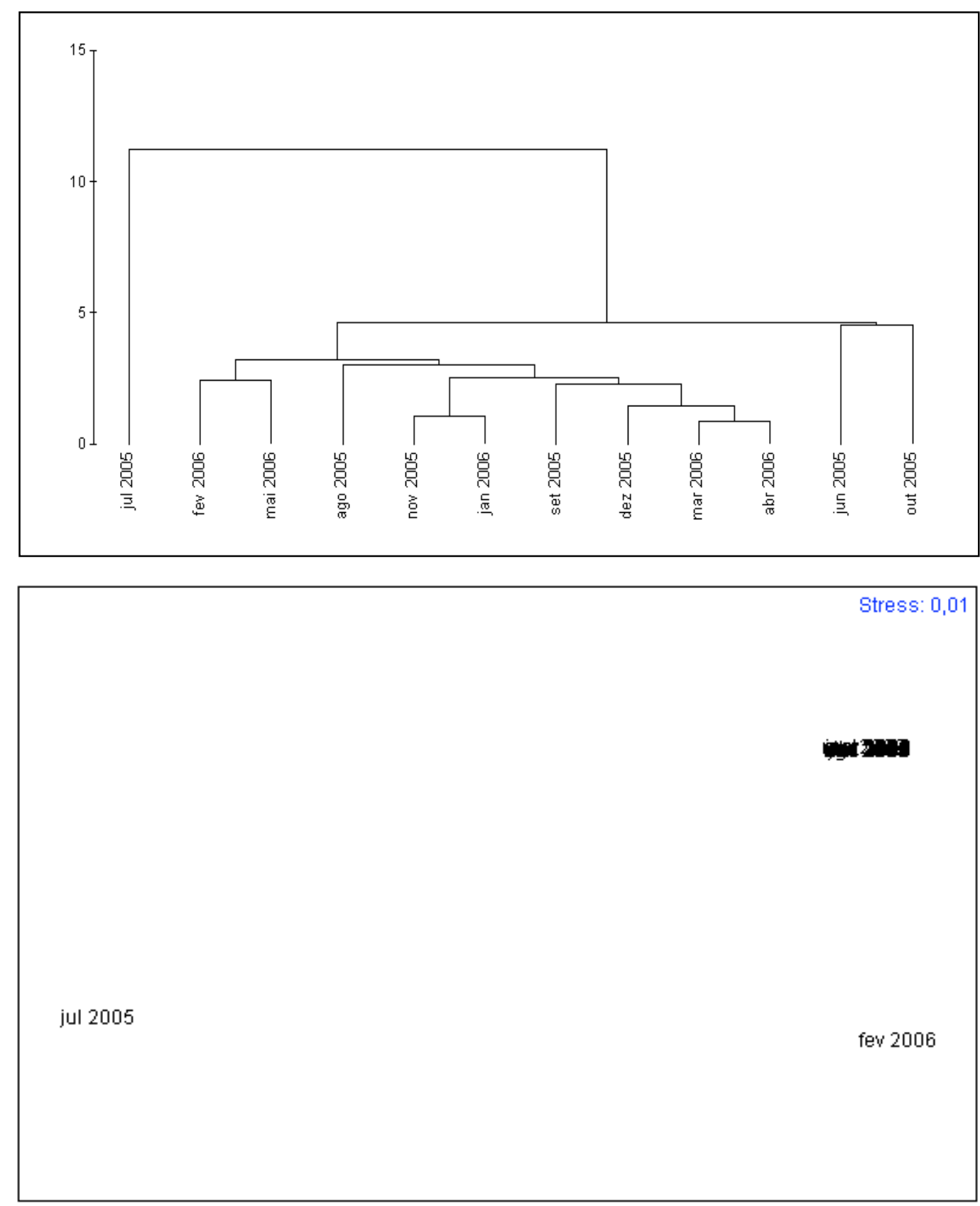

Figura 1.7. Cluster (distância euclidiana) e mapa MDS bi-dimensional evidenciando o grau de similaridade dos resultados obtidos de todas as variáveis ambientais nos 12 meses estudo. Nota: a amostra de ATP do mês de julho não foi analisada. 
Tabela 1.3. Resultados da análise ANOSIM para os fatores A, B, C e D (Outono, Inverno, Primavera e Verão) e a afinidade entre os resultados das amostras das variáveis ambientais obtidas em cada um dos 12 meses. Testes pareados. Amostra estatística (R Global: 0,217).

\begin{tabular}{lcc}
\hline Grupos & R estatístico & Nível de significância \\
\hline Outono, Primavera & 0,318 & 0,2 \\
Outono, Primavera & 0,278 & 0,5 \\
Outono, Verão & 0,217 & 1 \\
Inverno, Primavera & 0,128 & 4,4 \\
Inverno, Verão & 0,261 & 0,3 \\
Primavera, Verão & 0,155 & 2,8 \\
\hline
\end{tabular}

Os resultados encontrados apontam para certa estabilidade temporal das condicionantes ambientais do local estudado, tanto na coluna d água, mas principalmente quanto as variáveis do sedimento. O local estudado parece ser constantemente influenciado pelas condições de baixa energia hidrodinâmica, revelada pela pouca flutuação das frações sedimentológicas (finas e muito finas), pelo aporte freqüente de matéria orgânica no sedimento de origem autóctone e alóctone, com intensa atividade microbiana ao longo do ano. 


\section{Referências bibliográficas}

ALCÂNTARA, F.; WASHINGTON, D. C., An analytical synoptic-dynamic study about the severe weather event over the city of Rio de Janeiro on Jan 2, 1987. In: Magoon, O.; Neves, C. (Ed.). Coastlines of Brazil, American Society of Civil Engineers, New York, N.Y., 1989, p. 195-204.

AMADOR, E. S. Sedimentos de fundo da Baía de Guanabara - uma síntese. In: Anais do III Congresso da Associação Brasileira de Estudos do Quaternário - ABEQUA. Belo Horizonte, MG, Brasil. 1992, p. 199-224.

AMADOR, E. S. Baía de Guanabara e Ecossistemas Periféricos - Homem e Natureza. Edição do autor. p. 25 - 49. 1997.

AMADOR, E. S.; Kiffmann, W. S. Modificações morfométricas da Bacia dos Rios Macacu - Guapiaçu por ação antrópica - seu significado no assoreamento da Baía de Guanabara. Anais da Academia Brasileira de Ciências, v. 50, n. 2, 1978.

ARAÚJO, D. S. D.; MACIEL, N. C. Os manguezais do recôncavo da Baía de Guanabara. Relatório técnico. Cadernos FEEMA, série técnica 10/79. Rio de Janeiro, 1979.

BARRETO, M. K.; CUNHA, R. L. Indicador dos sedimentos orgânicos do fundo da Baía de Guanabara. In: FEEMA. Série técnica. Meio ambiente - vários estudos. Cadernos, v.2, p. 221-228. Rio de Janeiro. 1977.

BARTHOLOMEW, G. A. The role of natural history in contemporary biology. Bioscience, v. 36, p. $324-329$.

BATALHA, F.; GAMA, B. A. P.; SOARES-GOMES, A. Ensaio para avaliação de qualidade da água através da distribuição de moluscos na Baía de Guanabara, Rio de Janeiro, Brasil: 1389-1400. Anais do VIII Seminário Regional de Ecologia. São Carlos, 1998. 
BORGES, A. L. N., 1996. Concentração de metais pesados em sedimentos superficiais da Baía de Guanabara - RJ. Monografia de bacharelado. Instituto de Biologia Marinha. Universidade Federal do Rio de Janeiro, 38 p.

BOUZAN, P. E. C., 1985. Fauna bêntica de substrato móvel da enseada do catalão. Baía de Guanabara, R.J. Monografia de Bacharelado. Instituto de Biologia Marinha. Universidade Federal do Rio de Janeiro, 42 p.

BYERS, S. C.; MILLS, E. L.; STEWART, P. L. A comparison of methods to determining organic carbon in marine sediments, with suggestion for a standard method. Hidrobiol., v. 58, p. 43-37. 1978.

BOON, A. R.; DUINEVELD, G. C. A. Chlorophyll-a as a marker for bioturbation and carbon flux in southern and central North Sea sediments. Mar. Ecol. Prog. Ser., v. 162, p. 33-43. 1998.

CARREIRA, R. S.; WAGENER, A. L. R.; READMAN, J. W. Sterols as markers of sewage contamination in a tropical urban estuary (Guanabara Bay, Brazil): spacetime variations. Estuar. coast Shelf Sci., v. n. 60, n. 4, p. 587-598, 2004.

CARVALHO, C. E. V.; LACERDA, L. D. Heavy metals in Guanabara Bay biota: Why such low concentrations? Ciênc. Cult., v. 44, p. 184-186, 1992.

CRAVEN, D. B.; JAHNKE, R. A.; CARLUCCI, A. F. Fine-scale vertical distributions of microbial biomass and activity in California Bordeland sediments. Deep-Sea Res., v. 33, p. 379-390, 1986.

FEEMA, 1977. Baía de Guanabara - Ensaio tentativo de inter-relacionamento de dados físico-químicos com índices biológicos. In: FEEMA. Série técnica. Meio ambiente - vários estudos, Rio de Janeiro/ RJ. Cadernos, 2, p. 146-153.

FEEMA 1979. Avaliação biológica dos pontos críticos da Baía de Guanabara. In, FEEMA. Série técnica. Meio ambiente - vários estudos. Rio de Janeiro.Cadernos, 6, p. 337-359. 
FEEMA, 1990. Projeto de recuperação gradual do ecossistema da Baía de Guanabara, Vol 1. Fundação Estadual de Engenharia do Meio Ambiente, Rio de Janeiro, RJ, Brasil, 203 p.

FLORES, Jr. R. G.; BARRETO M. K.; COSTA, H. R. On the relationship between ecological and physico-chemical water quality parameters: a case study at the Guanabara Bay, Rio de Janeiro. In: Ecological Diversity in theory and practice. (Ed.). Fairland, Maryland: International Co-operative Publishing House, p. 195-206, 1979.

FUNDAÇÃO GETÚLIO VARGAS, 2000. Baía de Guanabara - Dossiê Sócio Ambiental. Gestão Sustentável da Baía de Guanabara. Seminário Internacional. Centro Internacional de Desenvolvimento Sustentável.

GRAF, G. Benthic-pelagic coupling in a deep-sea benthic community. Nature, v. 341, p. 437-439, 1989.

HIDROSERVICE-GEIPOT, 1974. Hidroservice Engenharia de Projetos e Grupo de Estudos para a Integração Política de Transporte (GEIPOT) - Prestação de serviços de consultoria para a elaboração de plano diretor para aproveitamento da área do contorno do fundo da Baía de Guanabara. Rio de Janeiro, Relatório final.

KARL, D. M. Cellular nucleotide measurements and applications in microbial ecology. Microb. Rev., v. 44, p. 739-796. 1980.

IBGE. Fundação Instituto Brasileiro de Geografia e Estatística. Censo demográfico - Rio de Janeiro, 1990. Home page da Fundação Instituto Brasileiro de Geografia e Estatística. http://www.ibge.gov.br [Acessada em 23/09/2002] 1991.

JICA. The study on recuperation of the Guanabara Bay ecosystem, Tokyo.: Japan International Cooperation Agency; Kokusai Kogyo Co., Ltd., 8 v., 1994. 
JUNQUEIRA, A. O. R.; FALCÃO A. P. C.; MAYER-PINTO, M.; VIANA, M. S.; SILVA S. H. G. Spatial and temporal variations on intertidal barnacle abundance in a tropical bay. Nauplius, v. 8, n. 2, p. 195-204. , 2000.

KARL, D. M. Total Microbial Biomass Estimation Derived from the Measurement of Particulate Adenosine-5'-Triphosphate. In: Kemp, P. F.; Sherr, B. F.; Sherr, E. B.; Cole, J. J. (Ed.). Handbook of methods in aquatic microbial ecology. Lewis Pub., Boca Raton. p. 359-368, 1993.

KJERFVE, B.; RIBEIRO, C. H. A.; DIAS, G. T. M.; FILIPPO, A. M.; QUARESMA, V. S. da, Oceanographic characteristics of an impacted coastal bay: Baía de Guanabara, Rio de Janeiro, Brazil. Cont. Shelf Res., v. 17, n. 13, p. 1609-1643, 1997.

LAVRADO, H. P., MAYR, L. M., CARVALHO, V., PARANHOS, R. Evolution (1980-1990) of ammonia and dissolved oxygen in Guanabara Bay, RJ, Brazil. In: O.T. Magoon, H. Converse and V. Tippie (Ed.). Proceedings of the 7th Symposium on Coastal and Ocean Management. Coastal Zone. American Society of Civil Engineers, New York, v. 4, p. 3234-3245, 1991.

LAVRADO, H. P., FALCÃO, A. P. C., CARVALHO-CUNHA, P.; SILVA, S. H. G. Composition and distribution of Decapoda from Guanabara Bay, RJ. Nauplius, v. 8, n. 1 , p. 15-23, 2000.

LORENZEN, C. J. Determination of chlorophyll and pheopigments: spectrophotometric equations. Limnol. Oceanogr., v. 12, p. 343-346, 1967.

MACHADO, M. C. S. Sistema planctônico da região do Emissário Submarino de Esgotos de Ipanema, Rio de Janeiro - RJ - Populações zooplanctônicas: Annelida Polychaeta. Dissertação de Mestrado. Museu Nacional da Universidade Federal do Rio de Janeiro, p. 220 , 1986. 
MACHADO, M. C. S.; QUIROGA, A. I. P.; TENÓRIO, M. M. B., 1998. Qualidade da água e biomassa fitoplanctônica de três ecossistemas marinhos com diferentes graus de eutrofização: Baía de Guanabara, Baía de Sepetiba e litoral de Ipanema (Rio de Janeiro). Anais do IV Simpósio de Ecossistemas Brasileiros. Águas de Lindóia, SP, vol. 2, p. 115-117, 1998.

MAYR, L. M.; TENENBAUM, D. R.; VILLAC, M. C., PARANHOS, R.; NOGUEIRA, R.; BONECKER, S. L. C.; BONECKER, A. C.. Hydrobiological characterization of Guanabara Bay. In: Magoon, O. T.; Neves, O. (Ed.). Coastlines of Brazil, American Society of Civil Engineers, New York, p. 124139.1989.

NONATO, E. Poecilochaetus australis sp. nov. (Annelida, Polychaeta). Neotropica, v. 9, n. 23, p. 17-26, 1963.

NOVITSKY, J. A.; KARL, D. M. Characterization of microbial activity in the surface layers of a coastal subtropical sediment. Mar. Ecol. Prog. Ser., v.28, p. 49-55, 1986.

OLIVEIRA, L. P. H. Contribuição ao conhecimento dos crustáceos do Rio de Janeiro. Gênero Uca (Decapoda: Ocypodidae). Mem. Inst. Osw. Cruz, v. 34, n. 1, p. 115-148, 1939.

OLIVEIRA, L. P. H., 1947. Distribuição geográfica da fauna e flora da Baía de Guanabara. Mem. Inst. Osw. Cruz, v. 45, p. 709-734, 1947.

OLIVEIRA, L. P. H. Levantamento biogeográfico da Baía de Guanabara. Mem. Inst. Osw. Cruz, v. 48, p. 363-391, 1950.

OLIVEIRA, L. P. H. Poluição das águas marítmas, estragos na flora e fauna do Rio de Janeiro. Mem. Inst. Osw. Cruz, v.56, p. 39-59, 1958. 
OlIVEIRA, L. P. H.; KRAU, L.; MIRANDA, A. A. S. Plâncton poluído da Guanabara com copépodos Cletocamptos e rotífera Rotaria. Arq. Mus. Nac., v. 54, p. 55-56, 1971.

OLIVEIRA, L. P. H.; KRAU, L. Estudos aplicados à recuperação biológica da Baía de Guanabara. Mem. Inst. Osw. Cruz, v. 74, n. 2, p. 99-145, 1976.

PARANHOS, R.; MAYR, L. M. Seasonal patterns of temperature and salinity in Guanabara Bay, Brazil. Mem. Inst. Osw. Cruz, v.2, p. 647-652, 1993.

PARANHOS, R.; NASCIMENTO, S. M.; MAYR, L. M. On the faecal pollution in Guanabara Bay, Brazil. Fres. Envir. Bull., v.4, p. 352-357, 1995.

PARSONS, T. R.; YOSHIAKI, M.; LALLI, C. M. A manual of chemical and biological methods for seawater analysis. Pergamon Press, Oxford, 173 p., 1984.

PINEDO, S. ; SARDA, R. ; MARTIN, D. Comparative study of the trophic structure of soft-bottom assemblages in the bay of blanes (Western Mediterranean Sea). Bull. Mar. Sci., v. 60, n. 2, p. 529 - 542 , 1997.

PLANTE-CUNY, M. R. Pigments photosynthétiques et production primaire des fonds meubles néritiques d'une région tropicale (Nosy-Bé, Madagascar). Trav. Doc. ORSTOM, v. 96, p. 1-359. 1978.

QUIROGA, A. I. P. Biomassa fitoplanctônica por classe de tamanho do litoral de Ipanema e da Baía de Guanabara, RJ. Dissertação de mestrado. Universidade Santa Úrsula. 114 p. , 1999.

REBEllO, A. de L.; PONCIANO, C. R.; MELGES, L. H. Avaliação da produtividade primária e da disponibilidade de nutrientes na Baía de Guanabara. An. Acad. Bras. Ciências, v. 60, p. 419-430 , 1988. 
REBELLO, F. A.; SILVA, S. H. G. Macrofauna bêntica de substratos móveis infralitorais da Baía de Guanabara, RJ - (1985). Anais do Simpósio sobre Ecossistemas da Costa Sul e Sudeste Brasileira. Cananéia. p.389-400, 1987

REDUC/DTSE - Consórcio de Universidades. Relatório final de avaliação das condições presentes de funcionamento do complexo industrial REDUC/DTSE sob o ponto de vista de suas implicações ambientais. Convênio SECT/ Petrobrás, 2000.

SANTI, L. Taxocenoses de Polychaeta e Mollusca sublitorais, substrato inconsolidado, em um estuário impactado: Baía de Guanabara, Rio de Janeiro, Brasil. Tese de Mestrado. Universidade Santa Úrsula, Rio de Janeiro, RJ. 206 p., 2003.

Patterns of species richness and species density of sublittoral softbottom polychaetes in a grossly polluted urban bay: Guanabara Bay, Rio de Janeiro, Brazil. J. Coast. Res., SI 39, p. 1127-1131, 2008.

The Polychaete assemblage of an impacted estuary, Guanabara Bay, Rio de Janeiro, Brazil. Braz. J. Oceanogr. Submetido. 2008 b.

Soft-bottom polychaeta bank (Spionida: Poecilochaetidae) recorded in a polluted tropical bay, Guanabara Bay, Rio de Janeiro, Brazil. Em preparação, 2008c.

SCHUBEL, L. Estuarine circulation and sedimentation in the estuarine environment, Short Course Lecture Notes. American Geological Institute: VI1VI-17. In: Amador, E. S. 1997. Baía de Guanabara e Ecossistemas Periféricos - Homem e Natureza. Edição do autor, p. 539, 1971. 
SCHUTZE, M. L. M. Estudo do plâncton, particularmente da bioecologia de Temora stylifera (Dana, 1849) (Copepoda, Calanoida). Rio de Janeiro - RJ: Emissário Submarino de Ipanema e Baía de Guanabara. Dissertação de Mestrado. Museu Nacional da Universidade Federal do Rio de Janeiro, p. 282, 1987.

SEVRIN-REYSSAC, J.; MACHADO, M. C.; SCHUTZE, M. L.; BIBAS, S. G.; LIMA, I. C., LIMA, C. A.; ESTEVES, C. P. Biomasse et production du phytoplancton de la Baie de Guanabara (État de Rio de Janeiro, Brésil) et du secteur océanique adjacent. Variations de mai à juillet 1978. Bull. du Mus. Nat. D’Historie Naturelle, v. 1, n. 4, p. 329-354, 1979.

SHEPARD, F. P. Nomenclature based on sand-silt-clay rations. Journ. of Sed. Petrol., 23: 117-119, 1954.

SILVA, F. S. S.; PERREIRA, D. C.; NUÑES, I. S.; KREPSK, N.; FONTANA, L. F.; NETO, J. A. B.; CRAPEZ, M. A. C. Bacteriological study of the superficial sediments of Guanabara Bay, RJ, Brazil. Braz. Journ. Ocean., v. 56, n. 1, p. 13-22, 2008.

SILVA, C. S.; RODRIGUES, J. C. V.; CÂMARA, N. L. Saneamento básico e problemas ambientais na região metropolitana do Rio de Janeiro. Rvsta. Bras. Geog., v. 52, p. 5-106, 1980.

SUGUIO, KIntrodução à sedimentologia. São Paulo, Edgard Blücher. 317 p., 1973.

SUN, M.; ALLER, R. C. ; LEE, C. 1991. Early diagenesis of chlorophyll-a in Long Island Sound sediments: A measure of carbon flux and particle reworking. J. Mar. Res., v. 49, p. 379-401, 1991. 
VERGARA FILHO, W., ALVES, J. R. P.; MACIEL, N. C., 1997. Diversity and distribution of crabs (Crustacea, Decapoda, Brachyura) in mangroves of the Guanabara Bay, Rio de Janeiro, Brazil, p. 155-162. In: Kjerfve, B., Lacerda, L. D. \& Diop, E. H. S. (Ed.). Mangrove ecosystem studies in Latin America and Africa. UNESCO, Paris, p. 349, 1997.

ZALMON, I. R. Estudo de comunidades incrustantes sobre painéis experimentais em três áreas da Baía de Guanabara, RJ, Brasil. Dissertação de Mestrado. Museu Nac. Universidade Federal do Rio de Janeiro, 214 p., 1988. 


\section{CAPÍTULO 2}

\section{Análise taxonômica do gênero Poecilochaetus e sua distribuição na costa brasileira *}

A família Poecilochaetidae Hartman, 1963b é formada pelo gênero Poecilochaetus, estabelecido por Claparède (in EHLERS, 1875), e tem como espécie-tipo Poecilochaetus fulgoris, não referida na descrição original à qualquer família conhecida. Atualmente vinte e oito espécies de Poecilochaetidae são reconhecidas, 16 delas nunca tiveram a região posterior do corpo descrita.

Caracterizam-se pela presença de prostômio arredondado com dois pares de olhos, uma antena mediana ventral, dois palpos longos sulcados e pelo primeiro parapódio dirigido para frente, com cerdas notopodiais e neuropodiais longas, formando uma gaiola cefálica. Os setígeros 2,3 e, às vezes, o 4 possuem ganchos falcados no neuropódio. Lobos parapodiais em forma de ampolas estão presentes do $7^{\circ}$ ao $10^{\circ}-17^{\circ}$ setígero. As cerdas podem ser lisas, pilosas, espiraladas, plumosas, aristadas e farpadas e as cerdas notopodiais posteriores são modificadas em ganchos ou espinhos, com grande variação de forma. Os lobos parapodiais em forma de ampola e as cerdas delgadas plumosas são apontados como sinapomorfias do grupo (FAUCHALD; ROUSE, 1997). A antena mediana ventral também parece exclusiva de Poecilochaetus (ALLEN, 1904), assim como as "papilas epidermais", estruturas estas bem diferentes daquelas encontradas nos Flabelligeridae (FAUCHALD; ROUSE, 1995) (Figuras 2.1 e 2.2).

Entre os fatores que dificultam o processo de identificação estão a grande variabilidade intraespecífica, a terminologia não padronizada das cerdas e a grande fragilidade dos animais, que raramente são coletados completos (MACKIE, 1996; MIURA, 1988; MILLIGAN; GILBERT, 1984). Por exemplo, os gêneros Elicodasia e o Gênero $A$, não nomeado formalmente, foram acrescentados à família, respectivamente por LAUBIER \& RAMOS (1973) e MILLIGAN \& GILBERT (1984). No entanto, MACKIE (1990) demonstrou que ambos os táxons eram, na verdade, fragmentos posteriores de Poecilochaetus. 
ROUSE \& FAUCHALD (1997) incluíram a família Poecilochaetidae no clado Spionida, com base na presença de palpos longos. Considerando informações sobre a biologia reprodutiva das famílias Spionidae e Poecilochaetidae, BLAKE \& ARNOFSKY (1999) sugeriram que a família deveria ser abandonada, colocando Poecilochaetus como um gênero da família Spionidae. RIBEIRO (2004) realizou uma análise cladística da família e identificou cinco grupos suportados por sinapomorfias, o que sugere que a condição monogenérica da família não reflete a ampla variedade morfológica do grupo. No entanto, diante do conhecimento insatisfatório de muitas espécies o autor optou por não propor uma nova classificação com a criação de novos gêneros. EIBYE-JACOBSEN (2006) apresentou uma análise filogenética das 27 espécies consideradas válidas. Trochochaetidae aparece como grupo-irmão de Poecilochaetidae e este último como grupo monofilético. O autor identificou dois grandes clados: um formado por espécies caracterizadas pela presença de papilas na superfície do corpo e sem lobo pós-setal dorsal no setígero 1 e o outro pelo órgão nucal alongado e uma placa dorsal quitinosa no setígero 9. No entanto, nenhuma nova proposta de classificação foi apresentada em função das dificuldades mencionadas nos parágrafos anteriores.

Os Poecilochaetidae são tubícolas e possuem a habilidade de obter recursos nutricionais tanto na superfície do sedimento, como na interface águasedimento, atuando como depositívoros de superfície e/ou suspensívoros, conforme disponibilidade alimentar (quantidade e valor nutricional) destes compartimentos (FAUCHALD; JUMARS, 1979). Os tubos, revestidos com muco, formam galerias em forma de $U$, mantendo desta forma a circulação de água (ALLEN, 1904). Estes tubos têm sido freqüentemente encontrados abrigando caranguejos comensais da família Pinnotheridae (TAYLOR, 1966). Os representantes da família estão distribuídos amplamente desde a zona entremarés até 10.687 m (MACKIE, 1990). Muito embora a família tenha ampla distribuição batimétrica, acredita-se que a maioria das espécies ocorra em águas quentes e rasas de mares temperados, em sedimentos predominantemente finos (READ, 1986). Os sexos são separados. O comportamento reprodutivo ainda não foi observado diretamente, apesar de que atualmente assume-se que a fertilização seja externa. Os estágios larvais planctotróficos são facilmente encontrados na coluna d'água dos mares 
temperados, tropicais e subtropicais. A larva aparentemente sobrevive por um longo período na coluna d'água (HANNERZ, 1956). NOZAIS et al. (1997) estudaram o deslocamento larval de uma espécie de Poecilochaetidae na coluna d'água e observaram a presença de um muco produzido pela própria larva que auxilia tanto a natação, como também a alimentação, facilitando, portanto, a dispersão larval da espécie.

Representantes do gênero Poecilochaetus são encontrados freqüentemente ao longo da costa brasileira, desde o estado do Rio Grande do Sul (NONATO, 1973; ORENSANZ; GIANUCA, 1974), passando por Santa Catarina e Paraná (NONATO, 1963; SOVIERZOSKI, 1991), pelos litorais paulista (e.g. NONATO, 1963, 1973, 1981, MUNIZ et al., 1996; PIRES-VANIN et al., 1997; PAIVA, 1990; 1993 a; LOPES, 1993) e fluminense (NONATO, 1981; ATTOLINI, 1997; SANTI, 2003), chegando até o litoral sergipano (SANTOS et al., 1994). O gênero já foi coletado na região entremarés (NONATO, 1981; RIZZO; AMARAL, 2001) até a profundidade de 197 metros (ATTOLINI, 1997), em sedimentos compostos por grãos predominantes de praticamente todas as feições, desde o lodo (TOMMASI, 1967) até areia muito grossa (CORBISIER, 1994) (Tabela 2.1.). Os estágios larvais planctotróficos também são facilmente observados ao longo do litoral paulista e da costa sul brasileira (NONATO, 1963; NONATO, 2004 - comunicação pessoal). No entanto, pouco se sabe sobre a biologia e a ecologia da família, sendo usualmente considerada, na maioria dos estudos, como espécie rara. Contrariando essa idéia, SANTI (2003) encontrou Poecilochaetus australis relativamente bem distribuída na Baía de Guanabara, RJ, sendo encontrada em certos pontos da Baía com densidade e biomassa por indivíduo extremamente elevadas (4.500 ind. $/ \mathrm{m}^{2}$ e peso seco livre de cinzas de até 42 $\left.\mathrm{g} / \mathrm{m}^{2}\right)$.

No momento do levantamento da hipótese do presente estudo, somente duas espécies haviam sido registradas para a costa brasileira: Poecilochaetus australis Nonato, 1963, localidade tipo Ubatuba, SP e Poecilochaetus serpens, registrada por Paiva (2001) no Arquipélago de Abrolhos. Duas novas espécies, Poecilochaetus perequensis e Poecilochaetus polycirratus, encontradas no médio-litoral de uma praia arenosa na Baía de Paranaguá, Paraná, foram descritas recentemente por SANTOS \& MACKIE (2008). 
As espécies coletadas não somente na localidade tipo da espécie, a região de Ubatuba, litoral norte do estado de São Paulo, mas também em todos os registros encontrados ao longo da costa brasileira para esta família foram, em sua totalidade, identificadas como Poecilochaetus australis. Em princípio os indivíduos coletados na Baía de Guanabara seriam da mesma espécie daqueles encontrados na região de Ubatuba, diferindo essencialmente no tamanho corporal. Os indivíduos da Baía de Guanabara apresentam biomassa corpórea duas vezes maior frente aos animais coletados em Ubatuba. Já que os animais coletados em Ubatuba seriam da mesma espécie, foi levantado que os indivíduos da Baía de Guanabara estariam se beneficiando das condições hipereutrofizadas da Baía.

Porém, um exame detalhado dos exemplares em ambos os locais revelaram diferenças morfológicas importantes que distinguiram as espécies em dois grupos de indivíduos: um grupo contendo os animais coletados na Baía de Guanabara, compatíveis com a descrição apresentada por Nonato, 1963 para Poecilochaetus australis e obtidos através de coletas realizadas em Ubatuba, nas enseadas do Flamengo, Ubatuba e Ilha Anchieta, nos anos de 2004 e 2005 (Projeto DIAGEN - Laboratório de Dinâmica Bêntica IOUSP) com caracteres semelhantes aos exemplares descritos como Poecilochaetus perequensis SANTOS \& MACKIE, 2008. A principal evidência que apontou para esta diferenciação foi a presença de carúncula trilobada com lobos laterais sub-iguais, típico de $P$. perequensis nos exemplares coletados em Ubatuba, comparado com a carúncula única de $P$. australis que atinge o 4-5 setígero da região dorsal do animal (Figura 2.3.).

Pouco se acrescentou ao conhecimento da família desde que a espécie Poecilochaetus australis Nonato, 1963 foi descrita. Cabe ressaltar que a diversidade da família ao longo da costa Sul Atlântica pode ter sido negligenciada em detrimento da crescente demanda por estudos ecológicos combinada com a falta de especialistas no grupo. É possível que a ampla distribuição e ocorrência atribuídas a Poecilochaetus australis na nossa costa sejam na verdade um reflexo dessa falta de especialistas (SANTI, 2006). O cenário atual do conhecimento da família Poecilochaetidae sugere que maior atenção deve ser empregada na coleta e identificação dos espécimes 
estudados, a fim de retratar corretamente a distribuição das espécies do gênero Poecilochaetus nos estudos realizados na costa brasileira.

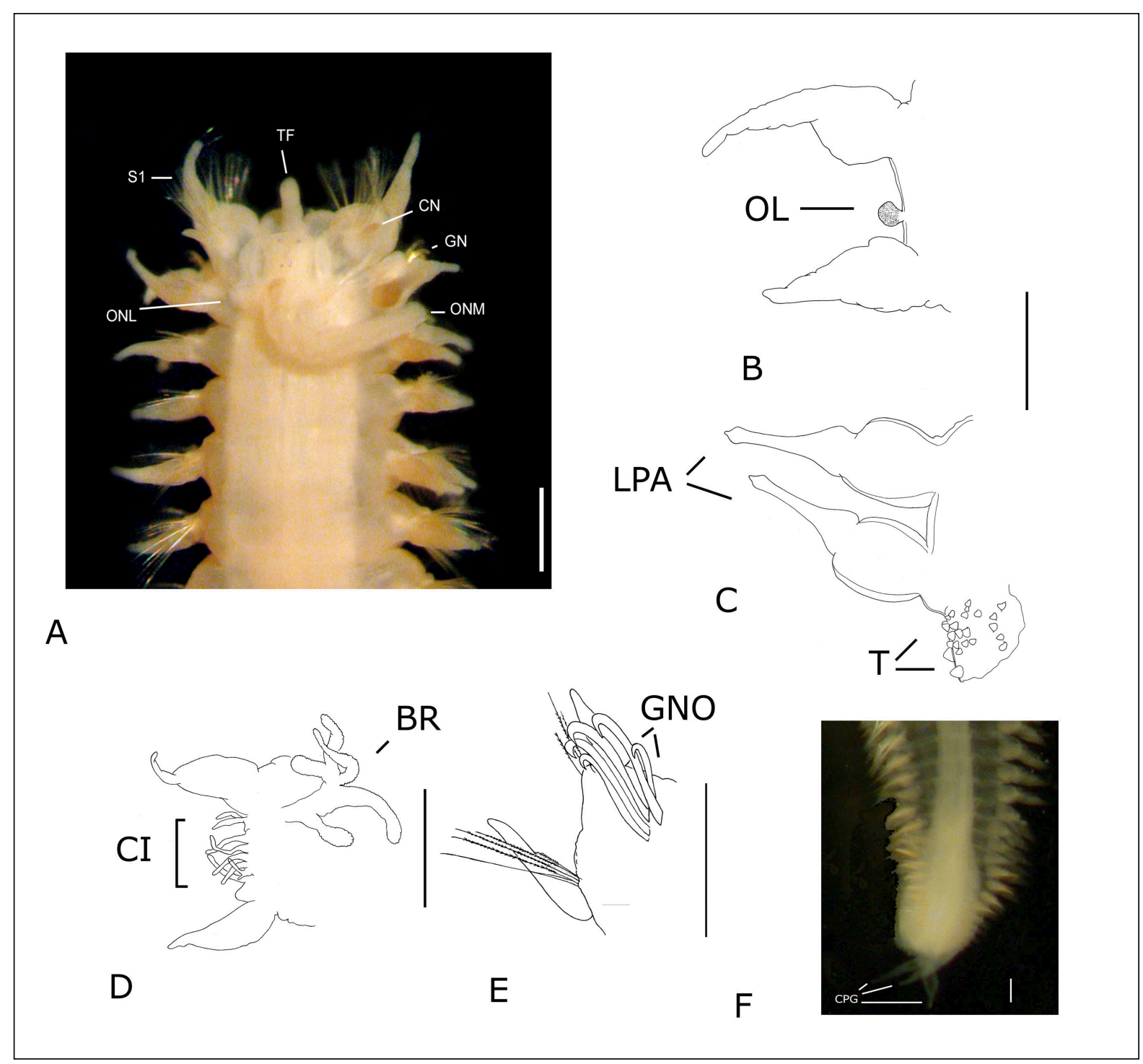

Figura 2.1. Esquema dos caracteres morfológicos da família Poecilochaetidae: A região anterior, vista dorsal; B. parapódio 5, vista anterior; C. parapódio 10, vista anterior; D. parapódio 55, vista anterior; E. parapódio 55, vista anterior; E. parapódio posterior, vista anterior; F. pígidio. Abreviações: $\mathrm{BR}$, brânquias; $\mathrm{Cl}$, cirros interramais, $\mathrm{CN}$, cirro notopodial; CPG, cirros pigidiais; GNE, ganchos neuropodiais; GN, ganchos notopodiais; LPA, lobos parapodiais; OL, órgãos laterais; ONM, órgão nucal mediano; T, tubérculo; TF, tubérculo facial; $\mathrm{S}$, setígero. Cerdas omitidas nas figuras 1B-D. 


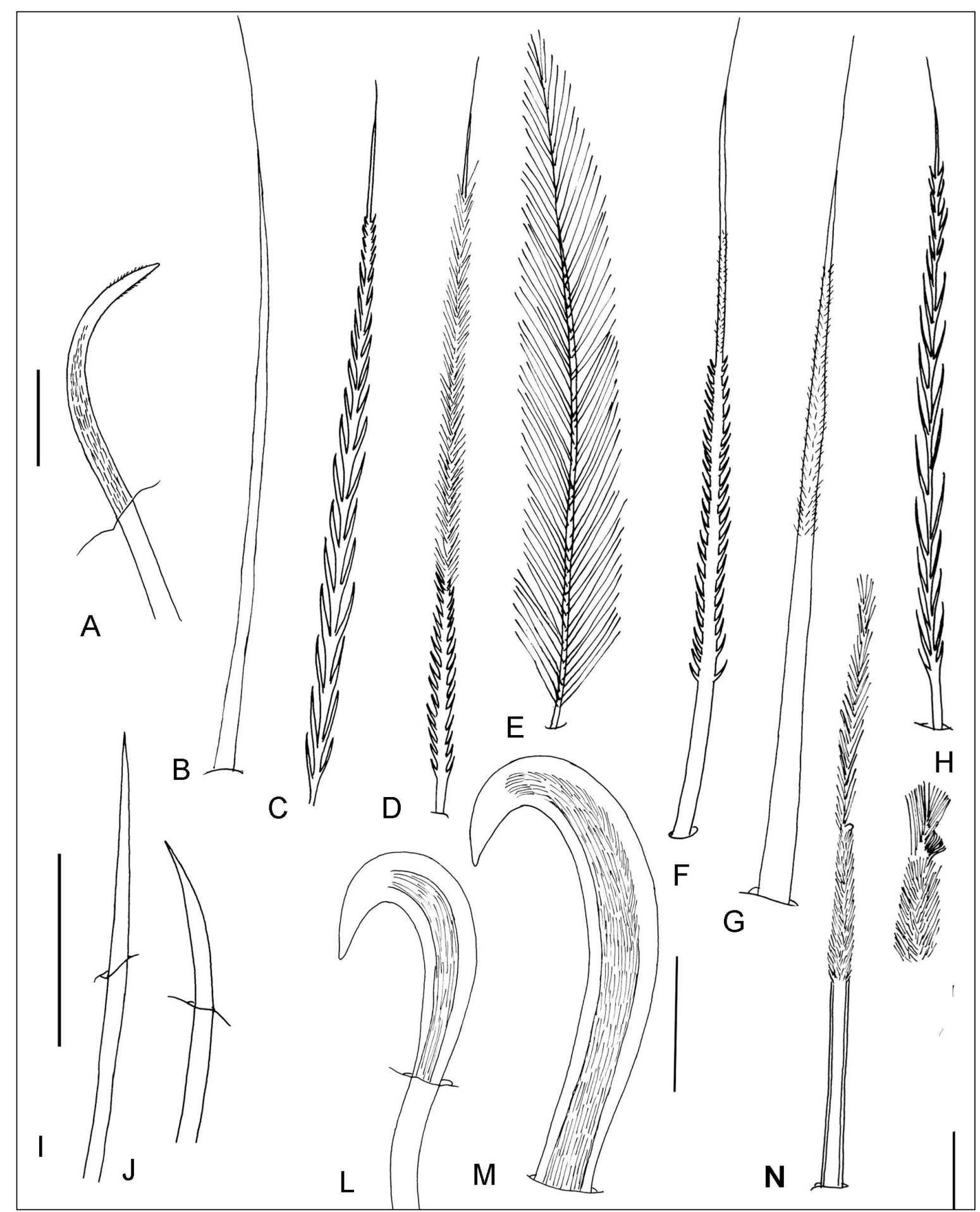

Figura 2.2. Cerdas família Poecilochaetidae. A, gancho neuropodial; B.capilar; C, espinhosa; $D$, espinhosa-plumosa; E, plumosa; $F$, espinhosa-plumosa; $G$, espinhosa-plumosa; $H$, simpodial;I, espinho notopodial; J. espinho notopodial; L. gancho notopodial; M, gancho notopodial; N, aristada. Escalas A-M.100 $\mu \mathrm{m}$, N. $50 \mu \mathrm{m}$. 


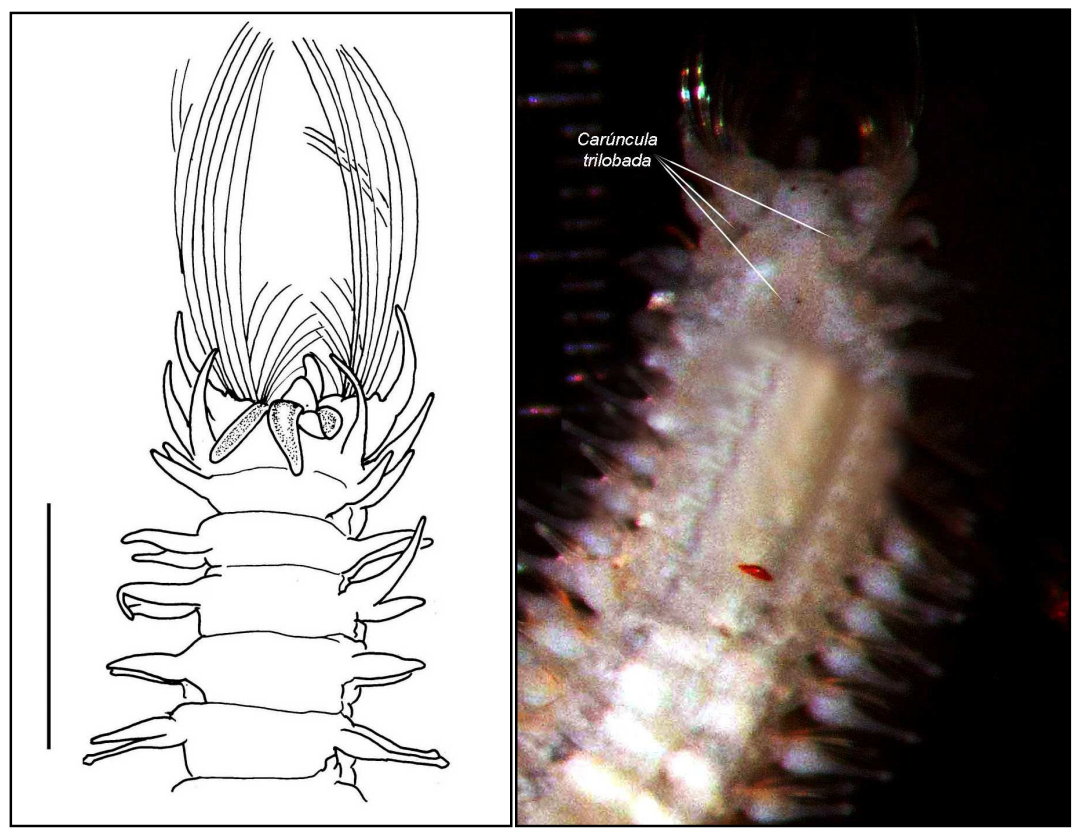

(A)

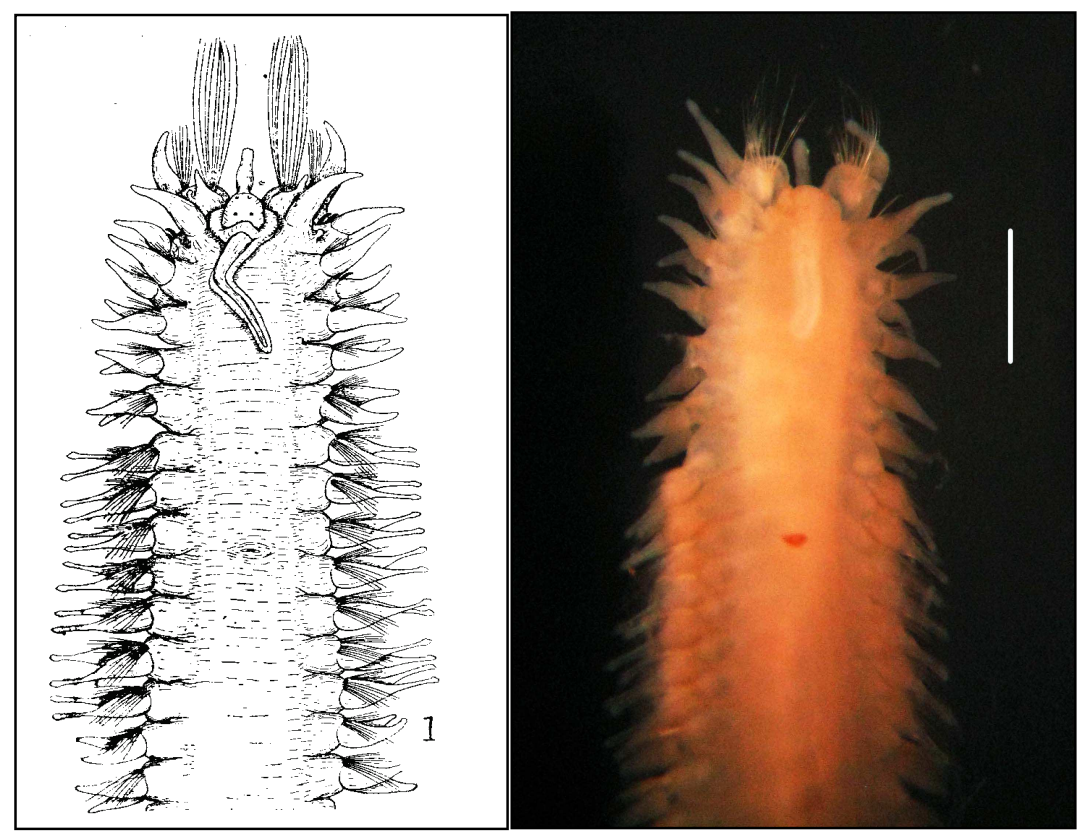

(B)

Figura 2.3. A, região anterior de Poecilochaetus perequensis Santos \& Mackie, 2008 evidenciando a carúncula trilobada com lobos laterais subiguais. B, região anterior de Poecilochaetus australis Nonato, 1963 com detalhe da carúncula única atingindo 0 4-5 setígero. Nota: a escala representa $1 \mathrm{~mm}$. Desenho figura A, fonte: Santos \& Mackie, 2008. Desenho figura B, fonte Nonato, 1963. 
Tabela 2.1. Locais de ocorrência de Poecilochaetus australis Nonato, 1963 na costa brasileira citados na literatura. Fonte: Amaral \& Nallin, 2004.

\begin{tabular}{|c|c|c|c|c|}
\hline Ocorrência & Região & Fácies & Prof.(m) & Bibliografia \\
\hline SP, Ubatuba & infra & $\mathrm{AF}$ & 3 & Ferreira, J.A 2004 \\
\hline SP, Ubatuba & infra & $A F, A M F, L$ & $5-15$ & Abreu, 1978 \\
\hline SP, Ubatuba & infra & $A, L$ & $1-2$ & Amaral, 1977b; 1980a \\
\hline $\begin{array}{l}\text { RJ, Bacia de } \\
\text { Campos }\end{array}$ & infra & $\begin{array}{l}\text { AMG, AM, AF, } \\
\text { AMF, L }\end{array}$ & $12-197$ & Attolini, 1997 \\
\hline SP, Ubatuba & infra & $\begin{array}{l}\text { AMG, AM, AF } \\
\text { e AMF }\end{array}$ & $\begin{array}{l}\text { Halodule ; } 0 \\
-5\end{array}$ & Corbisier, 1994 \\
\hline SP, Ubatuba & infra & $A, L$ & $4-20$ & Forneris, 1969 \\
\hline SP, Ubatuba & infra & $\mathrm{AF}, \mathrm{AMF}, \mathrm{L}$ & & Lana, 1981 \\
\hline PR, Paranaguá & infra & $A, A F, A M F, L$ & $\begin{array}{l}\text { Estuário; } 3 \\
6,15\end{array}$ & Lana, 1986b \\
\hline SP, São & & & & \\
\hline Sebastião & entre & $\mathrm{AF}, \mathrm{AMF}$ & & Lopes, 1993 \\
\hline SP, Ubatuba & infra & $A F, A M F, L$ & $10-25$ & Morgado, 1988 \\
\hline SP, Ubatuba & infra & $\mathrm{AF}, \mathrm{AMF}, \mathrm{L}$ & $10-25$ & Morgado \& Amaral, 1989 \\
\hline SP, Ubatuba & infra & $\mathrm{L}$ & $5-11 m$ & Muniz et al., 1996 \\
\hline SP, Ubatuba & infra & $A, L$ & $0-5$ & Nonato, 1963 \\
\hline Paraná & plâncton & & & Nonato, 1963 \\
\hline $\begin{array}{l}\text { Santa Catarina } \\
\text { Rio Grande do }\end{array}$ & plâncton & & & Nonato, 1963 \\
\hline $\begin{array}{l}\text { Sul } \\
\text { Rio Grande do }\end{array}$ & plâncton & & & Nonato, 1963 \\
\hline Sul & infra & & & Nonato, 1973 \\
\hline Rio de Janeiro & infra & & & Nonato, 1981 \\
\hline $\begin{array}{l}\text { SP, Ubatuba } \\
\text { Rio de Janeiro }\end{array}$ & $\begin{array}{l}\text { infra } \\
\text { entre }\end{array}$ & $A, L$ & 100 & $\begin{array}{l}\text { Nonato, } 1981 \\
\text { Nonato, } 1981\end{array}$ \\
\hline SP, Ubatuba & entre & $\mathrm{AL}$ & & Nonato, 1981 \\
\hline $\begin{array}{l}\text { SP, Santos } \\
\text { Rio Grande do } \\
\text { Sul }\end{array}$ & $\begin{array}{l}\text { entre } \\
\text { infra }\end{array}$ & $A L$ & & $\begin{array}{l}\text { Nonato, } 1981 \\
\text { Orensanz \& Gianuca, } \\
1974\end{array}$ \\
\hline $\begin{array}{l}\text { SP, Litoral Norte } \\
\text { SP, São }\end{array}$ & infra & $\mathrm{AF}, \mathrm{AMF}$ & $15-100$ & Paiva, 1990; 1993a \\
\hline $\begin{array}{l}\text { Sebastião } \\
\text { PR, Paranaguá }\end{array}$ & $\begin{array}{l}\text { infra } \\
\text { infra }\end{array}$ & $\begin{array}{l}\text { A, L } \\
\text { AM }\end{array}$ & $\begin{array}{l}8-40 \\
\text { Estuário; } 14 \\
-19\end{array}$ & $\begin{array}{l}\text { Pires-Vanin et al., } 1997 \\
\text { Sovierzoski, } 1991\end{array}$ \\
\hline $\begin{array}{l}\text { SP, Santos } \\
\text { SP, Cananéia }\end{array}$ & $\begin{array}{l}\text { infra } \\
\text { infra }\end{array}$ & $\begin{array}{l}A, L \\
A F, A M F\end{array}$ & $\begin{array}{l}2 \text { - } 60 \\
\text { Estuário; } 1 \\
-80\end{array}$ & $\begin{array}{l}\text { Tommasi, } 1967 \\
\text { Tommasi, } 1970\end{array}$ \\
\hline SE & & & & Santos, et al., 1994 \\
\hline $\begin{array}{l}\text { SP } \\
\text { SP, São }\end{array}$ & infra & & plataforma & Paiva, 1990 \\
\hline $\begin{array}{l}\text { Sebastião } \\
\text { SP, São }\end{array}$ & infra & & $8-40$ & Maciel, 1996 \\
\hline $\begin{array}{l}\text { Sebastião } \\
\text { SP, São }\end{array}$ & infra & & & Pires-Vanin, et al., 1997 \\
\hline $\begin{array}{l}\text { Sebastião } \\
\text { SP, São }\end{array}$ & entre & & & Amaral et al., 2003 \\
\hline $\begin{array}{l}\text { Sebastião } \\
\text { SP, São }\end{array}$ & entre & & & Rizzo, 1998 \\
\hline Sebastião & entre & & & Rizzo \& Amaral, 2001 \\
\hline SP, Ubatuba & & & & Petti \& Nonato, 2000 \\
\hline SP, Ubatuba & infra & & $5-10$ & Muniz et al., 1996 \\
\hline
\end{tabular}




\section{Referências bibliográficas}

ALLEN, E. J. The anatomy of Poecilochaetus Claparède. Q. J. Micr. Sci., London, v. 48, p. 79-151, 1904.

AMARAL, A. C. Z.; NALLIN, S. A. H. Catálogo das espécies dos annelida Polychaeta da Costa Brasileirra. Instituto de Biologia, UNICAMP, 2004.

ATTOLINI, F. S. Composição e distribuição dos anelídeos poliquetas na Plataforma Continental da região da Bacia de Campos, RJ, Brasil. Dissertação de mestrado, Instituto Oceanográfico, Universidade de São Paulo, p. 122, 1997.

BLAKE, J. A.; ARNOFSKY, P. L. 1999. Reproduction and larval development of the spioniform Polychaeta with application to systematics and phylogeny. Hidrobiologia., v. 402, p. 57-106, 1999.

CORBISIER, T. N. Macrozoobentos da Praia do Codó (Ubatuba, SP) e a presença de Halodule wrightii Ascherson. Bol. Inst. Ocean. São Paulo, v. 42, n. 1/2, p. 99-111, 1994.

EHLERS, E. Beiträge zur Kenntnis der Verticalverbreitung der Brostenwürmer in Meer. Z. wiss. Zool., v. 25, p. 1-102, 1875.

EIBYE-JACOBS, D. A preliminary phylogenetic analysis of Poecilochaetidae (Annelida: Polychaeta) at the species level. Mar. Ecol., v. 26, p. 171-180, 2006.

FAUCHALD, K.; JUMARS, P. The diet of worms: A study of polychaete feeding guilds. Oceanogr. Mar. Biol. Annu. Rev., v. 1, p. 193-284, 1979.

FAUCHALD, K.; ROUSE, G. W. Polychaete systematics: Past and present. Zool. Scripta, v. 26, n. 2, p. 71-138, 1997. 
HANNERZ, L. Larval development of the polychaete families Spionidae Sars, Disomidae Mensil, and Poecilochaetidae n. fam. in the Gullmar Fjord (Sweden). Zoologiska Bidrag frän Uppsala, v. 31, p. 1-204, 1956.

HAUSEN, H.; BARTOLOMAEUS, T. Setal structure and chaetogenesis in Scolelepis squamata and Malacoceros fuliginosus (Spionidae, Annelida). Acta Zool. (Stockholm). v. 79, n. 3, p. 149-161, 1998.

LAUBIER, L.; RAMOS, J. A new genus of Poecilochaetidae (Polychaetous annelids) in the Mediterranean: Elicodasia mirabilis. Proc. Biol. Soc. of Wash., v. 86, p. $69-77,1973$.

LOPES, P. P. Estrutura da comunidade de poliquetos da zona entremarés da região do Araçá, São Sebastião (SP). Dissertação de mestrado, Instituto de Biologia, Universidade Estadual de Campinas, 106 p., 1993.

MACKIE, A. S. Y. The Poecilochaetidae and Trochochaetidae (Annelida: Polychaeta) of Hong Kong. Proceedings of the Second International Marine Biological Workshop: The Marine Flora and Fauna of Hong Kong and Southern China, Hong Kong, 1986. p. 337-362, 1990.

MACKIE, A. S. Y. Taxonomy and phylogeny of spioniform polychaetes (Annelida) PhD thesis. Göteborg University Faculty of Natural Science. 1996.

MILLIGAN, M. R.; GILBERT, K. M. Family Poecilochaetidae Hannerz, 1956. Taxonomic guide to the Polychaetes of the northern Gulf of Mexico. 2a Ed. J. M. Uebelacker and P. G. Johnson. Mobile: Barry A. Vitor and Associates, p. 9.1-9.7, 1984.

MIURA, T. Poecilochaetus koshikiensis, a new polychaete species from ShimoKoshiki Island, Japan. Proc. of the Biol. Soc. of Wash., v. 101, n. 13, p. 671$675,1988$. 
MIURA, T. Two new species of the genus Poecilochaetus (Polychaeta, Poecilochaetidae) from Japan. Proc. Japan. Soc. Syst. Zool., v. 39, p. 8-19, 1989.

MUNIZ, P.; PIRES-VANIN, A. M. S.; BURONE, L.; SILVA, J. P. Density and distribution of polychaetes in the infralitoral of Mar Virado Bight (Ubatuba, SP) southeastern brazilian coast. An. Acad. Bras. Ciências, v. 68, n. 3, p. 453-462, 1996.

NONATO, E. F. Poecilochaetus australis sp. nov. (Annelida, Polychaeta). Neotropica, v. 9, n. 28, p. 17-26, 1963.

NONATO, E. F. Anelídeos poliquetas. Relatório sobre a segunda pesquisa oceanográfica e pesqueira do Atlântico Sul entre Torres e Maldonado (Lat. $2^{\circ}$ S - $35^{\circ}$ S). Programa Rio Grande do Sul II, Parte I.,1973.

NONATO, E. F. Contribuição ao conhecimento dos anelídeos poliquetas bentônicos da Plataforma Continental Brasileira, entre Cabo Frio e o Arroio Chuí. Tese de Livre-Docência, Instituto Oceanográfico, Universidade de São Paulo, p. 246, 1981.

NOZAIS, C.; DUCHENE, J. C.; BHAUD, M. Control of position in the water column by the larvae of Poecilochaetus serpens, (Polychaeta): the importance of mucus secretion. J. Exp. Mar. Biol. Ecol., v. 210, p. 91-106, 1997.

PAIVA, P. C. Soft-bottom polychaetes of the Abrolhos bank, eastern Brazil. VII International Polychaete Conference, 7, p. 145, 2001.

PAIVA, P. C. Padrões de distribuição e estrutura trófica dos anelídeos poliquetas da Plataforma Continental do litoral norte do Estado de São Paulo. Dissertação de mestrado, Instituto Oceanográfico, Universidade de São Paulo, 146 p., 1990. 
PAIVA, P. C., Anelídeos poliquetas da Plataforma Continental norte do Estado de São Paulo: I - Padrões de densidade e diversidade específica. Bol. Inst. Ocean. São Paulo, v. 41, n. 1/2, p. 69-80. 1993a.

PIRES-VANIN, A. M. S.; CORBISIER, T. N., ARASAKI, E.; MÖELLMANN, A. M. Composição e distribuição espaço-temporal da fauna bêntica no Canal de São Sebastião. Rel. Técn. Inst. Ocean., v. 41, p. 29-46, 1997.

READ, G. B. New deep-sea Poecilochaetidae (Polychaeta: Spionida) from New Zealand. J. Nat. Hist., v. 20, p. 399-413, 1986.

RIBEIRO, Z. A. Análise cladística de Poecilochaetidae Hannerz, 1956 (Annelida, Polychaeta). Tese de Doutorado. Universidade Federal do Paraná. p. 62, 2004.

RIZZO, A. E.; AMARAL, A. C. Z. Environmental variables and intertidal beach annelids of São Sebastião Channel (State of São Paulo, Brazil). Rev. Biol. Trop., v. 49, n. 3-4, p. 849-857, 2001.

ROUSE, G. W.; FAUCHALD, K. Cladistics and polychaetes. Zool. Scripta. v. 26, n. 2, p. 139-204, 1997.

SOVIERZOSKI, H. H. Estrutura temporal da comunidade macrobentônica da Foz do Rio Maciel, Baía de Paranaguá, Paraná. Dissertação de mestrado, Instituto de Biociências, Universidade Federal do Paraná, p. 98, 1991.

ROUSE, G. W.; PLEIJEL, F. Polychaetes. Oxford University Press. 2001.

TAYLOR, J. L. A Pacific polychaete in southeastern United States. Quart. J. Flor. Acad. Sci., v. 29, n. 21-26, 1966.

SANTOS, M. A.; SANTOS, C. S. G.; OLIVEIRA, C. M. M. Polychaeta in the estuary of the Piauí River, Sergipe, Brazil, mém. J.-C. Dauvinm L. Laubier and D. J. Reihs, Museum natn. Hist. Nat., Paris, p. 541-547. , 1994. 
SANTOS, C. S. G.; MACKIE, A. S. Y. New species of Poecilochaetus Claparède, 1875 (Polychaeta, Spionida, Poecilochaetidae) from Paranaguá Bay, southeastern Brazil. Zootaxa, v. 1790, p. 53-68, 2008.

SANTI, L. Taxocenoses de Polychaeta e Mollusca sublitorais, substrato inconsolidado, em um estuário impactado: Baía de Guanabara, Rio de Janeiro, Brasil. Tese de Mestrado. Universidade Santa Úrsula, Rio de Janeiro, RJ. P. 206, 2003.

SANTI, L. O status taxonômico de Poecilochaetus australis Nonato, 1963 (Poecilochaetidae, Spionida) - uma reavaliação. $1^{\circ}$ Simpósio Latino Americano de Polychaeta. Centro de Biologia Marinha - CEBIMar/USP, São Sebastião, São Paulo, Brasil, 2006.

TOMMASI, L. R. Observações preliminares sobre a fauna bêntica de sedimentos moles da baía de Santos e regiões vizinhas. Bol. Inst. Ocean., v. 16, n. 1, p. 43-65, 1967.

Parte do texto deste capítulo faz parte de contribuição elaborada por Cinthya S.G. Santos ${ }^{1}$ \& Leonardo Santi ${ }^{2}$ para o capítulo da família Poecilochaetidae do livro "Poliquetas da Costa Brasileira" (em preparação). Editora: Dra. Cecília Amaral, UNICAMP, SP.

1Departamento de Biologia Marinha, Instituto de Biologia, Universidade Federal Fluminense, Campus Valonguinho, Centro, Niterói, CP. 100.644, Rio de Janeiro.

${ }^{2}$ Laboratório de Dinâmica Bêntica, Departamento de Oceanografia Biológica, Instituto Oceanográfico da Universidade de São Paulo, São Paulo, 05508-120, São Paulo. 


\section{CAPÍTULO 3}

\section{Dinâmica estrutural da macroinfauna bêntica sublitoral em local sujeito à influência de efluentes urbanos não-tratados, Baía de Guanabara, Rio de Janeiro, Brasil}

\section{Introdução}

Os estudos sobre a dinâmica da macroinfauna bêntica de substratos inconsolidados têm uma história relativamente longa e bem desenvolvida no campo da ecologia bêntica marinha (exs. revisões PEARSON; ROSENBERG, 1978; THISTLE, 1981; HALL et al., 1994). A maioria dos estudos da estrutura da comunidade até os anos 80 baseavam-se nas teorias de fatores dependentes da densidade no controle das populações, tais como predação e competição (CODY, 1968; DIAMOND, 1978). Posteriormente, uma reavaliação dos processos de não-equilíbrio demonstrou a importância dos processos estocásticos, como o recrutamento, no controle da população e da estrutura da comunidade (PRICE; WARWICK, 1980; PERSSON, 1983; BACHELET, 1986; BUCHANAN et al. 1986). O papel das estruturas biogênicas na distribuição e composição das comunidades bênticas sublitorais já demonstrou que estes hábitats são responsáveis por agregar a fauna sublitoral pela diversidade e disponibilidade de nichos (REISE et al. 2001).

Os efeitos deletérios do enriquecimento orgânico na estrutura da comunidade e na biologia populacional dos organismos da macroinfauna de substratos inconsolidados já são conhecidos há algum tempo (PEARSON; ROSENBERG, 1978; LEVIN et al., 1994; GRAY et al., 2002). É de conhecimento também que o aumento do input orgânico (PEARSON; ROSENBERG, 1978) e a carência de oxigênio associados a esta adição extra de material orgânico (GRAY et al. 2002) são capazes de alterar a dinâmica estrutural e a composição espacial da fauna bêntica.

Uma das maneiras mais recorrentes dos contaminantes atingirem a região costeira é através da descarga de esgoto não tratado (BOURDEAU; BARTH, 1986). Os rejeitos mais comuns na costa são de origem industrial e doméstico, alcançando as águas através do saneamento urbano inadequado. 
As diversas categorias de poluentes associadas a estes rejeitos incluem metais pesados, compostos sintéticos, carbono orgânico, elementos nutritivos e patógenos (CAPUZZO et al., 1985). O influxo de elevadas quantidades de material orgânico provenientes de esgotos domésticos exercem uma demanda elevada de oxigênio, ao mesmo tempo em que liberam nutrientes e contribuem com gás metano e sulfídrico, resultado da decomposição bacteriana dos compostos orgânicos (KENNISH, 1991). Em princípio, essa degradação da matéria orgânica é um processo natural e necessário em muitas cadeias alimentares no oceano. Entretanto, se a taxa de importação de matéria orgânica exceder a degradação bacteriana, então haverá acumulação no ambiente (CLARK, 1997). É sabido também que a poluição orgânica diminui a diversidade biológica, favorecendo a dominância de espécies oportunistas. Ambientes com alta carga orgânica promovem ainda a redução ou aumento drástico da densidade e o aumento do tamanho corpóreo dos indivíduos (GRASSLE; GRASSLE, 1974; PEARSON; ROSENBERG, 1978; LEVIN, 1986).

As fontes de matéria orgânica são numerosas (sedimentação da matéria orgânica produzida na zona fótica, aporte terrígeno, produção bêntica primária e secundária) e variam espaço-temporalmente em importância. As características quantitativas e funcionais dos organismos bênticos são fortemente condicionadas pelo fluxo de matéria orgânica particulada (MOP) disponível na coluna d'água (GOODAY, 2002). Pesquisas realizadas em mares temperados, sobre as respostas dos organismos bênticos depositívoros ao input sazonal de matéria orgânica, demonstraram que estes animais são limitados pela oferta de alimentar em grande parte do ano (LOPEZ; LEVINTON, 1987; LEVIN, L. A., 1986; LEVIN; CREED, 1986).

A fauna bêntica é limitada em grande parte não somente pela quantidade, mas também e principalmente, pela qualidade e disponibilidade dos recursos tróficos (e.g. GALÉRON et al., 2001). Os alimentos em potencial para organismos depositívoros, por exemplo, incluem desde bactérias, microalgas, protozoários, fungos e meiofauna, até matéria orgânica não viva. Para estes organismos também é útil a divisão do material orgânico não vivo contendo primariamente restos de materiais vegetais (e.g., frústulas de diatomáceas e fragmentos de plantas vasculares) e amorfos, os quais estão incluídos geopolímeros húmicos, exsudatos microbianos e moléculas 
adsorvidas, assim como moléculas dissolvidas são alimento em potencial para os depositívoros (BOWEN, 1984; RICE; HASON, 1984). Em estudo conduzido na Baía de Naragansett, Rhode Island, EUA, por exemplo, verificou-se que durante a primavera ocorre aumento da densidade de organismos depositívoros em resposta à deposição recente do bloom de diatomáceas. Por outro lado, o baixo crescimento e sobrevivência no verão ocorrem quando a demanda respiratória excede o input orgânico para o bentos (RUDNICK et al., 1985).

Um dos objetivos de estudos prévios de monitoramento é caracterizar a variabilidade natural da comunidade da macroinfauna bêntica e assim distinguir eventuais impactos em potencial ocasionados por fontes antropogênicas (HILBIG; BLAKE, 2000). Entretanto, no Brasil, existe uma enorme carência de estudos de longo prazo que acompanham a resposta da macroinfauna bêntica sublitoral em locais sujeitos a um alto grau de comprometimento ambiental.

No presente capítulo são apresentados os resultados de amostragens mensais na área de influência do Canal do Mangue, considerada um dos pontos mais comprometidos da Baía de Guanabara, Rio de Janeiro, Brasil. A estratégia amostral do presente estudo procurou acompanhar a dinâmica estrutural da macroinfauna bêntica sublitoral a fim de descrever o padrão estrutural e verificar se houve modificação ao longo do ano associado a alguma variável ambiental.

\section{Metodologia}

A dinâmica estrutural da macroinfauna foi acompanhada através de coletas mensais em um dos locais mais eutrofizados da Baía de Guanabara. Foram realizadas análises de variáveis ambientais da coluna d'água (transparência da água, oxigênio dissolvido, clorofila a, temperatura e salinidade), como também do sedimento (granulometria, potencial redox, matéria orgânica total, clorofila-a e feopigmentos e ATP-sedimentar).

A caracterização da área de estudo, contendo a localização do ponto de amostragem, o status ambiental da Baía de Guanabara, clima e hidrografia, 
assim como os procedimentos de campo para a coleta das variáveis ambientais e biológicas (macroinfauna) encontram-se descritas no capítulo 1.

A representanção dos dados biológicos obtidos foram tratados através de estatística básica através do uso do programa Excell (Microsoft ${ }^{\circledR}$ ) a fim de apresentar os resultados de abundância total de indivíduos coletados (nas 12 campanhas e a cada mês de coleta), abundância média, abundância relativa dos táxons mais representativos, percentual de contribuição dos táxons dominantes ( $10 \%$ de contribuição) no período estudado.

Os cálculos de riqueza específica (número de espécies) e a diversidade específica de Shannon-Wiener ( $\left.\log _{2}\right)$ (SHANNON; WIENER, 1963) por mês e a curva de dominância cumulativa (dados não padronizados e sem transformação) foram realizados através da rotina do pacote estatístico Primer $5^{\circledR}$. Os resultados da riqueza e diversidade específica foram representados através de gráficos gerados pelo programa Excell (Microsoft ${ }^{\circledR}$ ). Para categorizar as diversidades encontradas foi adotado o padrão de CAVALCANTI \& LARRAZÁBAL (2004), no qual se considera alta diversidade os valores acima

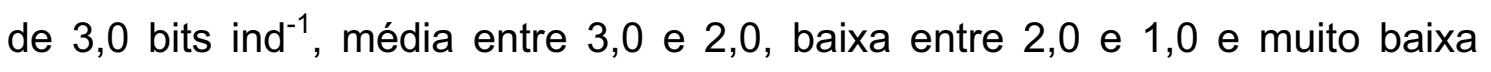
inferior a 1,0 bit ind $^{-1}$.

A análise estatística multivariada foi utilizada a fim de testar a hipótese de haver variabilidade estrutural da macroinfauna no ponto de amostragem estudado. Foram utilizados os métodos de agrupamento das similaridades entre os meses de coleta utilizando-se os dados de abundância dos táxons mais representativos em cada um dos doze meses de coleta. Conforme os pressupostos básicos do pacote estatístico utilizado (Primer $5^{\circledR}$ ), as abundâncias menores que $10 \%$ foram excluídas desta análise a fim de evitar ruídos que pudessem mascarar os resultados. Os dados de abundância dos táxons utilizados para esta análise não foram transformados, utilizando-se os valores de abundância de todos os táxons por mês. Os mesmos resultados obtidos para a análise de cluster foram plotados em mapa bi-dimensional MDS no intuito de verificar padrões de agrupamentos entre os meses estudados e assim testar a hipótese de haver modificação do padrão estrutural da macroinfauna ao longo dos 12 meses estudados.

A análise de similaridade unifatorial (ANOSIM) também foi feita para testar agrupamentos formados a priori (meses de coleta), os quais foram 
agrupados (fatores) de A a L conforme cada mês de coleta (ex: julho de 2005, réplica 1, réplica 2 e réplica 3 - fator B; agosto de 2005, réplica 1, réplica 2 e réplica 3 - fator $\mathrm{C}$, e assim por diante). Os resultados encontrados nesta análise testam, caso ocorram, aqueles encontrados no agrupamento de similaridade de cluster e MDS para os agrupamentos formados. A análise SIMPER (Similarity Percentages - species contributions) foi realizada para demonstrar a dominância específica encontrada em cada um dos 12 fatores (meses de coleta) determinados a priori a fim de testar se houve alteração do padrão estrutural da macroinfauna ao longo do período estudado. Os dados biológicos desta análise (abundância da macroinfauna) não foram padronizados e não houve transformação. O corte para as contribuições baixas foi em $90 \%$. O nome do fator utilizado foi "Meses do ano" sendo identificados de $\mathrm{A}$ a $\mathrm{L}$ como o teste ANOSIM descrito acima.

Com o objetivo de destacar as variáveis ambientais que melhor explicaram os padrões de agrupamento da comunidade foi usada a análise BIOENV (Biota-Environment matching). O método de correlação dos ranquits foi Spearman, com o número máximo de variáveis igual a 5 . A análise foi feita entre as amostras através de medidas de similaridade pela distância euclidiana. Não houve transformação dos dados, mas somente padronização dos valores encontrados na matriz de variáveis ambientais. Foram feitos dois testes: o primeiro dele utilizou todas as variáveis ambientais analisadas, o seguinte exclui as variáveis ambientais da coluna d'água obtidos na superfície. 


\section{Resultados}

\section{Variáveis ambientais}

A alta produtividade primária local condicionou altas concentrações de clorofila-a, assim como reduziu a transparência e a disponibilidade de oxigênio dissolvido na camada superficial da coluna d'água. O local amostrado apresentou sedimentologia do tipo silte-argila com pequenas frações de areia fina, altas concetrações de matéria orgânica total e clorofila a sedimentar, intensa atividade microbiana e substrato altamente reduzido (Eh -300mV) ao longo de todo o período amostrado.

Não houve diferença significativa dos resultados de todas as variáveis ambientais encontrados entre todos meses do estudo (ver capítulo 1, pág. 36). Os resultados encontrados apontam para certa estabilidade temporal dos condicionantes ambientais do local estudado, tanto na coluna d água, mas principalmente das variáveis do sedimento. O local estudado parece ser constantemente influenciado pelas condições de baixa energia hidrodinâmica, revelada pela pouca flutuação das frações sedimentológicas (finas e muito finas) e pelas altas concentrações de matéria orgânica total no sedimento, provavelmente associada a estas frações finas, apresentando intensa atividade microbiana ao longo do ano.

A descrição detalhada dos resultados obtidos na análise das variáveis ambientais pode ser encontrada no capítulo 1.

\section{Variáveis biológicas - Macroinfauna}

Foram triados e identificados 4265 indivíduos das amostras obtidas de junho de 2005 a maio de 2006. Uma listagem de todos os táxons identificados encontra-se no anexo 2. Polychaeta e Crustacea contribuiram com $99 \%$ da abundância encontrada, restando para os outros grandes grupos e Nemertea somente $1 \%$ da abundância do período estudado (Figura 3. 1). 


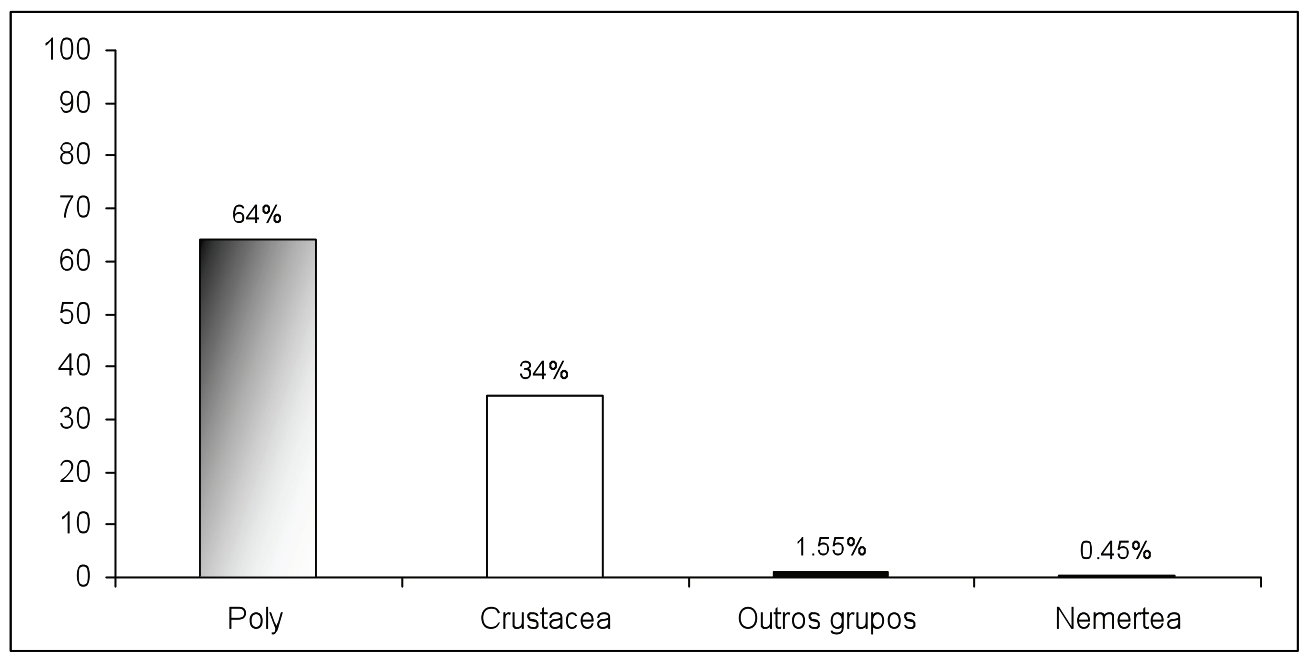

Figura 3.1. Percentual de contribuição dos táxons mais representativos encontrados no período estudado.

Os meses com as maiores abundâncias totais de indivíduos foram outubro de 2005, janeiro e abril de 2006 com 675, 440 e 403 indivíduos respectivamente (Figura 3.2.). A abundância média considerando as três réplicas, de indivíduos por mês seguiu a mesma tendência (Figura 3.3.). Em relação à contribuição dos táxons em cada mês estudado, representado pela abundância relativa dos táxons, foi observado que não houve modificação da predominância dos principais grandes grupos taxonômicos ao longo do período estudado (Figura 3.4.). Não foi observado diferença siginificativa da abundância entre os meses de coleta $(F=1.04 ; p=0.44)$.

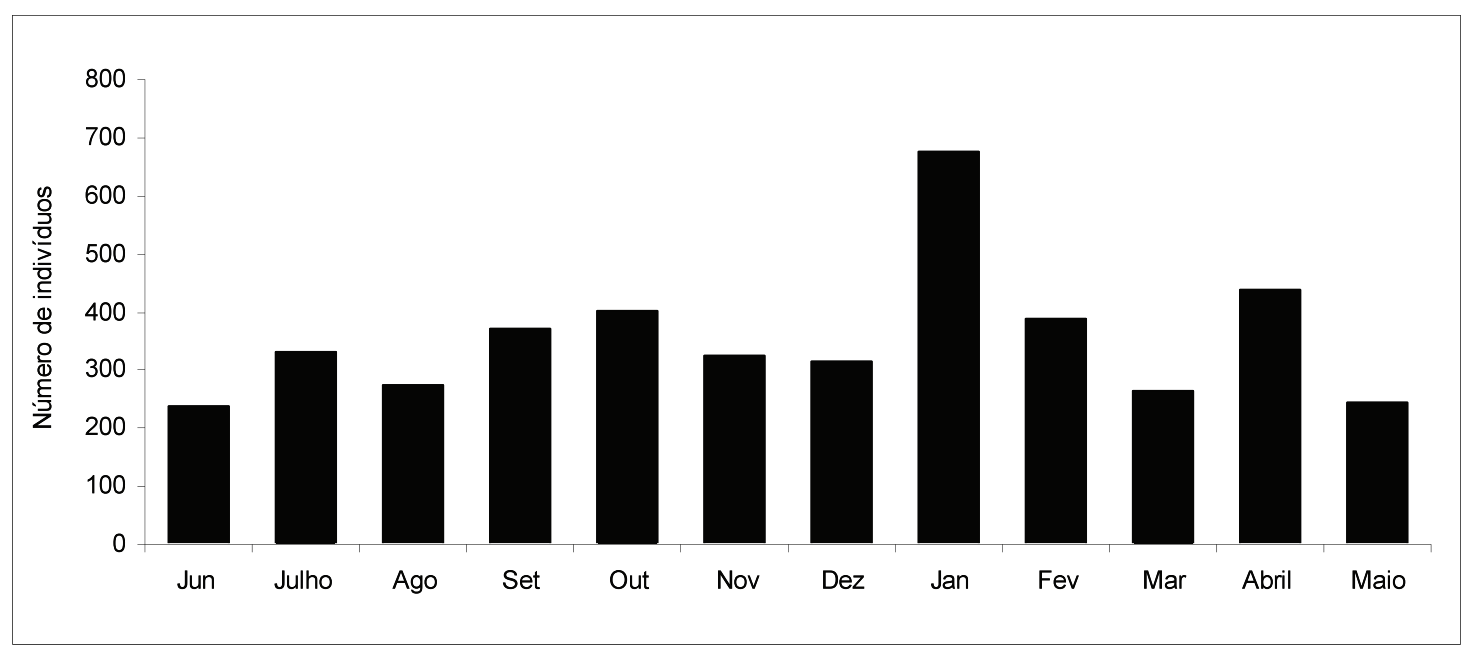

Figura 3.2. Abundância total de indivíduos da macroinfauna coletados ao longo dos 12 meses. 


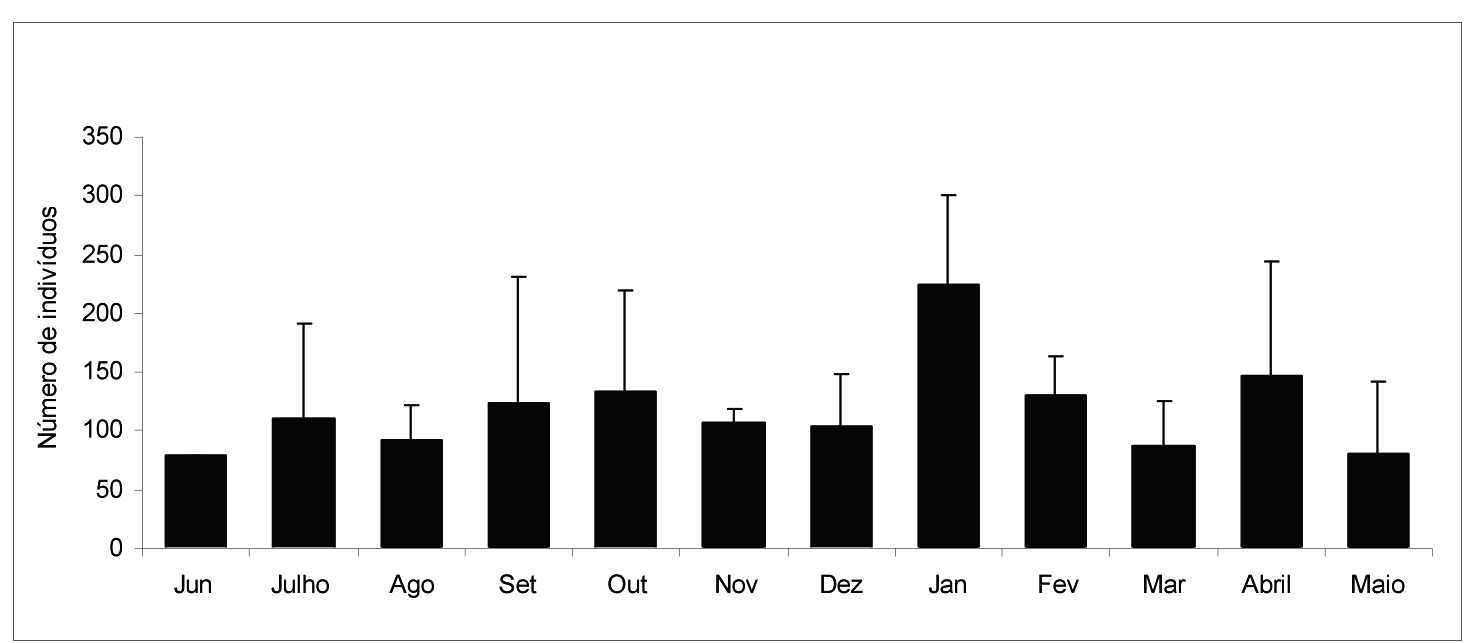

Figura 3.3. Abundância média de indivíduos da macroinfauna coletados ao longo dos 12 meses. Nota: barra verticais representam o desvio padrão.

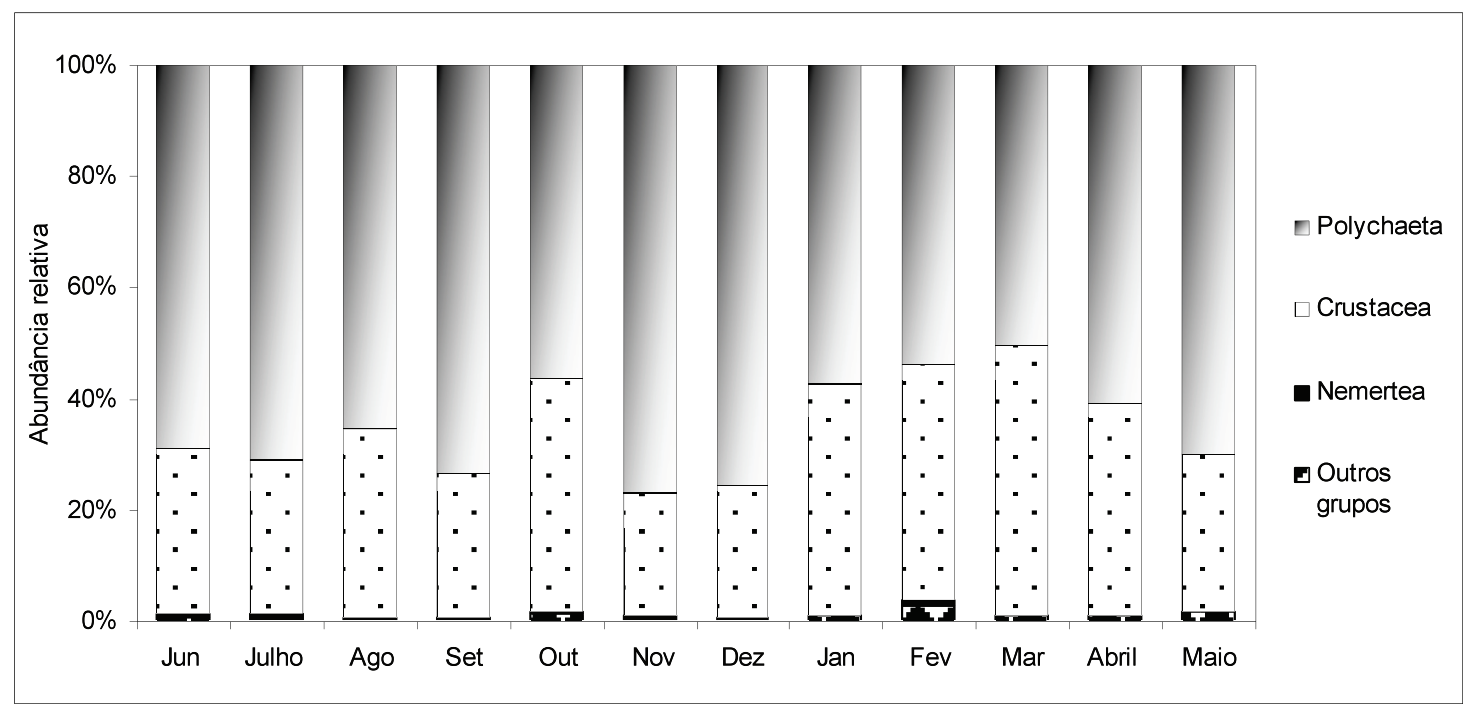

Figura 3.4 - Abundância relativa dos táxons mais representativos da macroinfauna coletada ao longo do período de coleta.

A Tabela 3.1. demonstra que apenas 13 táxons foram responsáveis por grande parte da abundância total da macroinfauna. Em pelo menos um dos meses estudados Os táxons mais abundantes foram: Poecilochaetus australis (Annelida, Spionida), Amphipoda Corophiidae, Spiochaetopterus nonatoi (Annelida, Chaetopteridae), Isopoda Anthuridae e Aricidea suecica simplex (Annelida, Paraonidae), com respectivamente 1544, 559, 345, 310 e 302 indivíduos identificados. A Figura 3.5., que apresenta a contribuição em número de indivíduos dos táxons mais representativos e sua distribuição ao longo do período estudado, e a curva de dominância cumulativa da macroinfauna (Figura 3.6) indicam ainda que o padrão apresentado é do tipo sigmóide intermediário sugerindo um padrão mais completo de diferenciação e 
sobreposição parcial de nichos (Whittaker, 1965). A predominância deste padrão pode ser observada na Figura 3.7. a qual aponta para a manutenção dos táxons dominantes durante o ano estudado.

Tabela 3.1. Táxons dominantes ( $\geq 10 \%$ de contribuição) em pelo menos 1 dos 12 meses de coleta. Os valores representados na tabela apresentam a abundância média no mês.

\begin{tabular}{lcccccccccccc}
\hline \multicolumn{10}{c}{ Meses do ano } \\
\hline Táxon & Jun 2005 & Jul 2005 & Ago 2005 & Set 2005 & Out 2005 & Nov 2005 & Dez 2005 & Jan 2006 & Fev 2006 & Mar 2006 & Abr 2006 & Maio 2006 \\
\hline Poecilochaetus australis & 43 & 45 & 21 & 55 & 39 & 52 & 46 & 82 & 29 & 16 & 67 & 21 \\
Corophiidae & 11 & 16 & 13 & 16 & 19 & 6 & 2 & 38 & 24 & 19 & 13 & 9 \\
Spiochaetopterus nonatoi & 2 & 10 & 16 & 2 & 14 & 8 & 19 & 14 & 11 & 8 & 2 & 11 \\
Isopoda Anthuridea & 6 & 8 & 7 & 4 & 20 & 7 & 0 & 25 & 11 & 5 & 2 & 6 \\
Aricidea suecica simplex & 5 & 12 & 11 & 10 & 6 & 10 & 5 & 11 & 18 & 8 & 2 & 2 \\
Prionospio steenstrupii & 2 & 2 & 3 & 17 & 13 & 10 & 5 & 7 & 5 & 5 & 7 & 2 \\
Tiburonella viscana & 3 & 4 & 4 & 2 & 5 & 3 & 0 & 3 & 6 & 6 & 16 & 3 \\
Pinnixa sp. & 3 & 1 & 6 & 9 & 4 & 7 & 2 & 4 & 3 & 2 & 3 \\
Capitellidae & 0 & 4 & 4 & 4 & 1 & 1 & 2 & 11 & 1 & 5 & 1 \\
Ampeliscidae & 0 & 0 & 1 & 0 & 0 & 0 & 4 & 10 & 2 & 3 & 11 \\
Cladocera (Daphinia sp.) & 0 & 0 & 0 & 0 & 0 & 0 & 8 & 1 & 1 & 1 & 6 \\
Paraonidae & 0 & 0 & 0 & 0 & 0 & 0 & 0 & 0 & 0 & 0 & 3 \\
Amphipoda sp. 1 & 0 & 0 & 0 & 0 & 7 & 0 & 4 & 0 & 0 & 0 & 0 \\
\hline
\end{tabular}

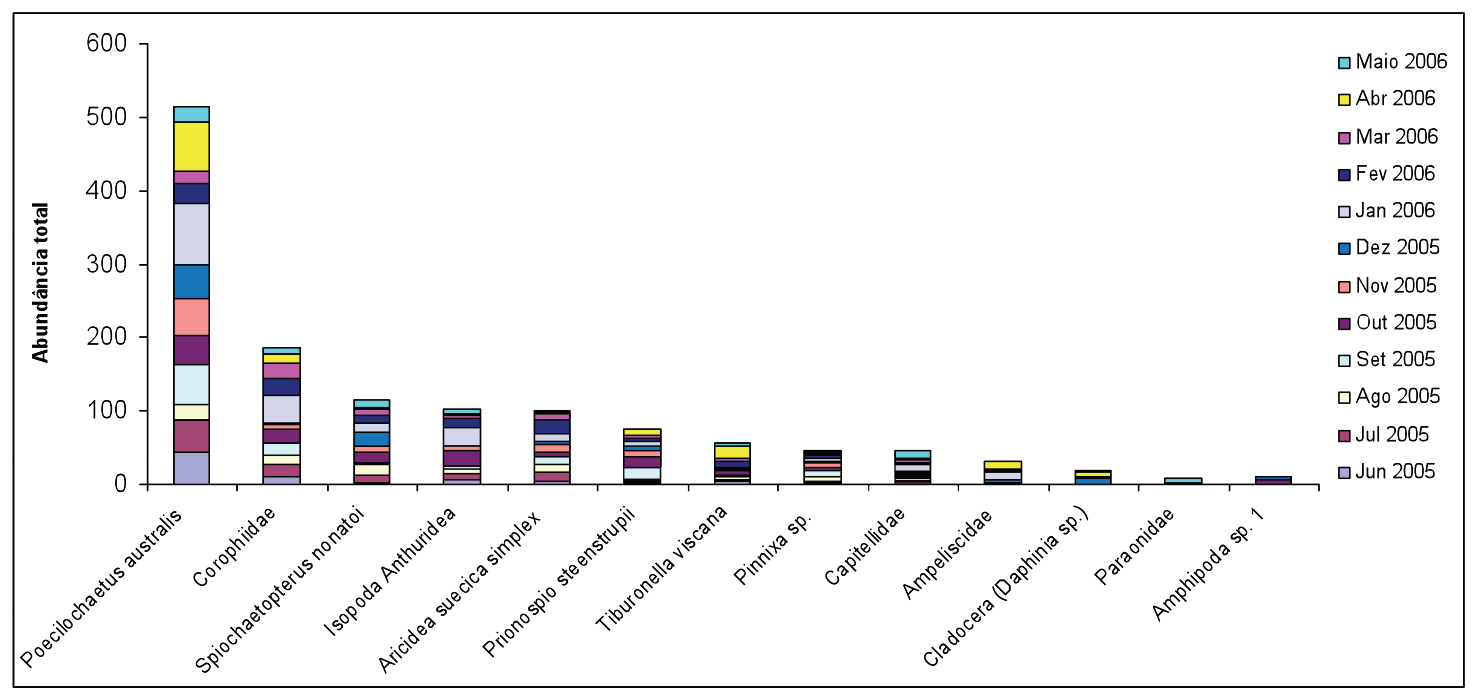

Figura 3.5. Contribuição em número de indivíduos dos 13 táxons dominantes e sua distribuição ao longodo período estudado. 


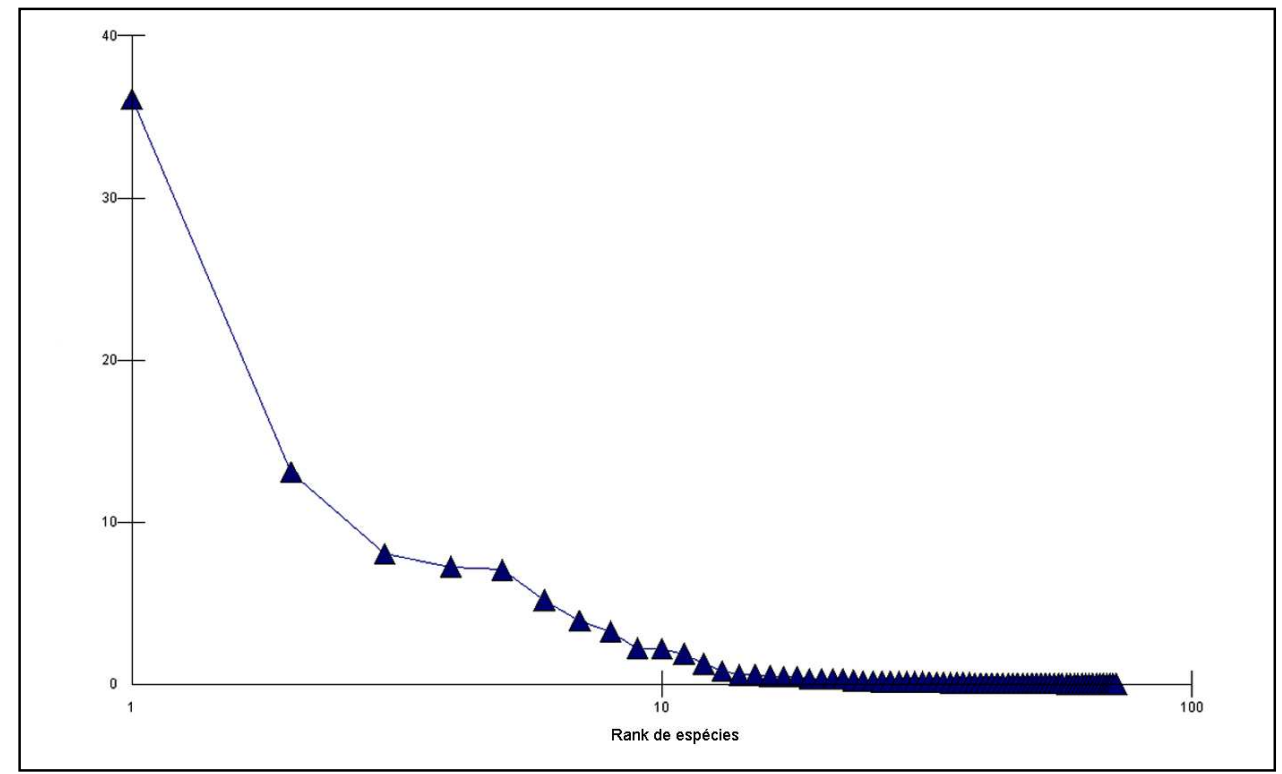

Figura 3.6. Curva de dominância cumulativa da macroinfauna plotando-se os 12 meses de coleta. Nota: eixo y corresponde às abundâncias.

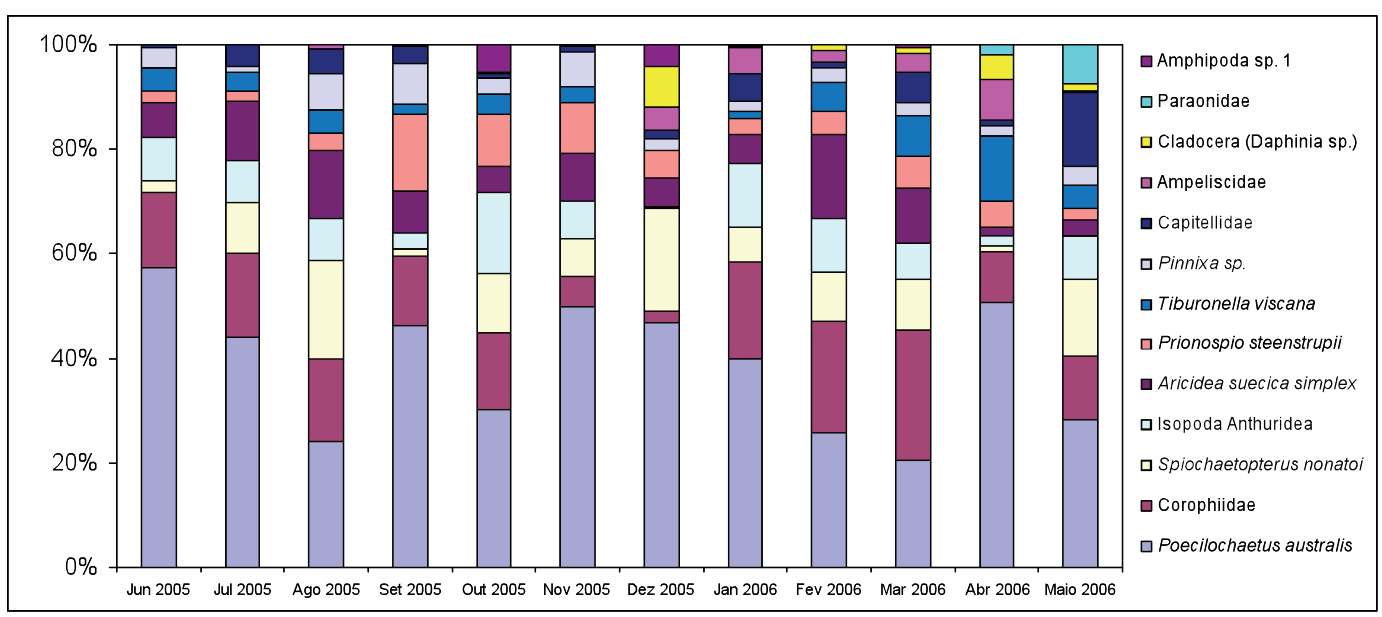

Figura 3.7. Distribuição do percentual de contribuição da abundância dos 13 táxons dominantes de Junho de 2005 a maio de 2006.

Não foram verificadas diferenças significativas entre as riquezas $(F=0.85 ; p=0.54)$ e as diversidades específicas $(F=1.07 ; p=0.42)$ encontradas ao longo do período estudado. A riqueza específica média durante o período estudado foi de 15 táxons, enquanto que para a diversidade específica de Shannon-Wiener o resultado ficou em 2,77 bits por indivíduo, sendo o local considerado como de nível médio de diversidade. As menores riquezas foram observadas nos meses de setembro, novembro e dezembro de 2005, com 13, 12 e 11 táxons identificados, respectivamente. Por outro lado, as maiores riquezas foram observadas em fevereiro de 2006, junho de 2005 e 
abril de 2006, com 20, 19 e 18 táxons identificados, respectivamente (Figuras 3.8. e 3.9.).

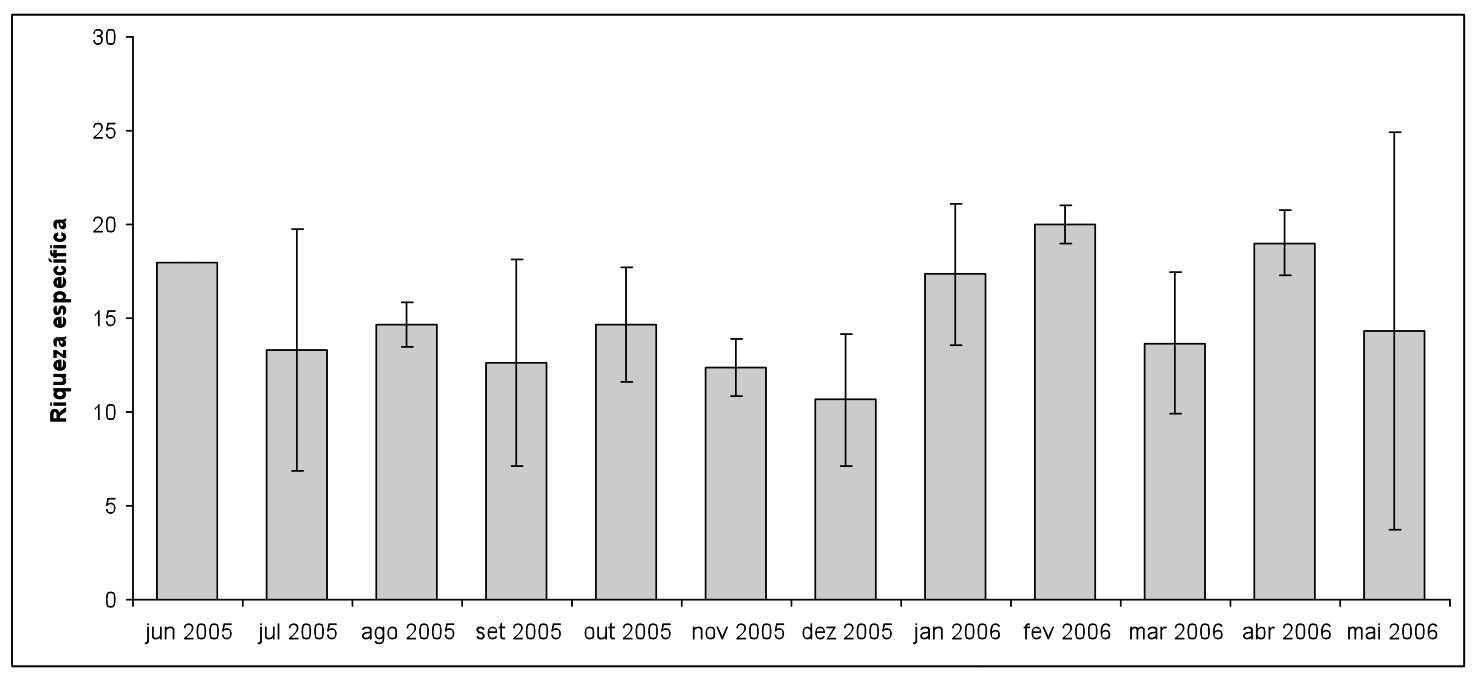

Figura 3.8. Riqueza específica ao longo do período de coleta. Nota: barras verticais representam o desvio padrão.

A diversidade específica de Shannon-Wiener ficou entre valores considerados médios e altos. Os menores valores encontrados para este índice foram observadas nos meses de junho, setembro e dezembro de 2005, com 2,3; 2,5 e 2,5 bits por indivíduo, respectivamente. Já as maiores diversidades foram observadas em fevereiro de 2006, agosto de 2005 e abril de 2006, com 3,$28 ; 3,13$ e 2,98 bits por indivíduo, respectivamente.

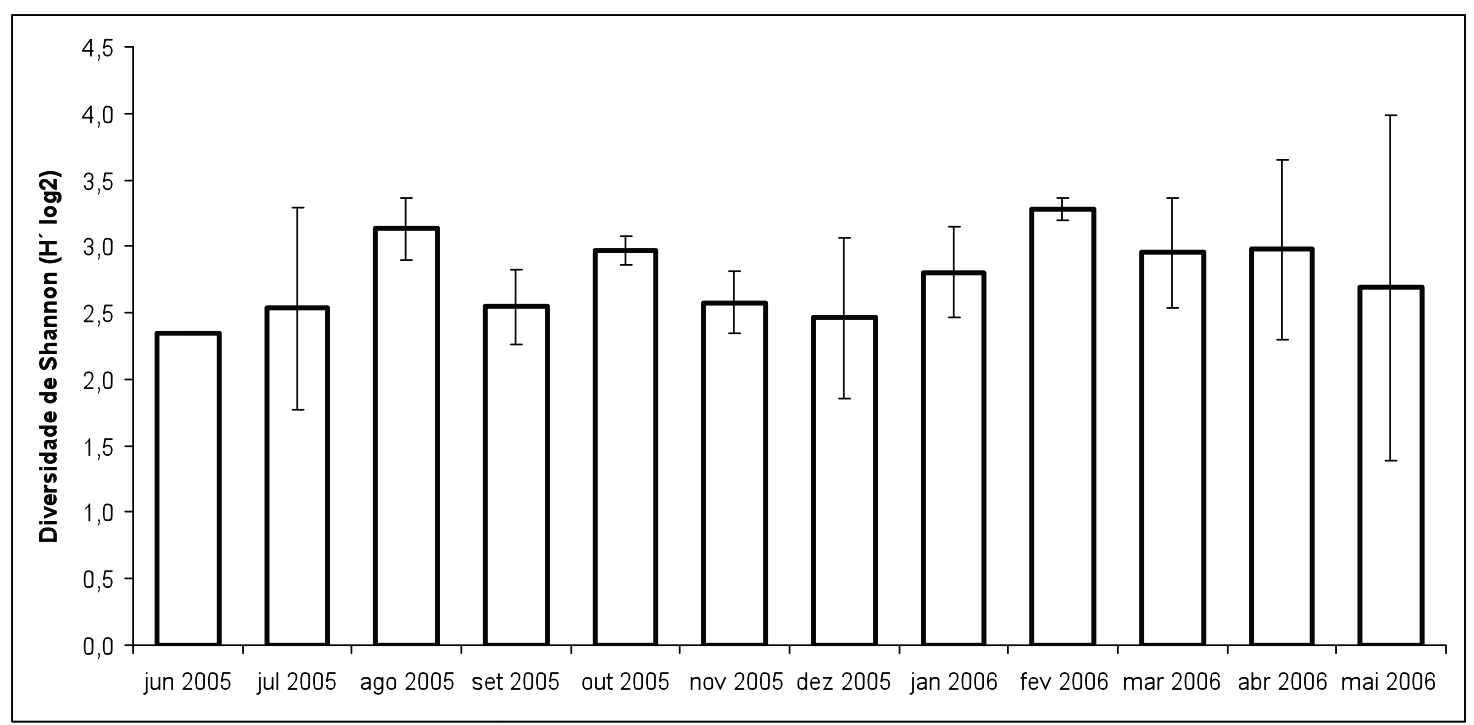

Figura 3.9. Diversidade específica de Shannon-Wiener (bits por indivíduo) ao longo do período de coleta. Nota: barras verticais representam o desvio padrão. 
A análise SIMPER demonstrou que não houve alteração do padrão estrutural da macroinfauna ao longo do período estudado, conforme demonstrado pelos percentuais de similaridade média de todos os meses analisados (Tabela 3.2.). Onze táxons contribuíram na estruturação da macroinfauna do local amostrado: os Annelida Polychaeta Poecilochaetus australis, Spiochaetopterus nonatoi, Aricidea suecica simplex, Prionospio steenstrupii, Paraonidae, amphipoda gamarídeo Corophiidae e Tiburonella viscana, Ampeliscidae, o Isopoda Anthuridae, o Brachyura Pinnixa sp. e o Cladocera Daphnia sp.

Como é típico em comunidades costeiras, as comunidades bênticas sublitorais são dominadas por poliquetas, tanto em número de espécies como número de indivíduos. A ocorrência de espécies indicadoras de poluição ou de ambientes enriquecidos organicamante (ex: Polydora cornuta, Streblospio benedicti ou Capitela capitata) foram raras ou até mesmo ausentes. Tomando como base estas espécies indicadoras, o local estudado não pôde ser considerado como um ambiente com alto grau de comprometimento ambiental.

Os táxons dominantes alternaram-se como dominantes e codominantes, sendo que a espécie Poecilochetus australis foi a que mais vezes foi a dominante, em 9 dos 12 meses, ou de julho de 2005 a fevereiro de 2006. Nos demais meses, março a maio de 2006, os Amphipoda Gamaridea Corophiidae e Tiburonella viscana, e o Annelida Chaetopteridae Spiochaetopterus nonatoi, foram os táxons dominantes nos meses de março, abril e maio de 2006, respectivamente. Poecilochaetus australis foi o táxon codominante nestes três meses. 
Tabela 3.2. Percentual de similaridade obtido através da análise SIMPER (percentuais de contribuição dos táxons) em todos os meses estudados. Nota: não houve coleta de réplicas no mês de junho de 2005 não sendo possível representar os resultados desta análise.

Grupo A (Junho 2005)

Menos de 2 amostras no grupo

Grupo B (Julho 2005)

Similaridade média: 40,67

\begin{tabular}{lccccc} 
Espécies/táxons & Abund.Méd & Sim.Méd. Sim/DP & \multicolumn{1}{c}{ Contrib\% Cum.\% } \\
\hline Poecilochaetus australis & 44,67 & 17,71 & 3,09 & 43,55 & 43,55 \\
Spiochaetopterus nonatoi & 10,00 & 8,46 & 1,15 & 20,80 & 64,35 \\
Corophiidae & 16,33 & 4,43 & 0,80 & 10,90 & 75,25 \\
Isopoda Anthuridea & 8,00 & 3,23 & 0,94 & 7,95 & 83,20 \\
Aricidea suecica simplex & 11,67 & 3,12 & 0,58 & 7,67 & 90,87 \\
\hline
\end{tabular}

DP - desvio padrão

\section{Grupo C (Agosto 2005)}

Similaridade média: 63,24

\begin{tabular}{lcrrrr} 
Espécies/táxons & Abund.Méd & Sim.Méd. Sim/DP & \multicolumn{2}{c}{ Contrib\% } & Cum.\% \\
\hline Poecilochaetus australis & 20,67 & 19,90 & 12,58 & 31,47 & 31,47 \\
Corophiidae & 13,33 & 11,00 & 3,24 & 17,40 & 48,86 \\
Spiochaetopterus nonatoi & 16,00 & 9,02 & 13,85 & 14,27 & 63,13 \\
Aricidea suecica simplex & 11,00 & 6,38 & 2,18 & 10,10 & 73,23 \\
Pinnixa sp. & 6,00 & 5,18 & 4,79 & 8,19 & 81,42 \\
Isopoda Anthuridea & 7,00 & 3,58 & 5,99 & 5,67 & 87,08 \\
Prionospio steenstrupii & 3,00 & 2,79 & 3,42 & 4,41 & 91,50 \\
\hline
\end{tabular}

Grupo D (Setembro 2005)

Similaridade média: 40,84

\begin{tabular}{lccccc} 
Espécies/táxons & Abund.Méd & Sim.Méd. Sim/DP & Contrib\% & Cum.\% \\
\hline Poecilochaetus australis & 54,67 & 14,83 & 1,50 & 36,31 & 36,31 \\
Corophiidae & 15,67 & 11,05 & 2,82 & 27,06 & 63,37 \\
Pinnixa sp. & 9,00 & 6,19 & 2,05 & 15,16 & 78,52 \\
Capitellidae & 4,00 & 2,41 & 2,80 & 5,90 & 84,42 \\
Tiburonella viscana & 2,33 & 1,99 & 1,85 & 4,88 & 89,30 \\
Isopoda Anthuridea & 3,67 & 1,62 & 1,86 & 3,97 & 93,27 \\
\hline
\end{tabular}

\section{Grupo E (Outubro 2005)}

Similaridade média: 44,45

\begin{tabular}{lcclrl} 
Espécies/táxons & Abund.Méd & Sim.Méd. Sim/DP & \multicolumn{1}{c}{ Contrib\% Cum.\% } \\
\hline Poecilochaetus australis & 38,67 & 15,41 & 3,67 & 34,67 & 34,67 \\
Isopoda Anthuridea & 20,00 & 6,62 & 1,02 & 14,89 & 49,56 \\
Spiochaetopterus nonatoi & 14,33 & 5,83 & 1,65 & 13,12 & 62,68 \\
Corophiidae & 18,67 & 5,22 & 2,06 & 11,75 & 74,43 \\
Tiburonella viscana & 5,00 & 3,73 & 1,26 & 8,39 & 82,82 \\
Pinnixa sp. & 4,00 & 2,54 & 2,78 & 5,71 & 88,54 \\
Aricidea suecica simplex & 6,33 & 2,32 & 0,94 & 5,23 & 93,76 \\
\hline
\end{tabular}

Grupo F (Novembro 2005) 
Similaridade média: 73,68

\begin{tabular}{lrrrrr} 
Espécies/táxons & Abund.Méd & Sim.Méd. Sim/DP & \multicolumn{2}{c}{ Contrib\% } & Cum.\% \\
\hline Poecilochaetus australis & 52,00 & 39,31 & 16,75 & 53,35 & 53,35 \\
Aricidea suecica simplex & 9,67 & 7,52 & 2,27 & 10,21 & 63,56 \\
Spiochaetopterus nonatoi & 7,67 & 5,79 & 3,59 & 7,85 & 71,41 \\
Pinnixa sp. & 6,33 & 5,52 & 3,76 & 7,49 & 78,91 \\
Corophiidae & 6,00 & 5,15 & 9,14 & 6,99 & 85,90 \\
Prionospio steenstrupii & 10,00 & 4,47 & 0,58 & 6,06 & 91,96 \\
\hline
\end{tabular}

\section{Grupo G (Dezembro 2005)}

Similaridade média: 52,85

\begin{tabular}{lcclrc} 
Espécies/táxons & Abund.Méd & Sim.Méd. Sim/DP & \multicolumn{2}{c}{ Contrib\% } & Cum.\% \\
\hline Poecilochaetus australis & 45,67 & 28,27 & 2,68 & 53,49 & 53,49 \\
Spiochaetopterus nonatoi & 19,00 & 17,06 & 3,39 & 32,29 & 85,78 \\
Cladocera (Daphinia sp.) & 7,67 & 2,70 & 1,02 & 5,11 & 90,89 \\
\hline
\end{tabular}

Grupo H (Janeiro 2006)

Similaridade média: 69,14

\begin{tabular}{lcrrrr} 
Espécies/táxons & Abund.Méd & Sim.Méd. Sim/DP & \multicolumn{2}{c}{ Contrib\% } & Cum.\% \\
\hline Poecilochaetus australis & 82,00 & 36,54 & 12,90 & 52,85 & 52,85 \\
Corophiidae & 38,00 & 15,04 & 9,06 & 21,75 & 74,60 \\
Spiochaetopterus nonatoi & 13,67 & 6,03 & 2,40 & 8,72 & 83,32 \\
Isopoda Anthuridea & 25,33 & 5,22 & 0,84 & 7,56 & 90,88 \\
\hline
\end{tabular}

\section{Grupo I (Fevereiro 2006)}

Similaridade média: 62,20

\begin{tabular}{lccccc} 
Espécies/táxons & Abund.Méd & Sim.Méd. Sim/DP & \multicolumn{1}{c}{ Contrib\% Cum.\% } \\
\hline Poecilochaetus australis & 28,67 & 20,67 & 7,98 & 33,23 & 33,23 \\
Corophiidae & 23,67 & 10,25 & 1,34 & 16,49 & 49,72 \\
Aricidea suecica simplex & 18,00 & 10,11 & 0,86 & 16,26 & 65,98 \\
Spiochaetopterus nonatoi & 10,67 & 8,50 & 8,36 & 13,67 & 79,65 \\
Isopoda Anthuridea & 11,33 & 7,34 & 2,78 & 11,81 & 91,45 \\
\hline
\end{tabular}

\section{Grupo J (Março 2006)}

Similaridade média: 42,55

\begin{tabular}{lcclrc} 
Espécies/táxons & Abund.Méd & Sim.Méd. Sim/DP & \multicolumn{2}{c}{ Contrib\% } & Cum.\% \\
\hline Corophiidae & 19,33 & 14,14 & 3,65 & 33,22 & 33,22 \\
Poecilochaetus australis & 16,00 & 10,67 & 0,58 & 25,07 & 58,29 \\
Aricidea suecica simplex & 8,33 & 6,00 & 1,06 & 14,11 & 72,40 \\
Ampeliscidae & 2,67 & 3,23 & 3,48 & 7,58 & 79,98 \\
Tiburonella viscana & 6,00 & 3,15 & 9,05 & 7,40 & 87,38 \\
Spiochaetopterus nonatoi & 7,67 & 2,13 & 0,58 & 5,01 & 92,39 \\
\hline
\end{tabular}


Grupo K (Abril 2006)

Similaridade média: 40,61

\begin{tabular}{lcrlrl} 
Espécies/táxons & Abund.Méd & Sim.Méd. Sim/DP & \multicolumn{2}{c}{ Contrib\% } & Cum.\% \\
\hline Tiburonella viscana & 16,33 & 10,01 & 2,50 & 24,64 & 24,64 \\
Poecilochaetus australis & 67,00 & 8,68 & 1,06 & 21,38 & 46,02 \\
Corophiidae & 12,67 & 7,99 & 2,71 & 19,67 & 65,69 \\
Ampeliscidae & 10,33 & 4,34 & 1,64 & 10,68 & 76,37 \\
Prionospio steenstrupii & 6,67 & 3,03 & 1,53 & 7,47 & 83,84 \\
Cladocera (Daphinia sp.) & 6,00 & 2,07 & 1,11 & 5,10 & 88,94 \\
Pinnixa sp. & 2,67 & 1,95 & 2,60 & 4,79 & 93,73 \\
\hline
\end{tabular}

Grupo L (Maio 2006)

Similaridade média: 37,65

\begin{tabular}{lccccc} 
Espécies/táxons & Abund.Méd & Sim.Méd. Sim/DP & \multicolumn{1}{c}{ Contrib\% } & Cum.\% \\
\hline Spiochaetopterus nonatoi & 11,00 & 12,34 & 2,30 & 32,76 & 32,76 \\
Poecilochaetus australis & 21,33 & 9,32 & 0,58 & 24,75 & 57,51 \\
Paraonidae & 5,67 & 5,05 & 2,23 & 13,41 & 70,92 \\
Corophiidae & 9,33 & 4,66 & 0,58 & 12,37 & 83,30 \\
Tiburonella viscana & 3,33 & 1,79 & 0,58 & 4,76 & 88,06 \\
Isopoda Anthuridea & 6,33 & 1,79 & 0,58 & 4,76 & 92,82 \\
\hline
\end{tabular}

A análise de agrupamento, a qual utilizou a matrix de abundância de táxons, realizada para verificar prováveis agrupamentos entre os meses de coleta revelou não haver padrão evidente entre os meses de coleta (Figura 3.10.). Os agrupamentos formados não foram suficientes para identificar modificação do padrão ao longo do período estudado. O agrupamento das diferentes réplicas da macroinfauna coleta em cada um dos 12 meses apresentado sugere que existe pouca variação temporal da estrutura básica da macroinfauna. Este padrão fica evidente no mapa bi-dimensional MDS gerado a partir da mesma matriz de dados biológicos (Figura 3.11.). O distanciamento espacial de algumas réplicas apresentado no mapa não é característico de agrupamentos distintos que possam caracterizar sazonalidade. 


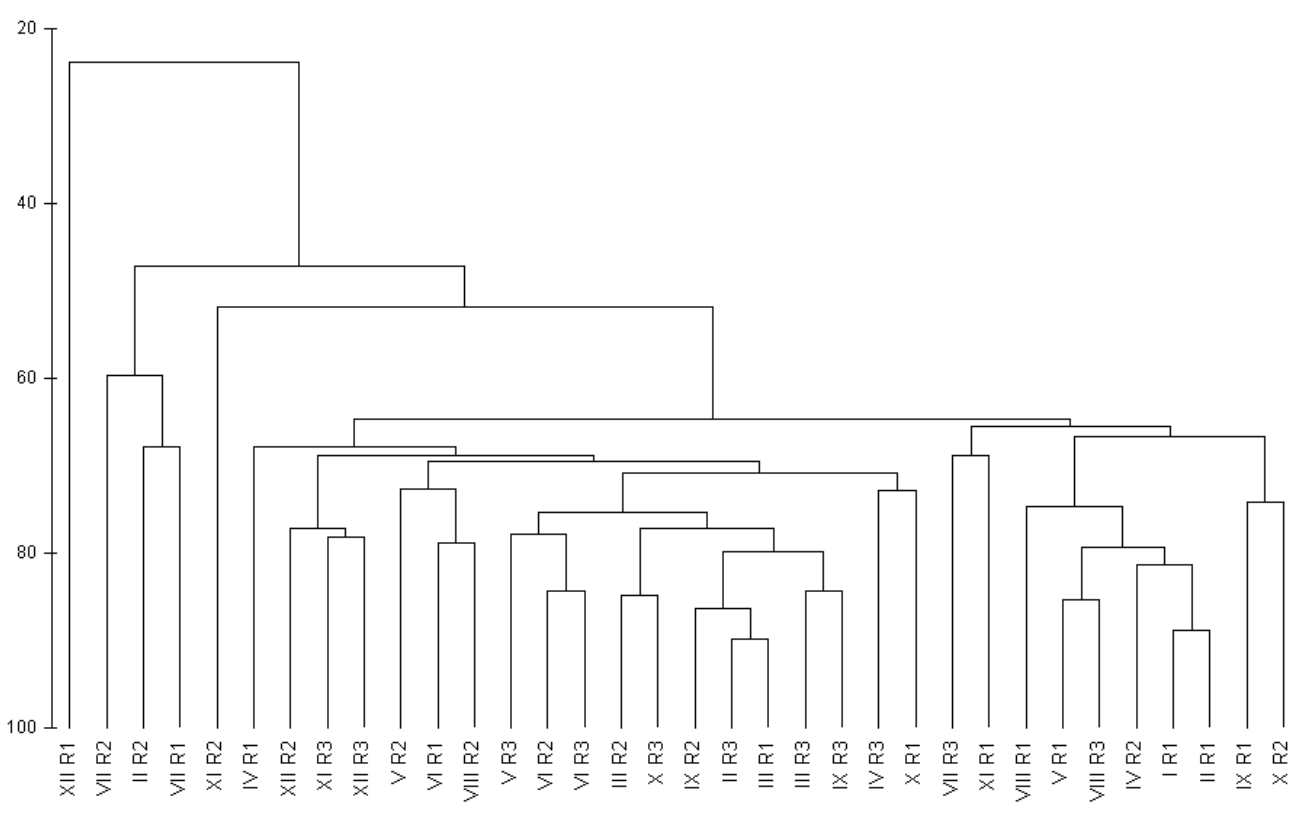

Figura 3.10. Similiaridade entre os meses de coleta levando-se em consideração os dados de abundância da macroinfauna coletadas no período estudado. Nota: os táxons utilizados nesta análise tiveram contribuição acima de $10 \%$ em pelo menos 1 dos 12 meses de coleta.

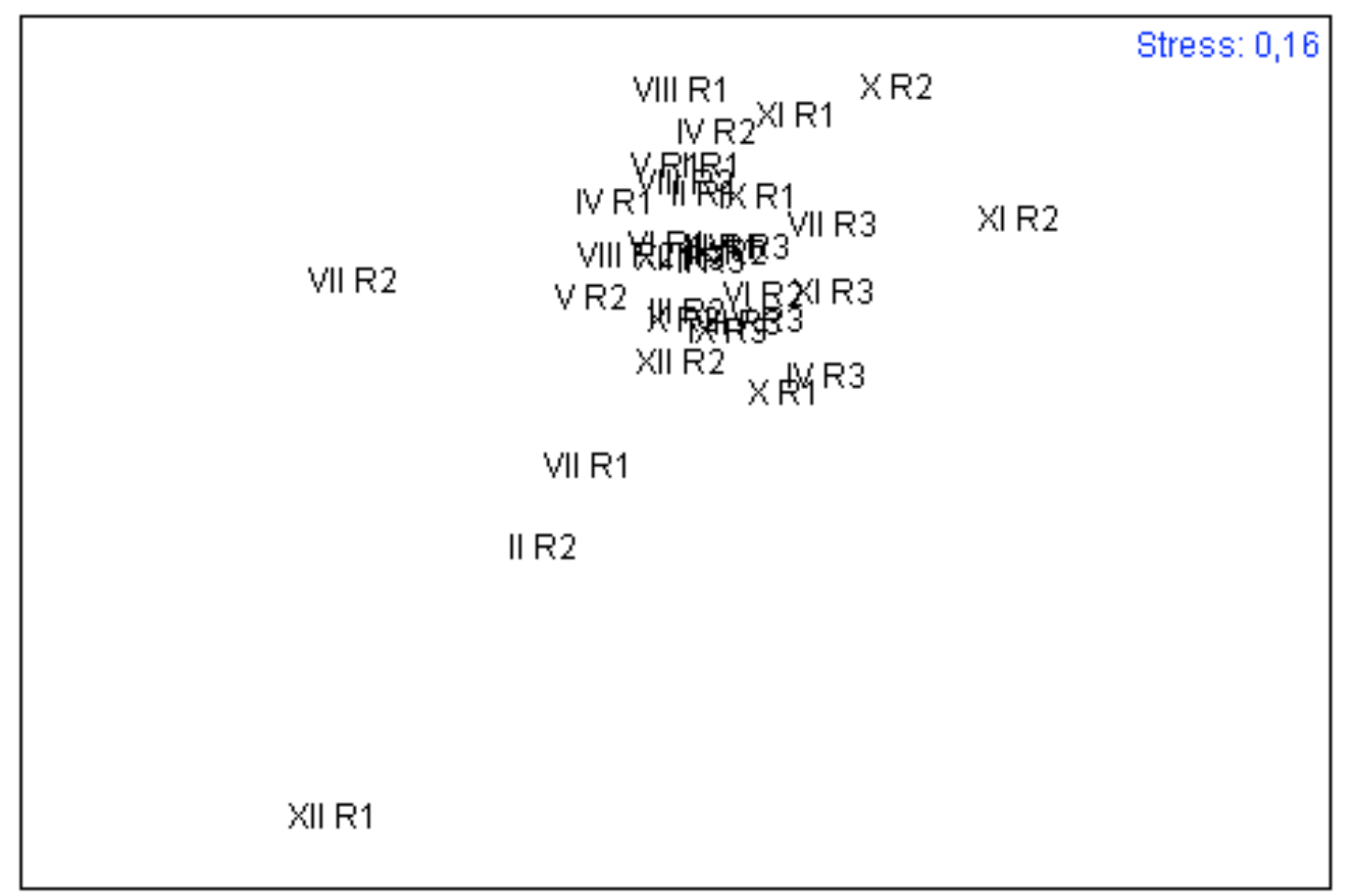

Figura 3.11. Mapa bi-dimensional MDS dos meses de coleta utilizando os dados de abundância da macroinfauna coletadas no período estudado. Nota: os táxons utilizados nesta análise tiveram contribuição acima de $10 \%$. 
Os resultados encontrados para a análise BIOENV confirmaram que não houve variável ambiental capaz de caracterizar o padrão de distribuição da macroinfauna, seja pela falta de padrão na matriz ambiental como pela ausência de agrupamentos biológicos. Os resultados descritos na tabela evidenciam fracas correlações das 16 variáveis utilizadas nesta análise quando a matriz de dados ambientais foi confrontada com a matriz biológica (Tabela 3. 3.).

Todos os resultados descritos apontaram para estabilidade das variáveis ambientais e biológicas durante o período estudado. As variáveis sedimentológicas sugerem que no ponto amostrado há pouca ação hidrodinâmica pela homogeneidade estrutural das frações granulométricas. $O$ elevado percentual de matéria orgânica total demonstra que, independentemente da época do ano, o local está sujeito a elevadas taxas de atividade microbiana, evidenciada pelo método do ATP, como também pela alta concentração de feopigmentos, o qual pode estar relacionado com a intensa decomposição dos compostos orgânicos na camada superficial do sedimento.

Esta estabilidade das variáveis ambientais coincidiu com a pouca variabilidade estrutural e temporal da macroinfauna. A fauna encontrada é composta essencialmente de organismos tubícolas com hábitos depositívoros que levam a sugerir algum grau de associação biológica, comentada na discussão. 
Tabela 3.3. Resultado da análise BIOENV (Biota and Environmental matching) realizada entre as matrizes ambiental e biológica (abundância da macroinfauna) utlilizando a correlação de Spearman.

\begin{tabular}{|c|c|c|}
\hline \multicolumn{3}{|c|}{ Variáveis ambientais } \\
\hline Variáveis & \multicolumn{2}{|c|}{ Descrição } \\
\hline 1 & \multicolumn{2}{|c|}{$\%$ granulos } \\
\hline 2 & \multicolumn{2}{|c|}{$\%$ areia } \\
\hline 3 & \multicolumn{2}{|c|}{$\%$ silte } \\
\hline 4 & \multicolumn{2}{|c|}{$\%$ argila } \\
\hline 5 & \multicolumn{2}{|c|}{$\% \mathrm{CaCO}_{3}$} \\
\hline 6 & \multicolumn{2}{|c|}{ Transparência (m) } \\
\hline 7 & \multicolumn{2}{|c|}{ Salinidade (superfície) } \\
\hline 8 & \multicolumn{2}{|c|}{ Salinidade (fundo) } \\
\hline 9 & \multicolumn{2}{|c|}{ Temperatura (superfície) } \\
\hline 10 & \multicolumn{2}{|c|}{ temperatura (fundo) } \\
\hline 11 & \multicolumn{2}{|c|}{ O.D. (mL/L) superfície } \\
\hline 12 & \multicolumn{2}{|c|}{ O.D. (mL/L) fundo } \\
\hline 13 & \multicolumn{2}{|c|}{ Cloro a (mg g-1) } \\
\hline 14 & \multicolumn{2}{|c|}{ Feopigmentos (mg g-1) } \\
\hline 15 & \multicolumn{2}{|c|}{ ATP } \\
\hline 16 & \multicolumn{2}{|c|}{$\% \mathrm{MOT}$} \\
\hline \multicolumn{3}{|c|}{ Todas as variáveis } \\
\hline \multicolumn{3}{|c|}{ Melhores correlações } \\
\hline Variáveis & Correlações & Var. Selecionada \\
\hline 1 & 0,054 & 1 \\
\hline 2 & 0,021 & 1,5 \\
\hline 1 & $-0,046$ & 5 \\
\hline 3 & $-0,118$ & $1,2,5$ \\
\hline 2 & $-0,119$ & 1,2 \\
\hline 2 & $-0,121$ & 2,5 \\
\hline 1 & $-0,122$ & 2 \\
\hline 3 & $-0,124$ & $1,4,5$ \\
\hline 2 & $-0,125$ & 1,4 \\
\hline 2 & $-0,125$ & 4,5 \\
\hline \multicolumn{3}{|c|}{ Variáveis da superfície excluídas } \\
\hline \multicolumn{3}{|c|}{ Melhores correlações } \\
\hline Variáveis & Correlações & Var. Selecionada \\
\hline 1 & 0,065 & 1 \\
\hline 2 & 0,035 & 1,5 \\
\hline 1 & $-0,046$ & 5 \\
\hline 3 & $-0,118$ & $1,2,5$ \\
\hline 2 & $-0,119$ & 1,2 \\
\hline 2 & $-0,121$ & 2,5 \\
\hline 1 & $-0,122$ & 2 \\
\hline 3 & $-0,124$ & $1,4,5$ \\
\hline 2 & $-0,125$ & 1,4 \\
\hline 2 & $-0,125$ & 4,5 \\
\hline
\end{tabular}




\section{Discussão}

Os dados apresentados no presente estudo sugerem que houve manutenção da estrutura básica da macroinfauna estudada em um ano de coleta. Estes resultados são similares aos apresentados por HILBIG \& BLAKE (2000), em estudo realizado na Baía de Massachusetts, Estados Unidos. Apesar de estes autores terem registrado variabilidade anual das variáveis ambientais, não houve alteração do padrão estrutural da macroinfauna, especialmente entre as amostras obtidas nas mesmas estações de coleta, durante cinco anos de amostragem. Padrão semelhante foi encontrado em outro estudo sazonal de três anos de amostragem (NEFF et al. 1989). Por outro lado, HILBIG \& BLAKE (2000) encontraram altas densidades de uma única espécie, assim como drásticas mudanças dos índices de diversidade, em dados históricos de 1982 a 1987. Dessa forma, vale lembrar que apesar de os resultados encontrados no presente trabalho apontarem para a estabilidade estrutural, estudos de longo termo são necessários a fim de identificar padrões naturais da variabilidade da macroinfauna.

O padrão apresentado pela curva de dominância cumulativa sugere que a macroinfauna sublitoral estudada apresenta perfil de comunidades maduras, nas quais há sobreposição no uso do espaço e dos recursos. Os grupos que exibem uma competição interespecífica intensa e uma conduta territorial tendem a harmonizar-se com a hipótese do nicho não sobreposto, embora muitas populações, especialmente aquelas que pertencem ao mesmo nível trófico básico, exibam padrões que sugerem o nicho sobreposto $\mathrm{e}$ padrões de competição que não a estrita exclusão competitiva (WHITTAKER, 1965). Os animais, em geral, coexistem aparentemente sob condições de competição parcial mais do que a competição direta em que certas adaptações promovem a diferenciação do nicho sem exclusão de um hábitat por competição (ODUM, 1988).

Não houve modificação do padrão básico da comunidade ao longo do período estudado, ao contrário do que era esperado em virtude das oscilações ambientais inerentes às diferentes épocas do ano. Quando a macroinfauna estudada é comparada com outra área da Baía de Guanabara com hidrodinamismo intenso, fica evidente nestes locais que os efeitos das 
ressacas traz como consequência a alternância das espécies dominantes, sendo este fator estruturador da macroinfauna sublitoral (HALL et al., 1994; RAYOL SOLA; PAIVA, 2001). Como não foram identificadas grandes alterações das variáveis ambientais aqui apresentadas, o local amostrado pode estar mais sujeito a sofrer influência das interações biológicas do que das variáveis ambientais.

A importância de estruturas biogênicas em sedimentos costeiros já é bem compreendida (DAME et al. 2001). Os vários processos físicos (translocação de material, transformação do hábitat e dos organismos) e biológicos (mobilidade, construção de hábitats e interações tróficas) são potencialmente responsáveis pela estruturação das comunidades bênticas compondo a matriz biogênica, a qual regula as interações biológicas. Já foi observado que tufos de algas verdes aderidas a conchas de moluscos bivalves agregam fauna, oferecendo abrigo para nemertíneos e anfípodes (THIEL; REISE, 1993). Raízes de plantas vasculares (e.g. angiospermas aquáticas) formam densos bancos que podem cobrir extensas áreas, reduzindo a hidrodinâmica local (REISE, 2002). Estas raízes estabilizam e em parte oxigenam o sedimento nos quais estão fixadas, beneficiando a fauna bêntica. Estes vegetais aprisionam partículas finas em suspensão e outros materiais flutuantes mais grosseiros, disponibilizando substrato para epífitas, epifauna e endofauna, inclusive fauna temporária e visitante, servindo até mesmo como berçários para peixes e crustáceos. É importante notar que nestes ambientes a composição sedimentológica e a comunidade associada é distinta daquela não vegetada. No caso de espécies bênticas, mais especificamente de moluscos suspensívoros, já foi observado que há tendência a formação de densos bancos destes organismos, trazendo como conseqüência a fixação do sedimento através do muco gerado pelos animais (HÜTTEL, 1986). Em áreas costeiras do oceano Antártico, espículas de esponjas depositadas nas camadas superficiais do sedimento possibilitam a formação de uma densa camada de organismos com hábito suspensívoro, como briozoários, ascídeas, cnidários e crinóides, estabilizadas por estas espículas. Entre esta estrutura gerada biogenicamente encontra-se uma vasta diversidade de anfípodes, isópodes e poliquetas (ARNTZ et al. 1994). 
Galerias formadas por organismos com hábitos tubícolas geram estruturas biogênicas capazes de fornecer uma ampla gama de hábitats para a macroinfauna (REISE et al. 2002). WOODIN (1976) já havia notado que os grupos de organismos da infauna que apresentam densidades elevadas podem ser de três tipos: depositívoros cavadores, suspensívoros e construtores de tubos. Tais grupos apresentam-se como comunidades discretas, geralmente dominados por uma classe de tamanho e possuem limites estreitos com grupos vizinhos. Estes organismos podem ser mais comuns em algumas áreas geográficas do que em outras, sendo restringidos principalmente por predadores da infauna, como crustáceos braquiúros (e.g. Callinectes sapidus) e quelicerados merostomados (e.g., Limulus polyphemus), comuns na costa leste americana e, em muitos casos, mais extensivamente, por peixes demersais costeiros, como o linguado-preto (Paralichthys brasiliensis), muito freqüente na costa brasileira.

Os hábitos alimentares e a construção de galerias de espécies bênticas influenciam a divesidade específica local e as propriedades sedimentológicas (RHOADS; YOUNG, 1970). Por exemplo, o sedimento e a matéria orgânica associada são misturados e alterados durante o enterramento, ingestão e construção de galerias temporárias ou permanentes. Organismos bioturbadores também transportam e redistribuem sedimentos na superfície em forma de fezes ou através de atividade de enterramento (BRENCHLEY, 1981) Também podem influenciar na matriz orgânica que agrega os grãos das areias (FRANKEL; MEAD, 1973), as quais levam à desestabilização do sedimento (BRENCHLEY, 1981). A desestabilização do sedimento é importante, visto que a estabilidade do mesmo é conhecida por controlar a estrutura da comunidade (DABORN, et a., 1993). A coesão de sedimentos organicamente enriquecidos depositados na superfície pela atividade de alimentação da poliqueta Laonereis acuta estabiliza o sedimento em condições de baixa energia hidrodinâmica (PALOMO; IRIBARNE, 2000).

CADÉE (2001) corroborou tais observações apontando para o fato que a não ser onde as condições de intensos distúrbios físicos (alto hidrodinamismo), água estagnada com condições anóxicas e poluição, organismos cavadores sésseis ou com mobilidade discreta colonizam áreas costeiras com seus tubos e galerias, podendo ser muitas vezes abundantes. 
Essa macroinfauna cavadora constitue uma estrutura de hábitat conspícuo, onde alguns tubos podem simplesmente terminar em galerias simples com apenas uma saída/entrada. Entretanto, grande parte delas apresentam formato em $Y$ ou $U$, geralmente intercomunicando-se umas com as outras através de pequenas ramificações e sub-galerias (REISE, et al., 2002), faciltando inclusive os hábitos reprodutivos de espécies de invertebrados marinhos (CANDISANI, et al., 2001) (Figura 3.12.). Estes tubos e galerias são compostos por lignina de polissacarídeos sólidos a qual age como uma peneira molecular, enquanto que as galerias são cimentadas com muco e geralmente com uma fina camada de partículas finas do sedimento (REISE, supra cit.).

Poecilochaetus australis Nonato, 1963 parece ter exercido papel fundamental na estruturação da comunidade sulitoral estudada. Os tubos de Poecilochaetus são em formato de $U$ e cobertos por muco, onde a corrente de água é mantida através do tubo (ALLEN, 1904). Conforme destacado por REISE (2002), os tubos e galerias mais do que dobram a área de interface água-sedimento. Estas estruturas servem como ao transporte de partículas, dissolvendo metabólitos e oxigênio através do sedimento (MEADOWS; MEADOWS, 1991).

Quando se observa a composição e o nicho ecológico dos táxons dominantes na comunidade estudada na Baía de Guanabara, nota-se que a grande maioria dos táxons apresenta hábitos depositívoros, outros ainda mais especificamente possuem características necrófagas como cladocera Daphnia sp. Em tubos de Poecilochaetus já foi encontrado o braquiúro comensal da família Pinnotheridae (TAYLOR, 1966), aqui representado pelo gênero Pinnixa $\mathrm{sp}$. e encontrado freqüentemente ao longo de todas os meses estudados. Estes tubos podem oferecer abrigo e refúgios a este grupo de organismos. Os anfípodes, Tiburonella viscana e os Corophiidae, também foram encontrados em grandes quantidades em todos os meses do ano, provavelmente associados à grande quantidade de pelotas fecais (LEVINTON 1995) depositadas em uma das extremidades do tudo em $U$ construído por Poecilochaetus. 


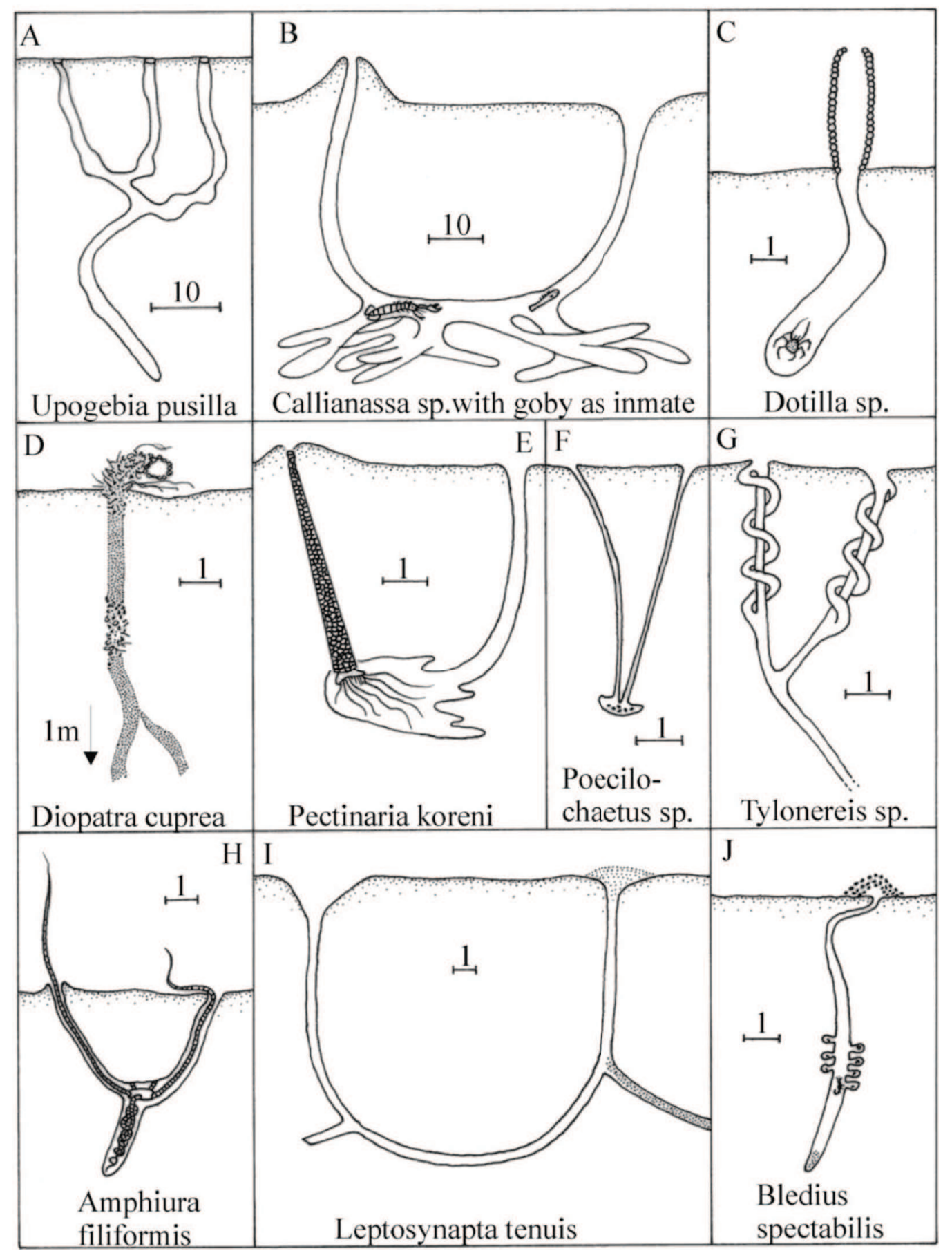

Figura 3. 12. Galerias e tubos de (A, B) camarões thalassinídeos, (C) Caranguejo ocypoda, $(D-G)$ poliquetas, $(H)$ ofiuróide, (I) holotúria ápoda e $(\mathrm{J})$ e uma staphylinid. A camada superficial do sedimento está sombreda; barras de escala em cm. Adaptado de REISE (2002). 
A comunidade encontrada na Baía de Guanabara sugere equivalente ecológico da espécie Arenicola marina (BREY, 1991), que pode estar ligada a interações inter e intra-específicas. Manchas de alimento e montes de pelotas fecais são estruturas instáveis, disponíveis para a maioria da macroinfauna, como as próprias arenícolas, pequenos organismos tubícolas como o anfípode Corophium spp. e os poliquetas Pygospio elegans no caso de A. marina e, possivelmente, de Prionospio steenstrupii para $P$. australis. Copépodos e seus respectivos predadores, por outro lado, agregam-se ao redor destes montes (REISE, 1987). O anfípode Bathyporeia sarsi também é abundante ao redor dos montes fecais excretado por $A$. marina, sugerindo que a espécie Tiburonella viscana, Baía de Guanabara, esteja preenchendo este mesmo nicho. O estudo das interações da espécie Arenicola marina demonstrou que a presença deste organismo revela um amplo espectro de efeitos diretos e indiretos (PHILIPPART, 1994) Devido ao hábito tubícola, a população de Poecilochaetus pode ter atuado como A. marina, estabilizando e oxigenando o sedimento, oferecendo abrigo a outros táxons e até mesmo gerando refúgio durante períodos reprodutivos para outras espécies, conforme representado na Figura 3.14.. Os resultados encontrados destacam a importância de táxonschave na estruturação da comunidade bêntica sublitoral, mesmo em locais extremamente eutrofizados.

Assim como apontado por HILBIG \& BLAKE (2000), pulsos de recrutamento de espécies podem ser suficientes para a manutenção destes organismos como táxons dominantes durante anos de amostragem. Claramente, informações adicionais sobre a história de vida de espécies dominantes são necessárias para melhor compreender a variabilidade anual da macroinfauna bêntica sublitoral. 


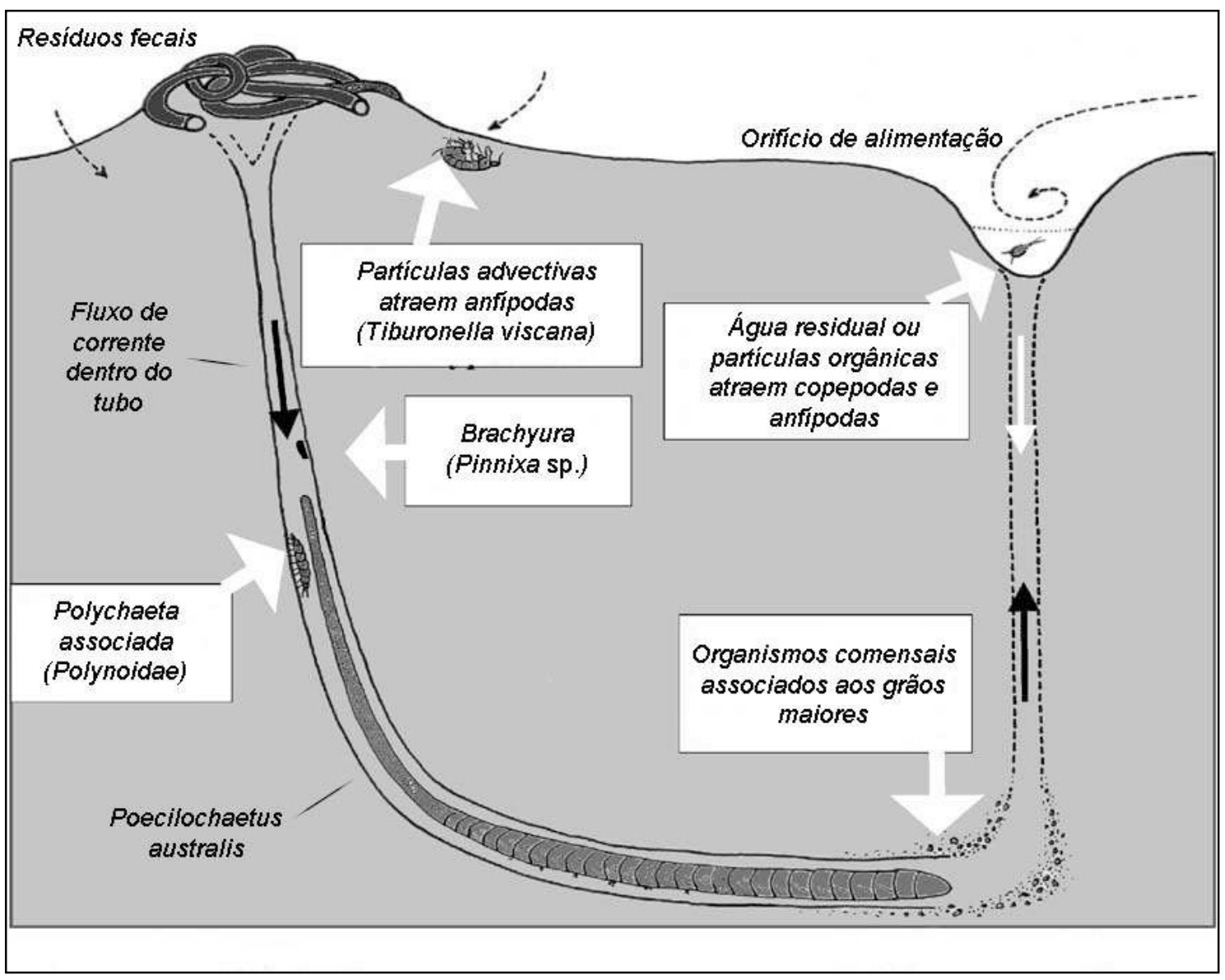

Figura 3. 13. Diagrama representando o tubo de Poecilochaetus australis e a respectiva fauna associada dominante encontrada ao longo do período estudado. Adaptado de REISE (2002). 


\section{Referências bibliográficas}

ALLEN, E. J. The anatomy of Poecilochaetus Claparède. Q. J. Micr. Sci., London, v. 48, p. 79-151, 1904.

ARNTZ, W. E.; BREY, T.; GALLARDO, V. A. Antarctic zoobenthos. Oceanogr. Mar. Biol. Ann. Rev., v. 32, p. 241-304, 1994.

BACHELET, G. Recruitment and year-to-year variability in a population of Macoma balthica (L.). Hydrobiologia, v. 142, p. 233-248, 1986.

BOURDEAU, P.; BARTH, H. Estuarine, coastal and ocean pollution: EEC policy and research: 36-37. In: Moulder, D. S. and Williamson, P. (Eds.). Estuarine and coastal Pollution: Detection, Research, and Control, vol 18, Pergamon Press, Oxford, 1986.

BOWEN, H. Microorganisms and detritus in the diet of a typical neotropical riverine detritivore, Prochilodus platensis (Pisces: Prochilodontidae). Limnol. Oceanogr., v. 29, n. 5, p. 1120-1122, 1984.

BRENCHLEY, G. A. Disturbance and community structure: an experimental study of bioturbation in marine soft-bottom environments. J. Mar. Res., v. 39, p. 767-790, 1981.

BREY, T. The relative significance of biological and physicaldisturbance: an example from intertidal and subtidal sandy bottom communities. Est. Coast. Shelf Sci., v. 33, p. 339-360, 1991.

BUCHANAN, J. B., BRACH, G. C.; MOORE, J. An analysis of a stable period in the Northumberland benthic fauna - 1973-1980. J. Mar. Biol. Ass. U.K., v. 66, p. 659-670, 1986. 
CADEÉ, G. C. Sediment dynamics by bioturbating organisms. In: Reise, K. (Ed.), Ecological Comparisons of Sedimentary Shores. Springer, Berlin, p. 127-236, 2001.

CANDISANI, L. C.; SUMIDA, P. Y. G.; PIRES-VANIN, A. M. S. Burrow morphology and mating behaviour in the thalassinid shrimp Upogebia noronhensis. J. Mar. Biol. Assoc. U.K., v. 81, p. 799-803, 2001.

CAPUZZO, J. M.; BURT, W. V.; DUEDALL, I. W.; PARK, P. K.; KESTER, D. R. In: Ketchum, B. H.; Capuzzo, J. M.; Burt, W. V.; Duedall, I. W.; Park, P. K.; Kester, D. R. (Eds.). Wastes in the ocean, vol 6, Nearshore Waste disposal, John Wiley \& Sons, New York, p. 491-512, 1985.

CLARK, R. B. Marine Pollution. 4th ed. Oxford: Clarendon Press, Oxford, p. $161,1997$.

CODY, M. L. On the methods of resource division in grassland bird communities. Am. Nat., v. 102, p. 107-147, 1968.

DABORN, G. R.; AMOS, C. L.; BRYLINSKY, M.; CHRISTIAN, H.; DRAPEAU, G.; FAAS, R. W.; GRANT, J.; LONG, B.; PATERSON, D. M.; PERILLO, G. M. E.; PICCOLO, M. C. An ecological cascade effect: migratory birds affect erodability of intertidal sediments. Limnol. Oceanogr., v. 38, p. 225-231, 1993.

DAME, R.; BUSHEK, D.; PRINS, T. Benthic suspension feeders as determinants of ecosystem structure and function in shallow coastal waters. In: Reise, K. (Eds.). Ecological comparisons of sedimentary shores. Springer, Berlin, p. 11-37, 2001.

DIAMOND, J. Niche shifts and the rediscovery of interspecific competition. Am. Sci., v. 66, p. 322-331, 1978.

FRANKEL; L.; MEAD, D. J. Mucilagenous matrix of some estuarine sands in Connecticut. J. Sed. Pet., v. 43, p. 1090-1095, 1973. 
GALÉRON, J.; SIBUET, M.; VANREUSEL, A.; MCKENZIE, K.; GOODAY, A. J.; DINET, A.; WOLFF, G.A. Temporal patterns among meiofauna and macrofauna taxa related to changes in sediment geochemistry at an abyssal NE Atlantic site. Prog. Oceanogr., v. 50, p. 303-324, 2001.

GOODAY, A. J. Biological responses to seasonally varying fluxes of organic matter to the ocean floor: a review. J. Ocean., v. 58; p. 305-332, 2002.

GRASSLE, J. F.; GRASSLE, J. P. Opportunistic life histories and genetic systems in marine benthic polychaetes. J. Mar. Res., v. 32, n. 2, p. 253-284, 1974.

GRAY, J. S.; WU, R. S.; OR, Y. Y. Effects of hypoxia and organic enrichment on the coastal marine environment. Mar. Ecol. Progr. Ser., v. 238, p. 249-279, 2002.

HALL, S. J.; RAFFAELLI; D.; THRUSH, S. F. Patchiness and disturbance in shallow water benthic assemblages. In, A. G. Hildrew, P. S. Giller \& D. Raffaelli (Eds.). Aquatic Ecology: Scale, Pattern and Processes. Blackwell Scientific, Oxford, England, p. 333-375, 1994.

HILBIG, B; BLAKE, J. A. Long-term analysis of polychaete-dominated benthic infaunal communities in Massachusetts Bay, U.S.A. Bull. Mar. Sci., v. 67, n. 1 , p. 147-164, 2000.

HÜTTEL, M. Active aggragation and downshore migration in the trochid snail Umbonium vestiarium (L.) on a tropical sand flat. Ophelia, v. 26, p. 221-232, 1986.

KENNISH, M. J. Ecology of estuaries: anthropogenic effects. CRC Press. Boca Raton, Florida, p. 494p, 1991. 
LEVIN, L. A.; PLAIA, G. R.; HUGGETT, C. L. The influence of natural organic enhancement on life histories and community structure of bathyal polychaetes. In, Reproduction, larval biology, and recruitment of the deep-sea benthos. YOUNG, C. M.; ECKELBARGER, K. J. (Eds.). Chapter Thirteen, p. 261-283. Columbia University Press, New York, 1994.

LEVIN, L. A.; CREED, E. L. Effect of temperature and food availability on reproductive responses of Streblospio benedicti (Polychaeta: Spionidae) with planktotrophic or lecitrotrophic develolpment. Mar. Biol., v. 92, p. 103-113, 1986.

LEVIN, L.A. Effects of enrichment on reproduction in the opportunistic polychaete Streblospio benedicti (Webster): A mesocosm study. Biol. Bull., v. 171, p. 143-160, 1986.

LEVINTON, J. S. Marine Biology - Function, Biodiversity, Ecology. Oxford University Press, New York, 1995.

LOPEZ, G. R.; LEVINTON J. S. Ecology of deposit-feeding animals in marine sediments. Q. Rev. Biol., v. 62, n. 3, p. 235-260, 1987.

MEADOWS, P. S., MEADOWS, A., The environmental impact of burrowing animals and animal burrows. Symp. Zool. Soc. Lond., v. 63, p. 1- 349. 1991.

NEFF, J. M.; BOTHNER, M. H.; MACIOLEK, N. J.; GRASSLE, J. F. Impacts of exploratory drilling for oil and gas on the benthic environment of Georges Bank. Mar. Env. Res., v 27, p. 77-114, 1989.

ODUM, E. P. Fundamentos de ecologia. $4^{a}$ edição. Fundação Calouste Gulbenkian, Lisboa, 1988.

PALOMO, G; IRIBARNE, O. Sediment bioturbation by polychaete feeeding may promote sediment stability. Bull. Mar. Sci., v. 67, n. 1, 2000. 
PEARSON, T. H.; ROSENBERG, R. Macrobenthic succession in relation to organic enrichment and pollution of the marine environment. Oceanogr. Mar. Biol. Ann. Rev., v. 16, p. 229-311, 1978.

PERSSON, L. E. Temporal and spatial variation in coastal macrobenthic community structure, Hano Bay (Southern Baltic). J. Exp. Mar. Biol. Ecol., v. 68, p. 277-293, 1983.

PHILIPPART, C. J. M. Interactions between Arenicola marina and Zostera noltii on a tidal flat in the Wadden Sea. Mar. Ecol. Prog. Ser., v. 111, p. 251- 257, 1994.

PRICE; R.; WARWICK, R. M. Temporal variations in annual production and biomass in estuarine populations of two polychaetes, Nephtys hombergii and Ampharete acutifrons. J. Mar. Biol. Ass. U. K., v. 60, p. 481-487, 1980.

RAYOL SOLA, M. C.; PAIVA, P. C. Variação temporal da macrofauna bentônica sublitoral da praia da Urca após a ocorrência de ressacas. Rvsta Bras. Oceanogr., Universidade de São Paulo, v. 49, n. (1/2), p. 137-142, 2001.

REISE, K. Spatial niches and long-term performance in meiobenthic Plathelminthes of an intertidal lugworm flat. Mar. Ecol. Prog. Ser., v. 38, 1-11, 1987.

REISE, K. Sediment mediated species interactions in coastal waters. J. Sea Res., v. 48, p. 127-141, 2002.

RHOADS; D. C.; YOUNG, D. K. The influence of deposit-feeding organisms on sediment stability and community trophic structure. J. Mar. Res., v. 28, n. 2, p. 150-178, 1970.

RICE, D. L.; HANSON, R. B. A kinetic model for detritus nitrogen: role of the associated bacteria in nitrogen accumulation. Bull. Mar. Sci., v. 35, p. 326$340,1984$. 
RUDNICK, D. T.; ELMGREN, R.; FRITHSEN, J. B. Meiofaunal prominence and benthic seasonality in a coastal marine ecosystem. Oecologia (Berlin), v. 67, p. 157-168, 1985.

SHANNON, C. E.; WIENER, W. The mathematical theory of communication. The University of Illinois Press. p. 360, 1963.

TAYLOR, J. L. A Pacific polychaete in southeastern United States. Quartley Journal of the Florida Academy of Science, v. 29, p. 21-26, 1966.

THIEL; M.; REISE, K. Interaction of nemertines and their prey on tidal flats. Neth. J. Sea Res., v. 31, p. 163-172, 1993.

THISTLE, D. Natural physical disturbances and the communities of marine soft bottoms. Mar. Ecol. Progr. Ser., v. 6, p. 223-228, 1981.

WOODIN, S. A. Settlement of infauna: larval choice? Bull. Mar. Sci., 39: 401407, 1986.

WHITTAKER, R. H. Dominance and diversity in land plant communities. Science, v. 147, p. 250-260, 1965. 


\section{CAPÍTULO 4}

Estratégia reprodutiva de uma população de Poecilochaetus australis Nonato, 1963 (Polychaeta: Spionida) em uma baía tropical eutrofizada: Baía de Guanabara, Rio de Janeiro, Brasil.

\section{Introdução}

Os Polychaeta são animais bem representados em comunidades bênticas marinhas e atualmente comportam 9000 espécies reconhecidas (ROUSE \& PLIEJEL, 2001). Este grupo também apresenta uma diversidade espetacular de ciclos de vida e hábitos reprodutivos (SCHROEDER; HERMANS, 1975; WILSON, 1991; GIANGRANDE, 1997).

A plasticidade reprodutiva das poliquetas deriva em parte da relativa simplicidade do sistema reprodutivo e exerce um papel fundamental no sucesso do grupo nos sistemas bênticos marinhos (DALES, 1962). O conhecimento dos ciclos de vida de organismos é de grande importância no manejo e conservação de ambientes, visto que a reprodução parece apresentar uma menor tolerância ao estresse do que outras funções vitais, sendo a fecundidade útil como um indicador sensível de perturbações subletais em invertebrados marinhos. Apesar disso, entre os invertebrados marinhos se conhece o ciclo de vida de apenas $5 \%$ das espécies (VENTURA; PIRES, 2002). Entre os poliquetas, este percentual é de somente $3 \%$ das espécies conhecidas (ECKELBARGER, 2005).

Uma porção substancial da fauna de invertebrados marinhos apresenta períodos reprodutivos notadamente sincronizados (HARRISON et al., 1984; BABCOCK et al., 1986; GIESE; KNATANI, 1987; WATSON et al., 2000). Em mares temperados, por exemplo, uma destas estratégias reprodutivas é a liberação dos gametas dentro de condições específicas ocasionadas por variações sazonais inerentes ao ambiente (OLIVE, 1995). Os sinais sazonais incluem fatores físicos mais complexos que afetam os movimentos, a energia mecânica e o hidrodinamismo das massas de água, as quais apresentam influências marcantes na dispersão de desovas pelágicas (BHAUD \& CHA, 1992; DENNY \& SHIBATA, 1989). Os sinais ambientais sazonais também incluem suporte a fatores bióticos secundários, tais como, disponibilidade alimentar, presença e abundância de competidores, predadores, como também 
a presença e a concentração de substâncias biologicamente ativas. Tais substâncias podem ser toxinas, produzidas por dinoflagelados (SOUTHGATE et al., 1984; DUTZ, 1998; IANORA et al., 1999) e diatomáceas (IANORA et al., 1996; BUTTINO et al., 1999), assim como produtos da excreção metabólica dos organismos e feromônios liberados no ambiente, como demonstrado para várias espécies da família Nereididae (HARDEGE et al., 1996; ZEECK et al., 1990). Entretanto, para compreender as conseqüências das mudanças do ambiente físico na biologia reprodutiva dos organismos, é necessário compreender não somente os sinais ambientais, como também as pressões seletivas que determinam o período ótimo para a procriação. Por outro lado, estas pressões são, em grande parte, desconhecidas (OLIVE et al., 2000). Um paradigma geralmente aceito diz que as condições nas quais as desovas são lançadas têm sido otimizadas pela seletividade que as espécies possuem em "escolher" o período com condições mais favoráveis de temperatura, luz e alimento, aumentando as chances de sobrevivência (GIESE; KNATANI, 1987). Contrariando este paradigma, OLIVE (1995) considera que essas hipóteses não foram amplamente testadas, e ainda que algumas observações têm sido feitas sugerindo que este paradigma é somente em parte verdadeiro (SEWELL ; YOUNG, 1999). Este cenário agrava-se, já que grande parte dos estudos do ciclo de vida de invertebrados marinhos é baseada essencialmente nos grupos echinodermata e molusca (LEVIN, 2006).

O controle ótimo da desova pode também envolver interações com a temperatura ambiente (GOERKE, 1984; WATSON et al., 2000), sinais das fases da lua e das marés (FRANKE, 1986) ou sinais bioquímicos, como por exemplo, aqueles causados por florescimentos de fitoplâncton (STARR et al., 1990). No intuito de prever as conseqüências das variações de longo termo, é claramente necessário compreender os efeitos de pequenas variações nas condições ambientais nos processos de desenvolvimento e qual o grau de sincronia da reprodução sazonal e seu impacto no padrão geral da comunidade.

Os poliquetas apresentam a maior diversidade de modos reprodutivos entre os invertebrados marinhos (GIANGRANDE, 1997). Nos poliquetas, os sexos são geralmente separados, i.e. gonocóricos (SCRÖREDER; HERMANS, 1975), e raramente são encontrados dimorfismos sexuais. Hermafroditas são 
conhecidos. A fertilização é geralmente externa, sendo os produtos da reprodução lançados na água com períodos variáveis de desenvolvimento larval no plâncton, seguido de metamorfose. Durante o período reprodutivo, alguns poliquetas passam por modificações de diversas magnitudes, incluindo o aumento dos olhos associado à grande sensibilidade à luz, aumento dos lobos parapodiais, adição de cerdas capilares ou substituição das cerdas por outras que facilitem a natação e histólise dos músculos da parede do corpo e do trato disgestório, tornando-se os chamados adultos epitocos (WILSON, 1991). Aqueles poliquetas que não desovam seus gametas na coluna de água protegem sua prole de diferentes formas. Os ovos podem estar presos ao corpo da fêmea por câmaras de incubação, incubados em um tubo parental ou deixados em massas gelatinosas fixas ao substrato, tomando-se posteriormente o desenvolvimento direto. A viviparidade é conhecida em poucas espécies. Algumas também podem reproduzir-se asexuadamente (FAUCHALD, 1977; SCHOREDER \& HERMANS, 1975).

Quanto ao número de eventos reprodutivos, os organismos podem ser considerados semélparos (apenas um período reprodutivo no ciclo de vida) ou iteróparos (mais de um evento reprodutivo) (COLE, 1954). Cada espécie pode ainda ser classificada como k-estrategista ou r-estrategista. No primeiro caso, os indivíduos são de maior tamanho, iteróparos, reproduzindo-se esporadicamente e investindo mais na sobrevivência da prole e não no número de gametas. As espécies denominadas r-estrategistas, referidas muitas vezes como oportunistas, são de menor tamanho, atingem a maturidade sexual em estágios mais iniciais de desenvolvimento, de curto período de vida, muitas vezes semélparos e com alta fecundidade (MCARTHUR; WILSON, 1967). O termo oportunista caracteriza espécies que colonizam rapidamente áreas que sofreram algum distúrbio antes de serem substituídas por colonizadores finais, usualmente necessitam de muita matéria orgânica, além de modificar o meio bêntico através do distúrbio do sedimento. Apresentam crescimento acelerado dos indivíduos, sendo favorecidos em grande parte pela elevada quantidade de matéria orgânica disponível no meio (GRASSLE; GRASSLE, 1974). Por outro lado, em caso de carência ou falta de recursos nutricionais, a população rapidamente declina, obervando-se uma oscilação populacional marcante nesta categoria da população (CHESNEY, 1985). Tais organismos exibem 
peculiaridades semelhantes no ciclo de vida, incluindo curto período de desova, proteção parental, pequeno tamanho corporal, curto período entre as gerações e reprodução semicontínua. Estudar as respostas reprodutivas de espécies oportunistas pode ser particularmente interessante para elucidar os mecanismos da sucessão secundária das comunidades bênticas dos sedimentos (GRÉMARE et al., 1988).

WOODIN (1976) já havia notado que os grupos de organismos da infauna que apresentam densidades elevadas podem ser de três tipos: depositívoros cavadores, suspensívoros e construtores de tubos (capítulo 3). Por outro lado, locais com altas densidades de organismos também podem ser caracterizados pela presença de espécies com ciclo de vida do tipo oportunista. Algumas destas espécies podem apresentar, inclusive, ciclo de vida típico de espécies oportunistas, seja por restrições ambientais, exclusão competitiva e indução direta pela disponibilidade alimentar, como também por sinais endógenos e exógenos de compostos bioquímicos e/ou tóxicos presentes no ambiente (OLIVE, 1995). Desta forma, a composição faunística, a distribuição espaço-temporal e o status ambiental da comunidade sublitoral de substratos inconsolidados será fortemente influenciada pela habilidade da comunidade, população e dos indivíduos, em suportar pressões e flutuações das variáveis ambientais.

Investigações detalhadas obtidas em sua grande maioria de espécies de regiões temperadas, sobre as respostas individuais ao aumento da quantidade ou qualidade do alimento, têm revelado aumento na sobrevida, crescimento e fecundidade, antecipação da maturidade sexual e alterações na produção de ovócitos (LEVIN, 1986; LEVIN; CREED, 1986; GRÉMARE et al., 1988; MARSH et al., 1989; BRIDGES; LEVIN, 1991; QIAN \& CHIA, 1991). LINTON; TAGHON (2000) confirmaram a hipótese de que o desaparecimento do capitelídeo Capitella sp.l durante a sucessão ecológica é devida à diminuição da capacidade reprodutiva em sedimentos com concentrações de proteínas abaixo do limite ótimo para o crescimento e a reprodução.

Atualmente, vinte e oito espécies e uma subespécie de Poecilochaetidae (Annelida: Polychaeta) são reconhecidas (SANTOS; MACKIE, 2008). Os representantes da família estão distribuídos amplamente desde a zona entremarés até 10.687 metros de profundidade (MACKIE, 1990). 
É sabido que na família Poecilochaetidae os sexos são separados. Os ovos são grandes e com grande quantidade de vitelo e finas membranas. $O$ desenvolvimento ocorre no plâncton, onde a larva permanece por longos períodos até estágios avançados de desenvolvimento (até 50 setígeros). A pós-larva produz um muco que é responsável pela adesão de pequenas partículas. Estas larvas são capazes de nadar como os adultos quando perturbadas através de movimentos rápidos e ondulatórios de todo o corpo. São capazes de efetuar grandes deslocamentos verticais na coluna d água (NOZAIS et al., 1997).

Apesar de a Ordem Spionida ser a de maior diversidade de modos reprodutivos e uma das mais diversas e abundantes em ambientes bênticos (WILSON, 1991), poucas são as informações sobre biologia reprodutiva desta ordem no Brasil (MACCORD, 2005). Além da descrição detalhada da biologia da espécie Poecilochaetus serpens (ALLEN, 1904), não há nenhum outro estudo sobre a biologia, história de vida, dinâmica populacional e estratégias reprodutivas das demais espécies desta família. BLAKE \& ARNOFSKY (1999) utilizaram informações sobre a biologia reprodutiva das espécies na interpretação filogenética dos Spionida, porém com poucas evidências da família Poecilochaetidae devido à falta de informação sobre a biologia desta espécie que pudesse auxiliar tanto aos estudos filogenéticos como ecológicos.

Em locais com ampla oferta de recursos alimentares ao longo do ano (e.g. proteínas, lipídios, MOP, MOD, clorofila-a) para a macrofauna bêntica, e intensificada nos períodos chuvosos típicos de regiões tropicais, espera-se um modo de reprodução contínua ou semicontínua das espécies bênticas. Entretanto, estas respostas ainda não foram testadas, já que existe uma imensa lacuna de informações sobre a biologia reprodutiva de poliquetas sublitorais de substrato inconsolidado na costa brasileira.

Devido à grande disponibilidade de matéria orgânica ocasionada pelas altas taxas de produtividade primária fitoplanctônica, seguida pela sedimentação da matéria orgânica, do aporte terrígeno e da elevada produção bêntica primária e secundária, acredita-se que a reprodução da espécie Poecilochaetus australis encontrada na Baía de Guanabara seja contínua (iterópara). 
A hipótese a ser testada no presente capítulo sugere que a estabilidade das variáveis ambientais, principalmente altas concentrações de matéria orgânica total e concentração de clorofila $a$, encontradas no local amostrado (capítulos 1 e 3 ) favorecem a reprodução contínua (iterópara) da espécie $P$. australis. A fim de testar esta hipótese, os animais coletados foram analisados quanto à presença e tamanho dos gametas femininos (ovócitos) e a idade da primeira maturação.

\section{Metodologia}

A coleta e o tratamento dos animais ao longo do período de estudo encontram-se descritos no capítulo 1. Foi analisado um total de 664 indivíduos de Poecilochaetus australis. Os indivíduos tiveram a largura em $(\mathrm{mm})$ do $7^{\circ}$ setígero medido para estimativa da classe de tamanho (MACCORD; AMARAL, 2005). Não foi possível identificar dimorfismo sexual evidente nos indivíduos coletados. Portanto, os animais coletados não foram sexados. Foi feita análise da presença dos gametas femininos a fim de se identificar em qual época do ano há intensificação do esforço reprodutivo da população.

A análise do estágio de maturação dos ovócitos foi realizada com o auxílio de um microscópio óptico Zeiss ${ }^{\circledR}$ onde todos os animais foram analisados por transparência quanto à presença de ovócitos a fim de estimar a proporção de indivíduos da população que se encontrava em período reprodutivo. Quando possível, foi registrado em cada indivíduo o início, o fim e o número de setígeros a fim de classificá-los quanto ao estágio de desenvolvimento gonadal (RICHARDS, 1970; JOYNER, 1962; MACCORD, 2005).

É possível que, com a análise do tamanho dos ovócitos, as diferenças nas estratégias gametogênicas sejam avaliadas através da análise de variância. GRANT \& TYLER (1983) observaram que a análise de variância dos tamanhos dos ovócitos pode ser realizada entre as médias amostrais e que um alto valor das médias amostrais indica que o estágio de desenvolvimento em cada amostra é sincronizado. Parte das fêmeas maduras coletadas tiveram 30 ovócitos medidos (maior diâmetro). Foram observados se houve diferença 
significativa no grau de desenvolvimento dos ovócitos mensurados entre os meses através da análise de variância (ANOVA unifatorial; teste t) utilizando o pacote estatístico BioEstat 4.0. ${ }^{\circledR}$. Somente os ovócitos encontrados livres no celoma foram mensurados, já que são aqueles que estão em fase final de desenvolvimento (ALLEN, 1904). A mensuração dos ovócitos maduros foi realizada através de ovócitos coletados de fragmentos posteriores. Os ovócitos maduros têm o formato lenticular com o maior diâmetro, sendo o quase o dobro da espessura. Somente o maior diâmetro dos ovócitos foi medido.

A idade da primeira maturação foi identicada através da observação da presença de ovócitos maduros e sua correspondência com o tamanho do indivíduo (largura em $\mathrm{mm}$ ).

\section{Resultados}

A diferenciação entre machos e fêmeas foi eficiente através do método de transparência após identificação do aspecto de preenchimento de gametas entre machos e fêmeas. A presença de machos foi evidenciada através do preenchimento de setígeros maduros posteriores com um aspecto esbranquiçado que, após visualização ao microscópio estereoscópico, revelou se tratar de concentração elevada de espermatozóides (Figura 4.1. A e B). A visualização do estágio de desenvolvimento gonadal das fêmeas em cada classe de tamanho foi possível em poucos indivíduos já que a maioria sofreu fragmentação da integridade corpórea apesar dos cuidados no momento da coleta. Grande parte dos animais rompeu-se em média no setígero 60 e, ao contrário do que era esperado, os gametas maduros puderam ser observados somente nos segmentos mais posteriores, a partir do 90․ Não foi possível verificar em que segmento se inicia a gametogênese, entretanto notou-se que os gametas maduros concentram-se nos setígeros posteriores ficando mais evidente na parte mediana do animal. Utilizando metodologia descrita por McCord (2005) foi possível identificar com segurança dois estágios de desenvolvimento: indeterminado ou vazio e maduro (Figura 4.1. C).

Os resultados encontrados revelaram que fêmeas maduras estiveram presentes em todos os meses amostrados, com exceção de outubro de 2005. 

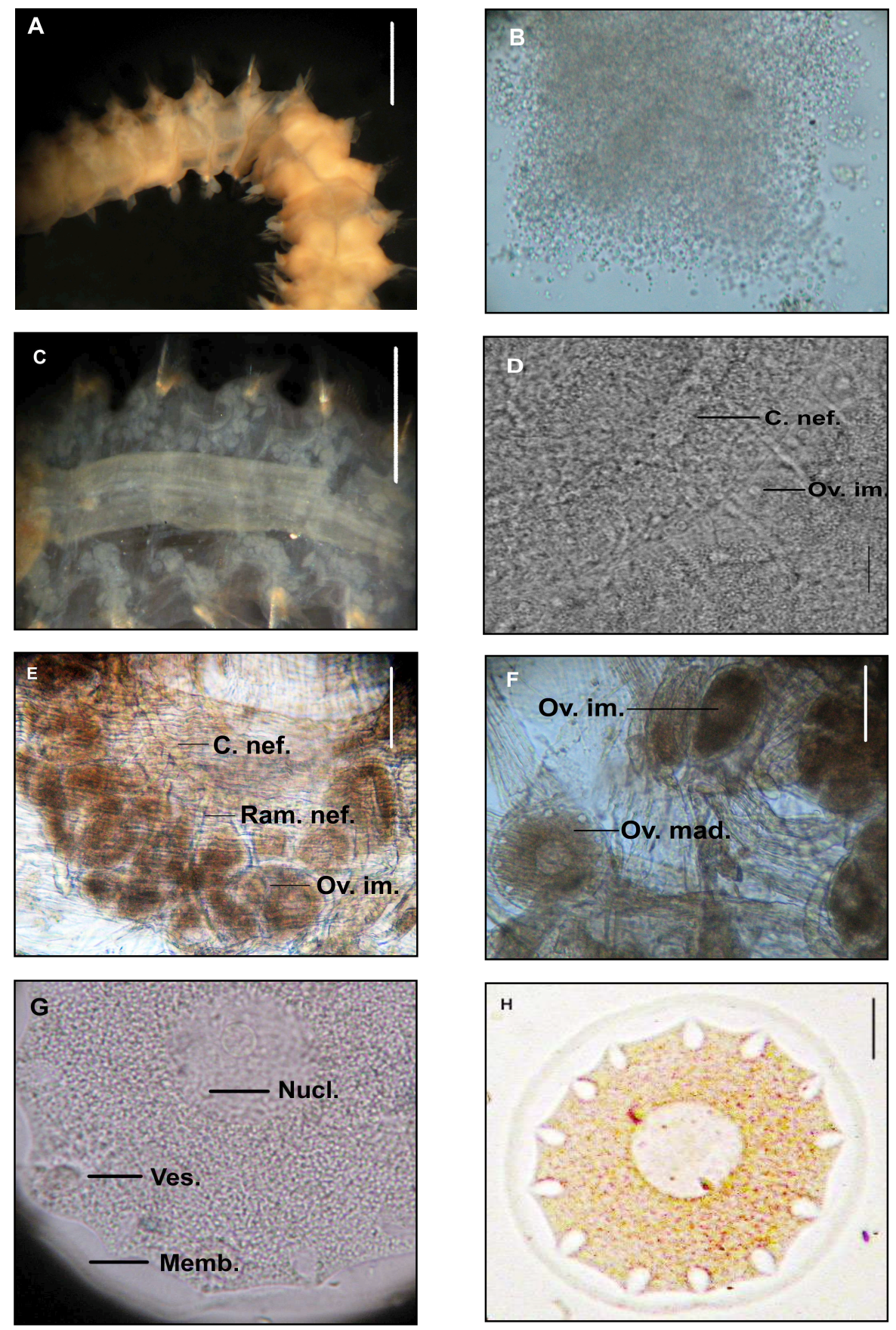

Figura 4.1. A, aspecto macroscópico do preenchimento dos setígeros maduros por gametas masculinos (aumento $5 \mathrm{x}$, escala $1 \mathrm{~mm}$ ); B, massa de espermatozóides vista ao microscópio óptico (aumento 40x); C, disposição do canal nefridial com ovócitos em desenvolvimento nos parapódios medianos (vista ventral, aumento 10x, escala $0,5 \mathrm{~mm}$ ); D, canal nefridial com ovócitos em fase inicial de desenvolvimento (aumento 40x, escala 10um); E, canal nefridial e ramificações deste canal evidenciando ovócitos bem desenvolvidos porém ainda imaturos (aumento 20x, escala $100 \mu \mathrm{m}$ ); $\mathbf{F}$, ovócito maduro livre na cavidade celomática e ovócito imaturo ainda preso ao canal nefridial (aumento $20 \mathrm{x}$, escala $100 \mu \mathrm{m}$ ); G, ovócito maduro evidenciado as vesículas internas fechadas (aumento 40x, escala $25 \mu \mathrm{m}$ ); $\mathbf{H}$, ovócito maduro (aumento 40x escala $100 \mu \mathrm{m}$ ). Legenda: C. nef., canal nefridial; Memb., membrana; Nucl., núcleo; Ov. Im., ovócitos imaturos; Ov. Mad., ovócito maduro ; Ram. nef., ramificação do nefrídio; Ves., vesícula. 
Houve frequência constante de fêmeas maduras, entretanto com pequeno número de representantes neste estágio de desenvolvimento gonadal (Figura 4.2). A menor fêmea madura foi encontrada com $0,8 \mathrm{~mm}$ em junho de 2005 , entretanto a grande maioria $(80 \%)$ dos indivíduos maduros estavam concentrados entre 1,1 e 1,3 mm e encontraram-se distribuídas ao longo do ano. As demais fêmeas maduras (13\%) concentraram-se em 0,9 mm. Foi possível observar macroscopicamente que o início do preenchimento dos gametas maduros ocorreu em média ao redor do setígero 81. Em um indivíduo com $0,9 \mathrm{~mm}$ o preenchimento ocorreu a partir do setígero 36. Por outro lado em um indivíduo com 1,3 mm a visualização dos gametas só foi possível no setígero 115. Devido à fragmentação dos exemplares coletados ao redor dos setígeros medianos $\left(60^{\circ}\right)$ não foi possível verificar a secção do animal com presença de gametas e assim determinar a fecundidade.

Os maiores ovócitos (média) foram encontrados no mês de dezembro de 2005 com $163 \mu \mathrm{m}$, e os menores em março de 2006 com $115 \mu \mathrm{m}$ (Tabela 4.1). Foi observado que houve tendência sutil de aumento do tamanho dos ovócitos do mês de junho de 2005 a setembro de 2005, com queda acentuada no mês de novembro e nova tendência positiva em dezembro deste mesmo ano atingindo o ápice do tamanho, com queda gradativa de janeiro a abril de 2006 e novo aumento do tamanho já em maio de 2006 (Figura 4.2).

Tabela 4.1. Tamanho médio dos ovócitos $(\mu \mathrm{m})$ mensurados entre os meses amostrados. Nota: *, não foram encontados ovócitos maduros.

\begin{tabular}{|c|c|c|}
\hline Ano & Mês & Ovócitos \\
\hline \multirow{7}{*}{$\begin{array}{l}\text { 오 } \\
\text { ㅁ }\end{array}$} & Junho & 133 \\
\hline & Julho & 128 \\
\hline & Agosto & 142 \\
\hline & Setembro & 157 \\
\hline & Outubro & $* * *$ \\
\hline & Novembro & 125 \\
\hline & Dezembro & 163 \\
\hline \multirow{5}{*}{$\begin{array}{l}\text { ஜ } \\
\text { 마 }\end{array}$} & Janeiro & 157 \\
\hline & Fevereiro & 146 \\
\hline & Março & 115 \\
\hline & Abril & 124 \\
\hline & Maio & 140 \\
\hline
\end{tabular}




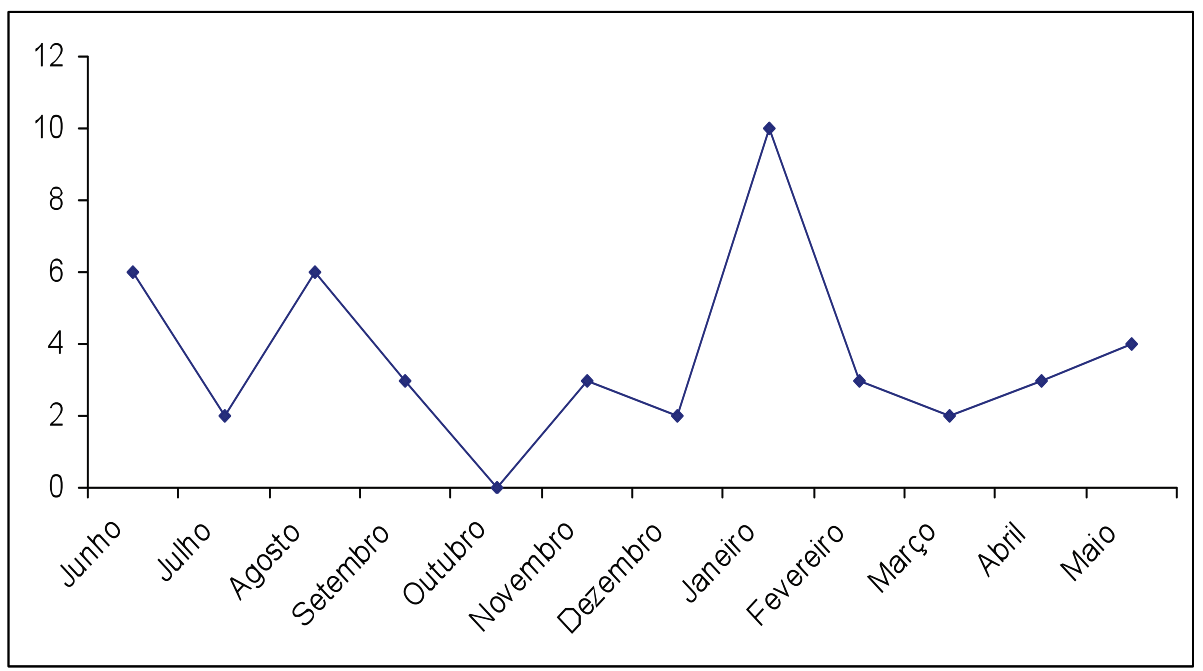

Figura 4.2. Número de fêmeas maduras observadas de junho de 2005 a maio de 2006.

Foram observadas diferenças significativas no grau de desenvolvimento dos ovócitos ao longo do ano (Tabela 4.2.). As diferenças significativas encontradas entre meses subseqüentes demonstraram que há certo grau de amadurecimento dos ovócitos de um mês para o seguinte. Não foi possível determinar se o alto valor das variâncias entre as médias demonstra sincronismo entre as fêmeas maduras, já que em cada mês poucos indivíduos foram coletados. Como mostra a Figura 4.3., os ovócitos tenderam a atingir seu ápice de desenvolvimento em dezembro de 2005. Os resultados apontam para um desenvolvimento contínuo dos ovócitos ao longo do ano.

Tabela 4.2. Análise de variância (ANOVA unifatorial) do tamanho dos ovócitos entre os meses coletados. Interseção entre os meses (barras horizontais) indica diferença significativa $(p<0,01)$.

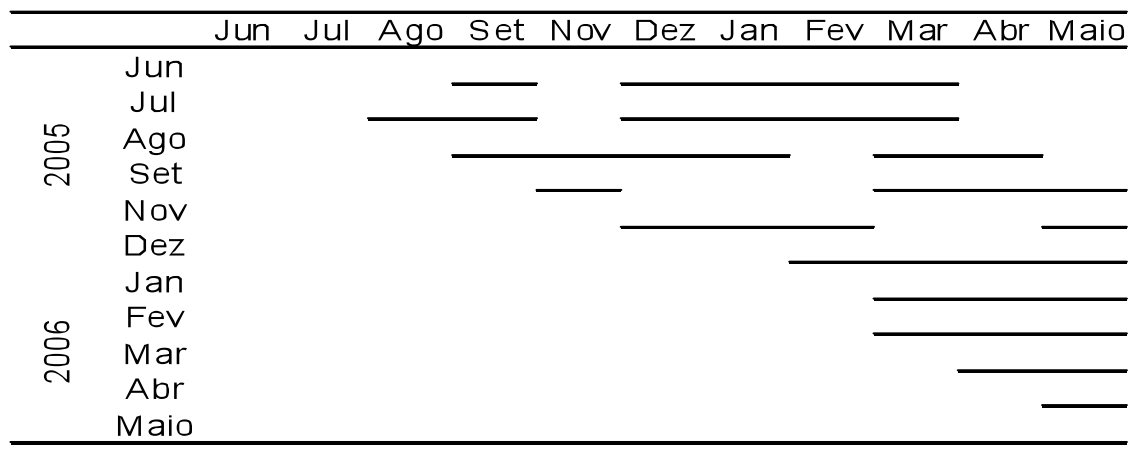




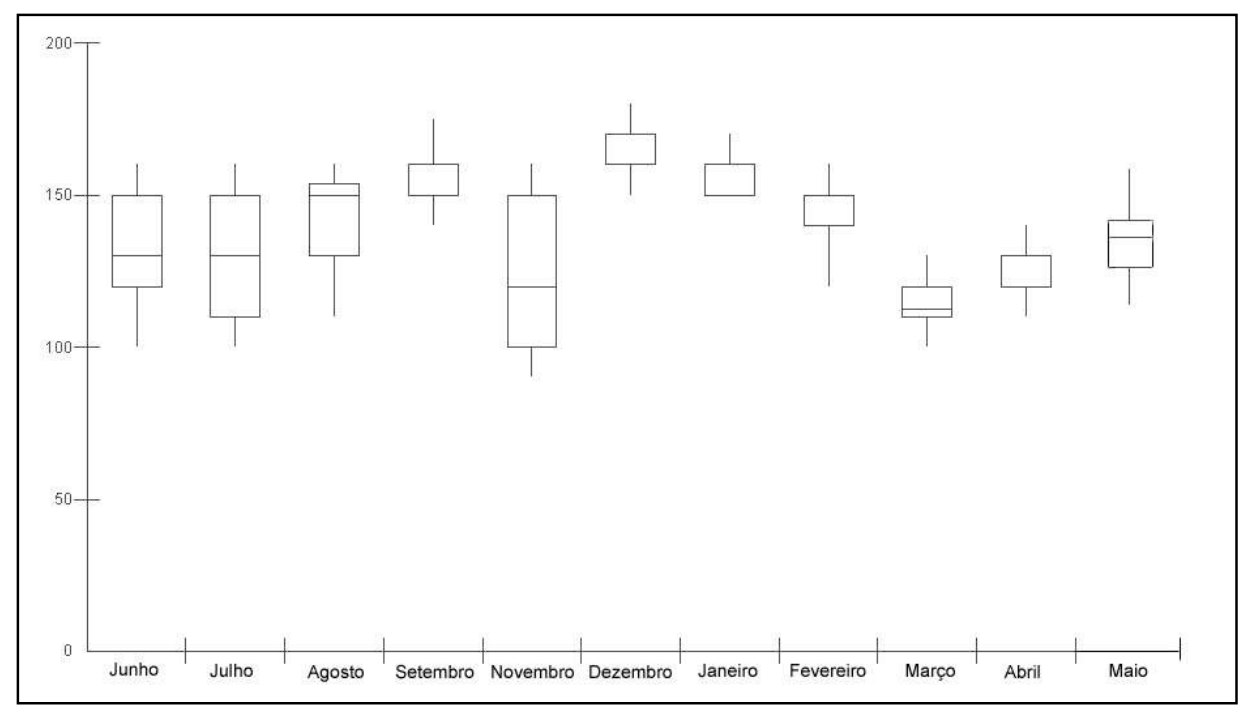

Figura 4.3. Tamanho dos ovócitos $(\mu \mathrm{m})$ encontrados durante o período amostral, junho de 2005 a maio de 2006. Nota: caixa indica a $95 \%$ dos dados, barras verticais - superior, maior escore; inferior, menor escore; linhas horizontais da caixa: superior, terceiro quartil; inferior, primeiro quartil; barra horizontal dentro da caixa - mediana.

Nenhum dimorfismo sexual ficou evidente, entretanto foi observado que existem indivíduos mais escuros, tendendo a um tom amarronzado e outros mais claros, com tonalidades que vão do laranja escuro ao avermelhado. Também foi observado, em alguns indivíduos, duas ou até três placas quitonosas ( $7^{\circ}$ e $9^{\circ}$ e $7^{\circ}$ e $8^{\circ}, 7^{\circ}$ ao $9^{\circ}$ setígeros), quando o padrão é de somente uma placa quitinosa dorsal no $9^{\circ}$ setígero. Somente em dois indivíduos maduros foi observada a presença de duas placas quitinosas. Ainda não foi possível identificar a função desta placa quitinosa, assim como estabelecer alguma relação desta anomalia em relação ao número de placas com o estágio de desenvolvimento gonadal.

Os segmentos genitais são um órgão composto, consistindo de um nefrídio e um funil genital As gônadas localizam-se ao longo dos tubos nefridiais. O ovócito inicia seu desenvolvimento ao longo destes tubos, e conforme seu crescimento separa-se das gônadas e passa a circular na cavidade celomática, onde continua o processo de maturação (extraovariano). Entre os ovócitos maduros de tamanho reduzido ( $120 \mu \mathrm{m})$ o grau de amadurecimento das vesículas periféricas foi menor, já que estas se apresentaram ainda fechadas (Figura 4.1.G). Estas estruturas também não tiveram sua função descrita, porém acredita-se que tenham ligação com a 
nutrição dos ovócitos quando na cavidade celomática ou ainda mesmo após serem liberados para fora da poliqueta.

Foram triadas e identificadas 587 larvas de poliqueta, sendo 194 de Poecilochaetus sp. (Tabela 4.3). A maior densidade de larvas foi registrada no mês de agosto de 2005, enquanto que a menor foi observada no mês de fevereiro de 2006. Devido à carência de informações sobre a família não foi possível afirmar se as larvas de Poecilochaetus encontradas são da espécie $P$. australis. De modo conservativo, os indivíduos encontrados foram denominados apenas como larvas de Poecilochaetus sp. (Figura 4.4.).

Tabela 4.3. Larvas de Polychaeta e de Poecilochaetus sp. encontradas entre Junho de 2005 e Maio de 2006. Nota: * arrasto vertical realizado na maré vazante $\mathrm{e}^{\star *}$ arrasto vertical realizado na maré enchente.

\begin{tabular}{lccccccc}
\hline Ano & \multicolumn{7}{c}{ 2005 } \\
\hline Campanha & Aust. I & Aust. II & Aust. III & Aust. IV & Aust. V & Aust. VI & Aust. VII \\
\hline Mês de coleta & Junho** & Julho** & Agosto** & Setembro** & Outubro** & Novembro** & Dezembro* \\
\hline Polychaeta & 46 & 19 & 358 & 25 & 18 & 33 & 12 \\
Poecilochaetus sp. & 23 & 5 & 120 & 10 & 0 & 13 & 2 \\
\hline
\end{tabular}

\begin{tabular}{lccccc}
\hline Ano & \multicolumn{2}{c}{ 2006 } & & \\
\hline Campanha & Aust. VIII & Aust. IX & Aust. X & Aust. XI & Aust. XII \\
\hline Mês de coleta & Janeiro** & Fevereiro** & Março * & Abril $^{*}$ & Maio * $^{*}$ \\
\hline Polychaeta & 33 & 3 & 14 & 12 & 14 \\
Poecilochaetus sp. & 10 & 0 & 2 & 4 & 5 \\
\hline
\end{tabular}

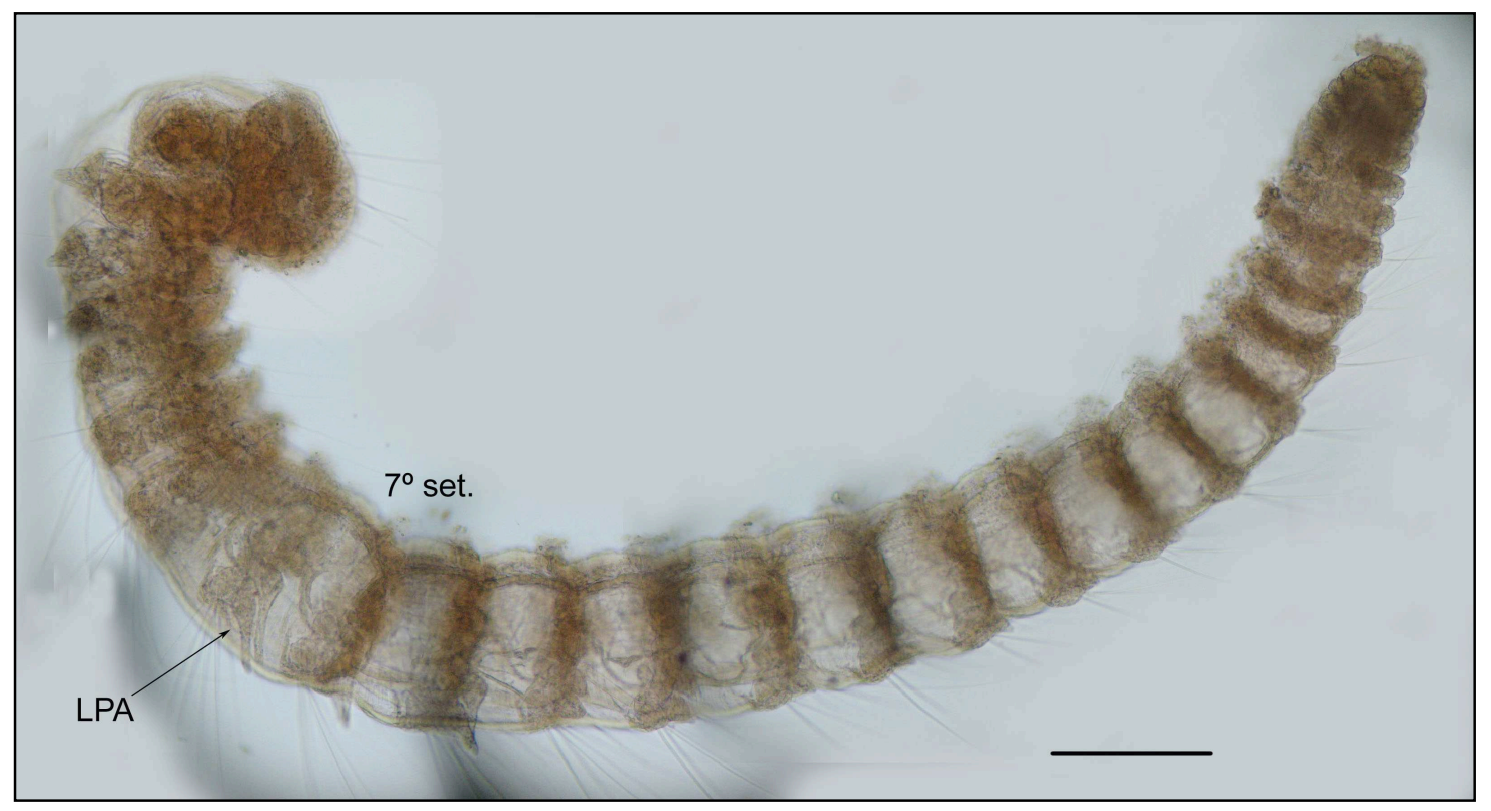

Figura 4.4. Larva de Poecilochaetus sp. com 25 setígeros. Legenda: LPA, lobo parapodial dorsal em forma de ampôla, set., setígero. Escala: 0,2mm. 


\section{Discussão}

A presença de gametas nos setígeros medianos e posteriores em Poecilochaetus australis foi diferente daquela observada por ALLEN (1904) para $P$. serpens, que verificou presença de produtos reprodutivos a partir do $17^{\circ}$ setígero. Assim como em $P$. serpens os indivíduos analisados de $P$. australis também não apresentaram gametas na parte terminal do animal. Conforme verificado no presente trabalho não parece que o início da maturação dos ovócitos se dê nos segmentos anteriores, os quais não apresentaram nenhum grau de modificação dos nefrídios, canal nefridiano e presença de gametas. Os canais nefridiais com presença de gametas em desenvolvimento somente foram observados nos setígeros posteriores ( 60$)$. Parece pouco provável que haja início da gametogênese nos segmentos mais anteriores, antes do setígero 60, interrupção em alguns segmentos e continuação posteriormente. Pelo que foi observado, nota-se que o desenvolvimento dos ovócitos maduros é extraovariano assim como em $P$. serpens. Entretanto, com a técnica de observação dos gametas utilizada no presente estudo não foi possível comprovar que nos setígeros anteriores não há início do processo de maturação/desenvolvimento dos ovócitos.

A maioria dos poliquetas tem ovários bem definidos e relativamente permanentes, com ao menos seis diferentes tipos (ECKELBARGER, 1988). Os ovários estão freqüentemente localizados nos parapódios ou ventrolateralmente onde podem estar associados ao tecido conjuntivo parapodial, aos septos intersegmentais, ao peritônio ventral, ou mais comumente aos elementos do sistema circulatório e especialmente com vasos nefridianos sanguíneos (ECKELBARGER, 2006 in Rouse; Pleijel 2006). O tamanho e a complexidade estrutural dos ovários variam de acordo com o padrão da ovogênese adotada pela espécie (ECKELBARGER, 1988). Nos poliquetas, dois padrões são bem definidos: extraovarianos e intraovarianos (ECKELBARGER, 1983). A ovogênese extraovariana ocorre quando pequenos ovócitos previtelogênicos são lançados do ovário no fluido celomático onde completam a vitelogênese. Nestas espécies, os ovários são geralmente pequenos. Dois tipos de ovogênese extraovariana foram identificados. Nas formas mais simples, ovócitos previtelogênicos são lançados no celoma onde 
prosseguem a maturação (e.g. Sabellidae, Glyceridae, Serpulidae, Oweniidae). Em outras famílias (e.g. Alciopidae, Nereididae, Phyllodocidae, Pholoididae, Sphaerodoridae, Terebellidae, Cirratulidae, Ampharetidae, Pectinaridae), agrupamentos de ovócitos previtelogênicos são lançados no celoma envoltos por células foliculares. A ovogênese intraovariana ocorre quando os ovócitos são retidos pelos ovários durante grande parte ou até mesmo toda a ovogênese e vitelogênese (ECKELBARGER, sup. cit.).

BLAKE (2006) observou ovogênese extraovariana em dois gêneros da família Spionidae, Polydora e Spio. Os ovários são presos aos músculos próximos da linha mediana ventral, sendo os ovócitos lançados no celoma onde continuam a se desenvolver. Os ovários aparecem como um saco de ar que se projeta no celoma. In Polydora ciliata e Polydora cornuta, os ovócitos permanecem nos ovários até atingirem 25-30 $\mu \mathrm{m}$ de diâmetro, quando são lançados na cavidade celomática. Em seguida, os ovócitos deslocam-se posteriormente e acumulam-se nas cavidades parapodiais dos segmentos medianos onde continuam a crescer e amadurecer até um tamanho máximo de cerca de $130 \mu \mathrm{m}$. Foi observado que, em Poecilochaetus australis, a ovogênese ocorre nos setígeros mais posteriores. Nos setígeros onde foram identificados ovócitos ainda imaturos, presos aos canais nefridianos, o tamanho medido foi em média de $80 \mu \mathrm{m}$. Os menores tamanhos de ovócitos encontrados na cavidade celomática ficaram em torno de $90-100 \mu \mathrm{m}$. Pode ser que o padrão apresentado por Blake através do trabalho realizado por ALLEN (1904) não seja o mesmo encontrado para $P$. australis, mas sim mais próximo ao de Polydora ciliata, onde os ovócitos permanecem nos ovários até alcançarem 25-30 $\mu \mathrm{m}$ de diâmetro, quando são então liberados para a cavidade celomática. Este padrão parece ser o mesmo para Polydora cornuta. ECKELBARGER (2006) apontou que os anelídeos apresentam grande diversidade de complexidade ovariana, mecanismos vitelogênicos e padrões reprodutivos. O ovário e os mecanismos vitelogênicos desempenham papel fundamental na produção de ovos, freqüência de maturação e o tamanho e a energia contida nos ovócitos que tem conseqüência no desenvolvimento e na dispersão. Faz-se necessário, portanto, o estudo da gametogênese utilizando cortes histológicos e microscopia eletrônica a fim de verificar se o processo de 
maturação é extraovariano ou um tipo combinado de desenvolvimento intra e extraovariano.

A presença de gametas nos indivíduos é usualmente utilizada para análise da época reprodutiva e dinâmica populacional de Spionidae (ZAJAC, 1991; SHIMIZU, 1997; SOUZA; BORZONE, 2000). Poucos são os trabalhos que estudam a relação do tamanho dos ovócitos e o conteúdo orgânico (BRIDGES; TODD, 1993). Eckelbarger \& Watling (1995) concluíram que a história filogenética das espécies determina diversos atributos fisiológicos, tais como a habilidade de processar alimento de alta qualidade, armazenar nutrientes e alocá-los nas gônadas, regulando a vitelogênese e até mesmo a taxa que a ovogênese (produção de ovócitos) possa estar completa. Juntos, esta combinação de características controla a taxa de conversão de alimento em ovócitos. É sabido que pulsos sazonais de matéria orgânica (e.g. deposição de fitodetritos) podem regular a dinâmica populacional de bactérias e alguns protozoários (flagelados e foraminíferos), bem como a reprodução e ciclos de crescimento de alguns metazoários (GODAY; TURLEY, 1990). Sabe-se também que pulsos sazonais de alimento ativam alguns processos reprodutivos, como o início da gametogênese, o desenvolvimento de gametas incluindo a acumulação de vitelo (vitelogenesis), a desova e o assentamento larval (SUMIDA et al., 2000; GODAY, 2002). Os resultados dos estágios de maturação ao longo do ano na população de $P$. australis estudada sugerem que a oferta de matéria orgânica ao menos não é o fator limitante, tendo em vista as altas concentrações de matéria orgânica, clorofila a e feopigmentos (capítulo 1). A oferta de material nutritivo em altas concentrações nas camadas superficiais do sedimento aponta que há condições necessárias para que haja ativação da gametogênese ao longo do ano.

Em geral, a maioria das espécies de Spionidae estudadas parece reproduzir-se quando a temperatura da água é mais elevada (BLAKE, 1969; LEVIN, 1984a; LEVIN; CREED, 1986; SATO-OKOSHI et al., 1990). Caracteristicamente, tais espécies são politélicas, sendo capazes de entrar em período de reprodução mais do que uma vez durante suas histórias de vida. MACCORD (2005) verificou que houve redução do período reprodutivo em períodos mais frios em duas populações de Scolelepis em São Sebastião, São Paulo, ao contrário do que foi encontrado em populações de Streblospio, que 
se reproduziram continuamente em águas mais quentes (SARDÁ; MARTIN, 1993). Ainda foi observado que, em ambas as espécies de Scolelepis, houve tendência de presença de fêmeas nos estágios finais de desenvolvimento gonadal, visto que as fêmeas necessitam liberar maior quantidade de ovócitos possíveis para garantir o sucesso reprodutivo, enquanto que nos machos os espermatozóides contidos em poucos setígeros podem ser suficientes para fecundar dezenas de ovócitos. Muitas espécies são capazes de estabelecer densas populações durante a época de reprodução porque uma grande quantidade de gametas e desovas é produzida por uma única fêmea (BLAKE, 2000). Estes indícios sugerem que a estratégia reprodutiva de $P$. australis concentra a ovogênese contínua em poucos indivíduos, garantindo o suprimento de ovócitos a serem lançados na coluna d'água durante um longo período.

As variáveis ambientais analisadas apontam que a temperatura da coluna d'água junto ao fundo foi relativamente alta, assim como as concentrações de matéria orgânica total e quantidade de clorofila-a e feopigmentos foram relativamente constantes, sem que houvesse um estímulo ambiental agudo que pudesse alterar o padrão encontrado. Parece razoável supor que a estabilidade ambiental a que a população de $P$. australis foi submetida não criou condições para paralisação da gametogênese, mas pelo contrário. A presença de gametas maduros ao longo de todo o período estudado, evidenciando-se a constante produção de ovócitos, associada a presença freqüente de larvas de Poecilochaetus na coluna d'água, coloca a espécie no grupo de reprodução como iterópara (GIANGRANDE, 1997).

O tamanho dos ovócitos é provavelmente a característica da história de vida mais freqüentemente registrada entre os invertebrados marinhos (LEVIN et al., 1991; QIAN; CHIA, 1991). O tamanhos dos ovócitos maduros dos poliquetas variam entre 20-40 $\mu \mathrm{m}$ in Polyphtalmus pictus (FAGE; LEGENDRE 1927) e 1,17 mm de diâmetro em Paronuphis antarctica (HARTMAN, 1967). Acredita-se que o diâmetro dos ovócitos é relativamente constante e que a qualidade dos ovos é relacionada com seu tamanho. Entretanto, tem sido observado que os ovócitos podem variar de tamanho em resposta a variações dos parâmetros ambientais (QIAN; CHIA 1991; PREVEDELLI; ZUNARELLI VANDINI, 1998). Estas diferenças já foram vistas em populações de Dinophilus 
gyrociliatus, um poliqueta oportunista, assim como em quase todas as espécies do gênero Ophryotrocha (SIMONINI; PREVEDELLI, 2003 A, B). Como não há estudos reprodutivos, mais especificamente dos ovócitos, entre as espécies do gênero Poecilochaetus, a comparação com a literatura científica fica impossibilitada. A ausência de fêmeas maduras (outubro 2005) e o decréscimo do tamanho médio dos ovócitos (novembro 2005) podem estar associados a alguma variável ambiental que condicionou esta resposta. Não foi possível, com os dados coletados e analisados, estabelecer qualquer relação, visto que houve tendência à estabilidade dos parâmetros ambientais durante o período estudado. Comparando-se os resultados do tamanho dos ovócitos de Poecilochaetus com espécies que adotam estratégia de dispersão do tipo planctotrófica, pode ser inferido que o tamanho do ovo de Poecilochaetus está entre os maiores até então referidos na literatura (GIANGRANDE, 1997). Alguns autores (NONATO, 1963; BLAKE, 2000; NOZAIS et al., 1997) já haviam apontado que a espécie é bastante freqüente na coluna d'água, possui habilidade de deslocamento e permanece longos períodos na coluna d'água, o que pode estar relacionado com o valor nutritivo estocado nos ovócitos desta espécie, que auxilia na estratégia de dispersão das larvas.

Acredita-se que a maioria das espécies de espionídeos desove na coluna d'água (e.g. Paraprionospio, Prionospio, Dispio, Aonides, Aonidella, Lindaspio, Spiophanes, Rhynchospio, Scolecolepsides, Malacoceros, Marenzelleria, Scolelepis, Parascolelepis, Laonice, Heterospio, Uncispio, Poecilochaetus e Trochochaeta) (BLAKE, 2000). Entretanto, BLAKE \& ARNOFSKY (1999) notaram que grande parte das observações são inconsistentes devido à falta de estudos elaborados em reprodução e desenvolvimento. Estes autores destacaram que dois padrões principais de desova ocorrem: (1) disseminação dos ovocitos e espermatozóides na coluna d'água, onde os ovos fertilizados desenvolvem-se em larvas livre-natantes; (2) produção de ovocitos e espermatozóides por pares de machos e fêmeas resultando em uma massa de ovos dentro das quais se desenvolvem até um estágio que entram no plâncton como uma larva funcional. Na população de Poecilochaetus australis estudada, a presença de ovócitos em indivíduos maiores que $0,9 \mathrm{~mm}$ pode estar associada a questões evolutivas da espécie. Poecilochaetus apresenta estrutura corpórea extremamente frágil, 
principalmente nos segmentos posteriores onde estão concentrados os ovócitos maduros. Nos indivíduos menores que $0,9 \mathrm{~mm}$, a parte mediana a posterior do animal é muito fina e delgada. O investimento da produção de ovócitos em indivíduos abaixo desta classe de tamanho pode ser inviável do ponto de vista energético (custo - demanda energética / benefício gametogênese eficiente). A idade elevada da primeira maturação pode estar associada a um melhor aproveitamento do investimento energético do início da ovogênese verificado através do sucesso reprodutivo e do estabelecimento da espécie no ambiente estudado. 


\section{Referências bibliográficas}

ALLEN, E. J. The anatomy of Poecilochaetus Claparède. Q. J. Micr. Sci., London, v. 48, p. 79-151, 1904.

BABCOCK, R. C., BULL, G. D., HARRISON, P. L., HEYWARD, A. J., OLIVER, J. K., WALLACE, C. C. AND WILLIS, B. L. Synchronous spawnings of 105 scleractinian coral species on the Great Barrier Reff. Mar. Biol., v. 90, p. 379394, 1986.

BHAUD; M.; CHA, J. H. Sources de fluctuation et de stabilité dans le cycle de vie d' Eupolymnia nebulosa (Polychète) en Méditerranée, Ann. Inst. Océanogr. Paris, v. 68, p. 25-35, 1992.

BLAKE, J. A. Spionida. In, Reproductive biology and phylogeny of Annelida. ROUSE, G.; PLEIJEL, F. (Eds.). Chapter 13, Enfeld, NH, USA: Science Publishers. 688p., 2006.

BLAKE, J. A. ARNOFSKY, P. L. Reproduction and larval development of the spiniform Polychaeta with application to systematics and phylogeny. Hydrobiologia, v. 402, p. 57-106, 1999.

BRIDGES, T. S. Reproductive investment in four developmental morphs of Streblospio (Polychaeta: Spionidae). Biol. Bull. , v. 184, n. 2, p. 144-152, 1993.

BUTTINO, I.; MIRALTO, A.; IANORA, A.; ROMANO, G.; POULET, S. A., 1999. Water-soluble extracts of the diatom Thalassiosira rotula induce aberrations in embrionic tubulin organistion of the sea urchin Paracentrotus lividus. Mar. Biol., v. 134, p. $147-154,1999$.

CHESNEY, JR., E. J., 1985. Sucession in soft-bottom benthic environments: are pioneering species really outcompeted? In, Proccedings of the european marine biology symposium., Number 19, edited by Gibbs, pp. 277-286, 1985 
COLE, L. C. The population consequences of life history phenomena. $\mathbf{Q}$. Rev. Biol., v. 29, p. 103-137, 1954.

DALES, R. P. The polychaete stomodeum and inter-relationships of the families of Polychaeta. Proc. Zool. Soc. London, v. 139, p. 389-428, 1962.

DENNY, M. W.; SHIBATA, M. F., Consequences of surf-zone turbulence for settlement and external fertilization. Am. Nat., v. 134, p. 859-889, 1989.

DUTZ, J. 1998. Repression of fecundity in the neritic copepod Acartia clausi exposed to the toxic dinoflagellate Alexandrium lusitanicum: relationship between feeding and egg production. Mar. Ecol. Prog. Ser., v. 175, p. 97-107, 1998.

ECKELBARGER, K. J. Evolutionary radiation in polychaete ovaries and vitellogenic mechanisms and their role in life history patterns. Can. J. Zool., v. 61, p. 487-504, 1983.

ECKELBARGER, K. J. Oogenesis and female gametes. In, WESTHEIDE, W., HERMANS, C. O. (Eds.). The Ultrastructure of Polychaeta, Microfauna Marina, v. 4, p. 281-307, 1988.

ECKELBARGER, K. J. Oogenesis and oocytes. Hydrobiologia, v. 535-536, p. 179-198, 2005.

ECKELBARGER, K. J. Oogeneis. In, Reproductive biology and phylogeny of Annelida. ROUSE, G.; PLEIJEL, F. (Eds.). Chapter 2, Enfeld, NH, USA: Science Publishers. 688p., 2006.

FAUCHALD, K. The polychaete worms: definitions and keys to the orders, families and genera, Natur. Hist. Mus. Los Angeles Co. Ser., v. 28, p. 1-190, 1977. 
FRANKE, H.-D. Resetting a circalunar reproduction rhythm with artificial moonlight signals: Phase-response curve and "moon-off" effect. J. comp. Physiol. A., v. 159, p. 569-576, 1986.

GIANGRANDE, A. Polychaete reproductive patterns, life cycles and life histories: an overview. Ocean. Mar. Biol. an annual. Rev., v. 35, p. 323-386.

GIESE; A. C.; KANATANI, H. Maturation and spawing. In, Reproduction in Marine Invertebrates, Vol. 9. GIESE, A. C.; PEARSE, J. S. (Eds.). Academic Press, Los Angeles, CA, pp. 251-329, 1987.

GOODAY, A. J. Biological responses to seasonally varying fluxes of organic matter to the ocean floor: a review. J. of Ocean., v. 58, p. 305-332, 2002.

GOERKE, H. Temperature dependence of swarming in North Sea Nereidae, In, Polychaete Reproduction. FISCHER, A.; PFANNENSTEIL, H. D. (Eds.). Gustav Fischer, Stuttgart, pp. 39-51, 1984.

GRANT, A.; TYLER, P. A. The analysis of data in studies of invertebrate reproduction. II. The analysis of oocyte size/frequency data, and comparision of different types of data. International Journal of Invertebrate Reproduction, v. 6 , p. 271-283, 1983.

GRASSLE, J. F.; GRASSLE, J. P. Opportunistic life histories and genetic systems in marine benthic polychaetes. J. Mar. Res., v. 32, n. 2, p. 253-284, 1974.

GRÉMARE, A., MARSH, A. G.; TENORE, K. R., Short-term reproductive responses of Capitella sp. I (Annelida: Polychaeta) fed on different diets. J. of Exp. Biol. and Ecol., v. 123, p. 147-162, 1988.

HARRISON, P. H.; BABCOCK, R. C.; BULL, G. D.; OLIVER, J. K.; WALLACE, C. E.; WILLIS, B. L. Mass spawing in tropical reef corals. Science. v. 223, p. 1186-1189, 1984. 
HARDEGE, J. D.; M. G. BENTLEY, 1997. Spawning synchrony in Arenicola marina: evidence for sex pheromonal control. Proc. R. Soc. Lond., Ser. B: Biol. Sci., v. 264, p. 1041-1047, 1997.

HARTMAN, O. Polychaetes annelids collected by the USNS Eltanin to Bermuda and other North Atlantic areas. Allan Hancock Foundation, Occasional Paper, v. 28, p. 1-378, 1967.

IANORA, A., POULET, S.A., MIRALTO, A., \& GROTTOLI, R., 1996. The diatom Thalassiosira rotula affects reproductive success in the copepod Acartia clausi. Marine Biology, 125: 279-286.

IANORA, A., MiRAlto, A., BUtTINo, I., ROMANO, G., \& POULET, S.A., 1999. First evidence of some dinoflagellates reducing male copepod fertilization capacity. Limnol. Oceanogr., v. 44, p. 147-153, 1999.

JOYNER, A. Reproduction and larval life of Nerine cirratulus (Delle Chiaje) family Spionidae. Proc. Zool. Soc. London., v. 138, p. 655-666, 1962.

LEVIN, L. A., ZHU, J., CREED, E. The genetic basis of life history characters in a polychaete exhibiting planktotrophy and lecithotrophy. Evolution, v. 45, p. 380- 397, 1991.

LEVIN, L.A. Effects of enrichment on reproduction in the opportunistic polychaete Streblospio benedicti (Webster): A mesocosm study. Biol Bull., v. 171, p. 143-160, 1984a.

LEVIN, L. A. 2006. Recent Progress in Understanding Larval Dispersal: New Directions and Digressions. Integ. Comp. Biol., v. 46, p. 282-297, 2006.

LEVIN, L.A.; CREED, E.L. Effect of temperature and food availability on reproductive responses of Streblospio benedicti (Polychaeta: Spionidae) with planktotrophic or lecitrotrophic develolpment. Mar. Biol., v. 92, p.103-113, 1986. 
LINTON, D. L.; TAGHON, G. L. Feeding, growth, and fecundity of Capitella sp. I in relation to sediment organic concentration. Mar. Ecol. Prog. Ser., v. 205, p. 229-240, 2000.

MACCORD, F. S. Dinâmica populacional e biologia reprodutiva de duas espécies de Scolelepis (Spionidae) e de Laeonereis acuta (Nereididae) (Annelida: Polychaeta). Tese de doutorado. Instituto de Biociências da Universidade de São Paulo. Departamento de Zoologia. 130p. 2005

MACCORD, F. S.; AMARAL, A. C. Z. Morphometric analysis of two species of Scolelepis (Polychaeta: Spionidae). J. Mar. Biol. Assoc. U.K., v. 84, p. 769$784,2005$.

MACKIE, A. S. Y. The Poecilochaetidae and Trochochaetidae (Annelida:

Polychaeta) of Hong Kong. Proceedings of the Second International Marine Biological Workshop: The Marine Flora and Fauna of Hong Kong and Southern China, Hong Kong, p. 337-362, 1990.

MARSH, A. G., GRÉMARE, A., TENORE, K. R. 1989. Effect of food type and ration on growth of juvenile Capitella sp. I (Annelida: Polychaeta): macro- and micronutrients. Mar. Biol., v. 102, p. 519-527, 1989.

MCARTHUR; R. H.; WILSON, E. O. The theory of island biogeography. Princeton University Press, Princeton, NJ, 224 p., 1967.

NOZAIS, C.; DUCHÊNE, J-C; BHAUD, M. Control of position in the water column by the larave of Poecilochaetus serpens (Polychaeta): the importance of mucus secretion. J. Exp. Mar. Biol. Ecol., v. 210, p. 91-106, 1997.

OLIVE, P. J. W.; LEWIS, C; BEARDALL, V. Fitness components of seasonal reproduction: an analysis using Nereis virens as a life history model. Ocean. Acta, v. 23, n. 4, p. 377-389, 2000. 
OLIVE P. J. W. Annual breeding cycles in marine invertebrates and environmental temperature: probing the proximate and ultimate causes of reproductive synchrony. J. Thermal Biol., v. 20, p. 79-90, 1995.

PREVEDELLI, D.; ZUNARELLI VANDINI, R. Effect of diet on reproductive mode of Ophryotrocha labronica (Polychaeta: Dorvilleidae). Mar. Biol., v. 132, p. 163-170, 1998.

QIAN, P. Y.; CHIA, F. S. 1991. Effects of food concentration on larval growth and development of two polychaete worms, Capitella capitata (Fabricius) and Polydora ligni Webster. Bull. Mar. Sci., v. 48, n. 2, p. 477-484, 1991.

RICHARDS, S. L. Spawing and reproductive morphology of Scolelepis squamata (Spionidae: Polychaeta). Can. J. Zool, v. 48, p. 1369-1379, 1970.

ROUSE; G. W.; PLEIJEL, F. Polychaetes. Oxford University Press, Oxford, 354p., 2001.

SANTOS, C. S. G.; MACKIE, A. S. Y. New species of Poecilochaetus Claparède, 1875 (Polychaeta, Spionida, Poecilochaetidae) from Paranaguá Bay, southeastern Brazil. Zootaxa, v. 1790, p. 53-68, 2008.

SARDÁ, R.; MARTIN, D. , 1991.- Comparison between populations of polychaetes from two infralittoral zones of the Western Mediterranean (Balearic Islands and the Strait of Gibrtaltar). IInd International Polychaete Conference. Zoological Museum, Copenhague, Dinamarca, 1989. In, Sistematics, Biology, and Morphology of World Polychaeta, Ophelia (Suppl.), v. 5, p. 701.

SATO-OKOSHI; SUGAWARA, W.; NOMURA, T. Reproduction of the boring polychaete Polydora variegata inhabiting scallops in Abashiri Bay, North Japan. Mar. Biol., v. 104, p. 61-66, 1990. 
SCHOREDER; P. C. HERMANS, C. O. Annelida: Polychaeta. In: Giese, A. C.; PEARSE, J. S. (Eds.). Reproduction of Marine Invertebrates, vol. 3, Acameic Press, New York, 1975.

SEWELL, M. A.; YOUNG, C. M. Temperature limits to fertilization and early development in the tropical sea urchin Echinometra lucunter. J. Exp. Mar. Biol. Ecol., v. 236, p. 291-305, 1999.

SHIMIZU, R. M. Ecologia populacional de Scolelepis squamata (Muller, 1806) (Polychaeta: Spionidae) e Callichurus major (Say, 1818) (Crustacea: Decapoda: Thalassinidae) da Praia de Barequeçaba (São Sebatião, SP). Tese de doutorado, Departamento de Ecologia Geral, Insituto de Biociências, Universidade de São Paulo, 49pp., 1997.

SIMONINI R, PREVEDELLI D. Effects of temperature on two Mediterranean populations of Dinophilus gyrociliatus (Polychaeta: Dinophilidae). I. Effects on life history and sex ratio. J Exp Mar Biol Ecol., v. 291, p. 79-93, 2003a.

SOUTHGATE, T., WILSON, K., CROSS, T. F. AND MYERS, A. A. Recolonisation of a rocky shore in S. W. Ireland following a toxic bloom of the dinoflagellate, Gyrodinium auroleum. J. Mar. Biol. Assoc. U.K.., v. 64, p. 485492, 1984

SOUZA, J. R. B.; BORZONE, C. A. Population dynamics and secondary production of Scolelepis squamata (Polychaeta: Spionidae) in a exposed sandy beach, Southern Brazil. Bull. Mar. Sci., v. 67, p. 221-233, 2000.

STARR, M.; HIMELLMANN, J. H.; THERIAULT, J. C. Direct coupling of marine invertebrate spawning and phytoplankton blooms. Science, v. 247, p. 10711074, 1990.

SUMIDA, P. Y. G., TYLER, P. A., LAMPITT, R. S., GAGE, J. D. Reproduction, dispersal and settlement of the bathyal ophiuroid Ophiocten gracilis in the NE Atlantic Ocean. Mar. Biol., v. 137, p. 623-630, 2000. 
VENTURA C. R. R.; PIRES, D. O. P. Ciclos de vida de invertebrados marinhos. In, Biologia Marinha. Pereira, R. C.; SOARES-GOMES, A. (organizadores). Rio de Janeiro, Interciência, 382 pp., 2002.

WATSON, G. J.; WILLIAMS, M. E.; BENTLEY, M. G. Can synchronous spawning be predicted from environmental parameters? A case study of the lungworm Arenicola marina. Mar. Biol., v. 136, p. 1003-1017, 2000.

WILSON, W. H. Sexual reproductive modes in polychaetes: classification and diversity. Bull. Mar. Sci., v. 48, n. 2, p. 500-516, 1991.

WOODIN, S. A. The importance of structural heterogeneity in a marine infaunal system. In, COSTLOW, D. (Ed.). The ecology of fouling communities. Duke University Marine Laboratory, Beaufort, North Carolina, USA, p. 207-208, 1976.

ZAJAC, R. N. Population ecology of Polydora ligni (Polychaeta: Spionidae). I. Seasonal variation in population characteristics and reproductive activity. Mar. Ecol. Prog. Ser., v. 77, p. 197-206, 1991.

ZEECK, E.; HARDEGE, J. D.; BARTELS-HARDEGE, J. D. Sex pheromones and reproductive isolation in two nereid species, Nereis succinea and Platynereis dumerilli. Mar. Ecol. Prog. Ser., v. 67, p.183-188, 1990. 


\section{CAPÍTULO 5}

Dinâmica populacional de Poecilochaetus australis Nonato, 1963 (Polychaeta: Spionida) na Baía de Guanabara, Rio de Janeiro, Brasil

\section{Introdução}

As espécies da infauna formam uma das mais ricas coleções de espécies no oceano, e talvez da terra. A maioria da diversidade específica dos ecossistemas marinhos consiste de invertebrados que habitam o sedimento (SNELGROVE, 1999). Dentre estes, as poliquetas podem representar até 70\% do total da abundância e biomassa (GRAY, 1974). Devido à natureza de seu hábito locomotor, sedentário ou séssil, são organismos amplamente utilizados na interpretação de padrões espaciais e temporais da macrofauna de substratos inconsolidados sublitorais sujeitos a influências naturais e/ou antropogênicas (JONES; KALY, 1996; GRAY et al., 2002). O estudo da dinâmica populacional de macroinvertebrados torna-se ferramenta valiosa para o monitoramento de ecossistemas costeiros (OMENA; AMARAL, 2000). A flutuação populacional de espécies-chave no ambiente natural pode auxiliar de forma importante a interpretação dos padrões espaço-temporal da fauna sublitoral.

Apesar disso, existe uma grande lacuna de informação da dinâmica populacional da macroinfauna sublitoral em áreas costeiras tropicais no Brasil, e especialmente em locais sujeitos a alta contaminação orgânica. Apesar de muitos esforços já terem sido aplicados na compreensão da dinâmica populacional de espécies bênticas em mares temperados, um reduzido número de estudos vêm sendo realizados em regiões tropicais. Os poucos trabalhos que foram feitos na costa brasileira focaram o estudo da dinâmica populacional de espécies da família Spionidae, presentes em praias arenosas (SANTOS, 1991, 1994; SHIMIZU, 1997; MACCORD, 2005). Até o momento, nenhum trabalho realizado na costa brasileira ainda foi feito tendo como foco espécies bênticas sublitorais que habitam o substrato inconsolidado. Em nível mundial, nenhuma espécie da família Poecilochaetidae teve a dinâmica populacional estudada. 
Conforme foi observado e apresentado no capítulo 3, a espécie Poecilochaetus australis encontra-se presente na Baía de Guanabara em altas densidades em locais sujeitos a um grande aporte orgânico de origem urbana. Face às estratégias reprodutivas encontradas e descritas no capítulo 4, tornase importante investigar se o esforço reprodutivo da espécie traduziu-se na manutenção da população no ambiente estudado. Através do estudo da dinâmica populacional pretende-se buscar respostas ao grau da adaptação da espécie em um local teoricamente inóspito à sobrevivência e/ou manutenção de espécies bênticas, facilitando o entendimento das respostas biológicas ao problema apresentado.

O presente capítulo tem como objetivo verificar a dinâmica populacional de uma população de Poecilochaetus australis Nonato, 1963 habitando uma área de influência de efluentes urbanos, i.e. esgoto doméstico, e verificar se existe variabilidade temporal na população induzida por alguma variável ambiental.

\section{Metodologia}

A amostragem dos indivíduos de Poecilochaetus australis e das variáveis ambientais foram realizadas conforme procedimentos descritos no capítulo 1. O maior diâmetro do $7^{\circ}$ setígero (D7) (MACCORD; AMARAL, 2005) de todos os indivíduos, inclusive larvas planctônicas, foi medido como estimativa de tamanho conforme metodologia empregada no capítulo 4 . Foram confeccionadas tabelas de frequência para representação tabular da distribuição relativa das classes de tamanho de todos os indivíduos mensurados, em todos os meses, apresentando os intervalos de classe de acordo com a fórmula de Sturges através do uso do pacote estatístico BioEstat 4.0 .

Os parâmetros da curva de crescimento de von Bertalanffy (VBGC) foram estimados com base na análise das distribuições de frequência de tamanho através da rotina ELEFAN I (Electronic Length Frequency Analysis), contida no pacote FISAT (GAYANILLO; PAULY, 1997). Para se expressar a oscilação sazonal de crescimento, foi utilizada a função de crescimento modificada (PAULY; GASCHUTZ, 1979). Os valores dos parâmetros de 
crescimento sofrem muitas variações até que se obtenha o melhor ajuste (maior valor de $\mathrm{Rn}$ ).

O modelo de recrutamento foi determinado utilizando-se a rotina ELEFAN I, a partir da curva de crescimento de von Bertalanffy, utilizando-se os dados originais de freqüência de tamanho. A mortalidade total $(Z)$ foi obtida com a curva de captura convertida em tamanho ("Length Converted catch curve").

Foi utilizado o teste $Z$ para a comparação entre as médias amostrais. 0 teste não paramétrico Kruskal-Wallis foi utilizado para verificar se houve diferenças significativas entre as densidades encontradas em cada mês. Foi realizada uma análise de correlação de Spearman $\left(r_{\mathrm{s}}\right)$ a fim de verificar o grau de associação entre a abundância de Poecilochaetus australis e todas as variáveis ambientais analisadas em cada mês (capítulo 1).

\section{Resultados}

\section{Larvas Poecilochaetus (coluna d'água)}

Foram triadas e identificadas 587 larvas de poliqueta, sendo 194 de Poecilochaetus sp.. A maior densidade de larvas foi registrada no mês de agosto de 2005, enquanto que a menor foi observada no mês de fevereiro de 2006 (Figura 5.1.). A largura (D7) das larvas encontradas oscilou entre 0.15 e $0.20 \mathrm{~mm}$.

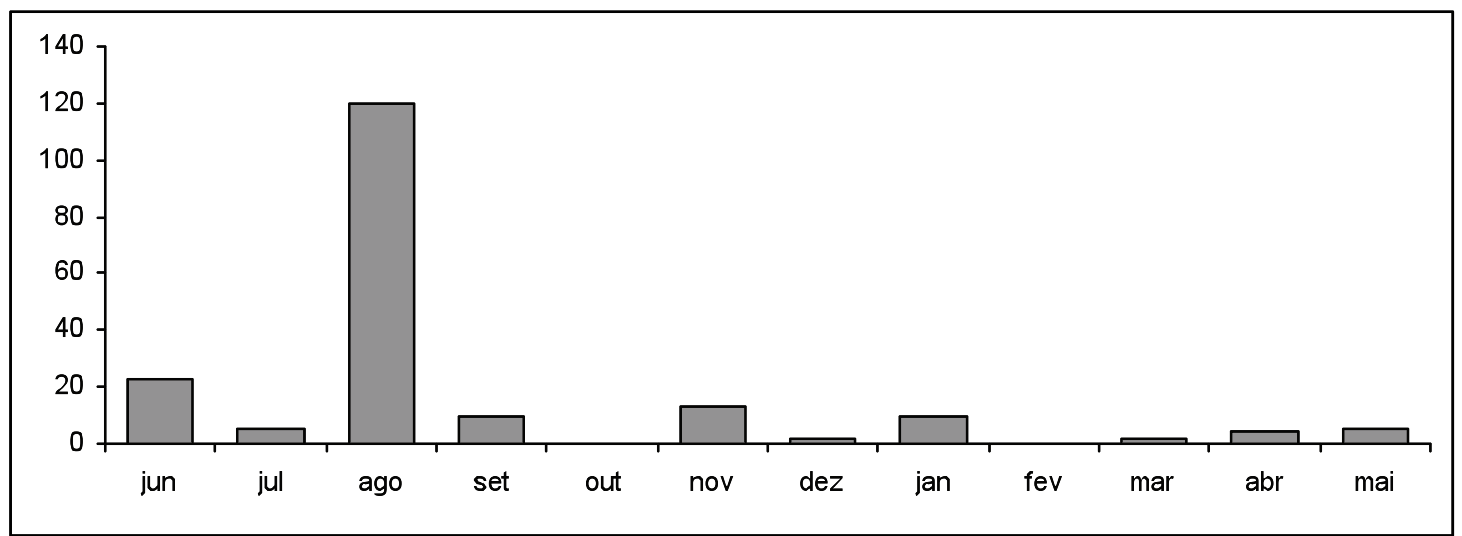

Figura 5.1. Abundância de larvas de Poecilochaetus coletadas entre Junho de 2005 e Maio de 2006. 


\section{Densidade $P$. australis (sedimento)}

No período de 12 meses de coleta foram amostrados e identificados um total de 1575 indivíduos de $P$. australis com média mensal de 43 indivíduos $(\mathrm{dp}=19,64)$. A comparação das médias amostrais apresentou variabilidade significativa $(Z=0,037 ; p<0,05)$. Os meses de agosto de 2005, março de 2006 e maio de 2006 apresentaram as menores abundâncias, enquanto que em janeiro e abril de 2006 foram observadas as maiores, com respectivamente, 21, 16, 21, 82 e 67 indivíduos (Figura 5.2). Apesar de a abundância atingir um pico superior em janeiro de 2006 com 246 indivíduos e um pico inferior em março de 2006 com 48 indivíduos, a variabilidade mensal das réplicas obtidas revelou não haver diferenças significativas da abundância durante o período estudado $(H=10,61, p<0,05)$.

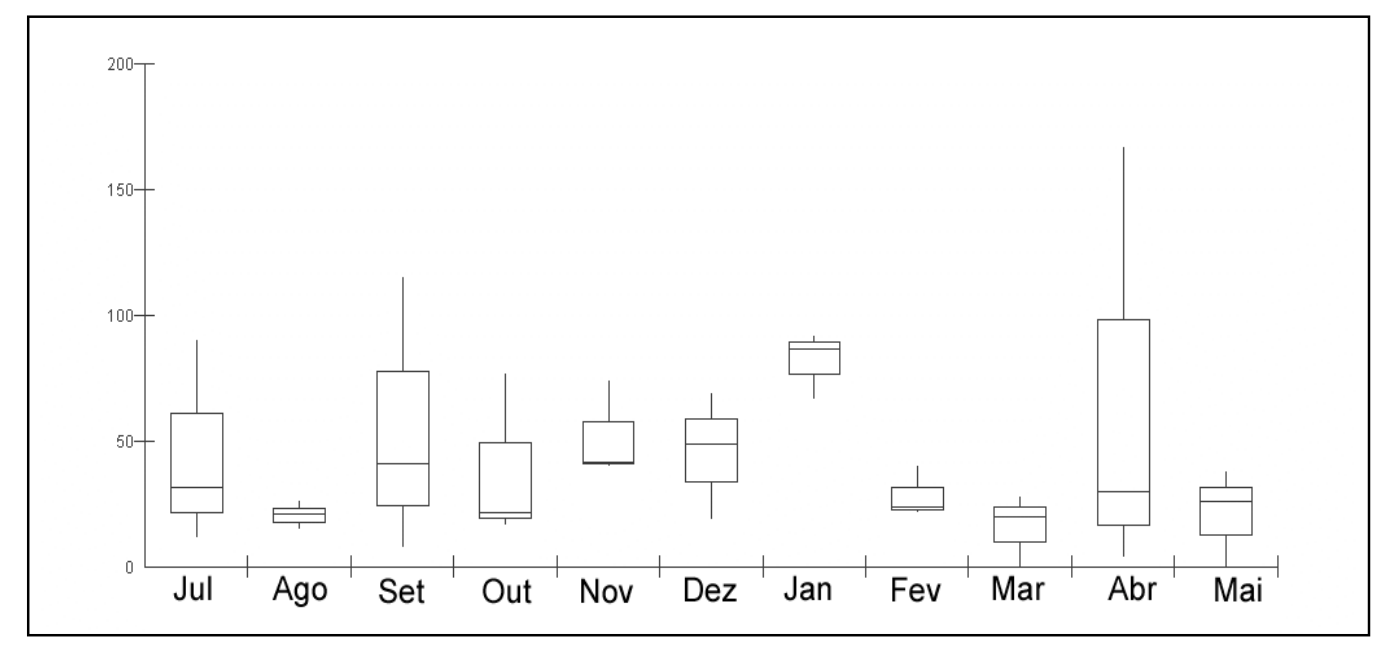

Figura 5.2. Densidade de Poecilochaetus australis encontrada entre julho de 2005 e maio de 2006. Notas: no mês de junho de 2005 não houve coleta de réplicas, amostra única com 130 indivíduos. Caixa indica a $95 \%$ dos dados, barras verticais - superior, maior escore; inferior, menor escore; linhas horizontais da caixa: superior, terceiro quartil; inferior, primeiro quartil; barra horizontal dentro da caixa - mediana. Eixo y = abundância.

Não foi observada nenhuma correlação das variáveis ambientais analisadas coletadas, na coluna d'água e no sedimento, com a variabilidade mensal de $P$. australis no local amostrado (Tabela 5.1.). As variáveis ambientais analisadas revelaram pouca variação, assim como apontado no capítulo 1. Nos meses em que ocorreram diferenças significativas das densidades de $P$. australis não foi possível identificar nenhuma variável que pudesse explicar o aumento do número de indivíduos naquele mês. Os resultados encontrados revelam manutenção da espécie ao longo do ano. 
Tabela 5.1. Resultados obtidos através da correlação de Spearman $\left(r_{s}\right)$ entre a abundância total e as variáveis ambientais da coluna d água e sedimento ao longo do período estudado. Legenda: Cloro a, clorofila a; Feopig., feopigmentos; O.D., oxigênio dissolvido; Sal., salinidade; sup., superfície; Temp., temperatura; Transp. $(m)$, transparência em metros; MOT, matéria orgânica total.

\begin{tabular}{|c|c|c|c|c|c|c|c|c|c|}
\hline & & & & Variáveis & mbientais & oluna d' & & & \\
\hline & & Transp. (m & Sal (super) & Sal (fundo & 「emp (su! & emp (fun & O.D. (sup.) & D. (fundo & \\
\hline$r_{s}$ & & -0.1111 & 0.0365 & -0.0925 & -0.3217 & -0.4807 & -0.0839 & 0.0632 & \\
\hline$t=$ & & -0.3537 & 0.1156 & -0.2939 & -1.0743 & -1.7336 & -0.2663 & 0.2001 & \\
\hline$(p)=$ & & 0.7309 & 0.9103 & 0.7748 & 0.3079 & 0.1136 & 0.7954 & 0.8454 & \\
\hline & & & & Variáve & ambiente & Sedimen & & & \\
\hline & Cloro a & Feopig. & $\%$ granulos & $\%$ areia & $\%$ silte & $\%$ argila & $\% \mathrm{CaCO}^{2}$ & ATP & \% MOT \\
\hline$r_{s}$ & 0.3007 & 0.3357 & -0.0437 & 0.028 & 0.3776 & -0.1678 & 0.1626 & 0.4895 & 0.2732 \\
\hline$t=$ & 0.997 & 1.1268 & -0.1382 & 0.0886 & 1.2896 & -0.5384 & 0.521 & 1.7752 & 0.8981 \\
\hline$(p)=$ & 0.3422 & 0.2861 & 0.8928 & 0.9311 & 0.2261 & 0.6021 & 0.6137 & 0.1062 & 0.3902 \\
\hline
\end{tabular}

\section{Crescimento}

O tamanho médio dos 1575 indivíduos de $P$. australis ficou em 0.71 mm D7 ( $\mathrm{dp}=0.36)$. O maior indivíduo foi uma fêmea com $1.5 \mathrm{~mm}$ coletada em maio de 2006. Os menores indivíduos foram encontrados nas larvas planctônicas com $0.15 \mathrm{~mm}$ e nos recrutas do sedimento com $0.20 \mathrm{~mm}$, estes últimos encontrados em junho, julho, outubro e novembro de 2005 e fevereiro, março e abril de 2006. Através dos indivíduos mensurados foram identificadas 8 classes de tamanho (Tabela 5.2.; Figura 5.3.).

Tabela 5.2. Classes de tamanho identificadas entre os indivíduos mensurados ao longo do ano. Nota: Xi - média observada; Fi - frequência observada.

\begin{tabular}{llcc}
\hline Classes & $\mathrm{Xi}$ & $\mathrm{Fi}$ & Percentual \\
\hline $0.20 \mid-0.38$ & 0.29 & 136 & $21.18 \%$ \\
$0.38 \mid-0.55$ & 0.46 & 128 & $19.94 \%$ \\
$0.55 \mid-0.73$ & 0.64 & 37 & $5.76 \%$ \\
$0.73 \mid-0.90$ & 0.81 & 108 & $16.82 \%$ \\
$0.90 \mid-1.08$ & 0.99 & 96 & $14.95 \%$ \\
$1.08 \mid-1.25$ & 1.16 & 105 & $16.36 \%$ \\
$1.25 \mid-1.43$ & 1.34 & 31 & $4.83 \%$ \\
$1.43-1.60$ & 1.51 & 1 & $0.16 \%$ \\
\hline
\end{tabular}

Na figura 5.4 encontra-se a distribuição das coortes identificadas ao longo dos 12 meses de estudo. Foram observadas 2 cortes em junho de 2005 com modas em $0.20-0.38 \mathrm{~mm}$ (coorte 1 ), menos representativa e outra entre a classe $0.90-1.08 \mathrm{~mm}$ (coorte 5). No mês de julho deste mesmo ano foi identificada uma moda expressiva na classe de tamanho entre 0.38 e $0.55 \mathrm{~mm}$ (coorte 2), provavelmente resultante de intenso recrutamento neste mês. A 
coorte 1 foi novamente observada com pequena expressão na classe $0.55 \mathrm{e}$ $0.73 \mathrm{~mm}$. Em agosto de 2005 foi observado que as classes de tamanho inferiores não foram representativas provavelmente devido ao insucesso dos recrutas neste mês, estando somente presentes as coortes 1 e 2 . No mês de setembro foi identificada uma nova coorte (C3) evidenciada pela classe de tamanho mais inferior que sustentou grande parte da densidade encontrada neste mês, já que demais classes tiveram pouca representatividade. No mês de outubro de 2005 ficou evidenciada nova entrada de recrutas (C4) na população, com mortalidade de cerca de $60 \%$ da coorte 3. No mês de novembro foi verificado o mesmo padrão de recrutamento na população (coorte 5) do mês anterior, porém com baixa mortalidade das coortes C3 e C4, não sendo possível a identificação da coorte 2.

Foi verificado que, em todos os meses, as classes de tamanho inferiores $(0.20-0.55 \mathrm{~mm})$ estiveram presentes, sendo responsáveis por grande parte da densidade encontrada nos meses de coleta, principalmente nos meses de setembro, outubro, novembro e dezembro de 2005. De fato, o padrão de recrutamento ficou evidente na análise da curva de crescimento de Von Bertalanffy que apontou estes meses como os de maiores picos de recrutas na população, seguido de um novo incremento, porém menos expressivo, em abril de 2006 (Figura 5.5.). Não obstante, nos meses seguintes (dezembro de 2005, janeiro e fevereiro de 2006) observou-se que o recrutamento foi menos intenso. A partir de janeiro de 2006, verificou-se então que a manutenção da densidade da população deslocou-se dos grupos de indivíduos menores para aqueles com maior diâmetro do $7^{\circ}$ setígero, ou seja, da classe 0.73 a $1.25 \mathrm{~mm}$.

Pela rotina ELEFAN estimou-se o tamanho assintótico de $P$. australis em $0,97 \mathrm{~mm}$, sendo que $79,14 \%$ dos indivíduos encontram-se neste ou abaixo deste tamanho. Quanto ao crescrimento a constante $\mathrm{K}$ ficou em 1,7. No mês de fevereiro de 2006, o crescimento (WP $=0,05)\left(R n=0,216, \phi^{\prime}=1,22\right)$. A taxa de mortalidade ficou em 3,12. 


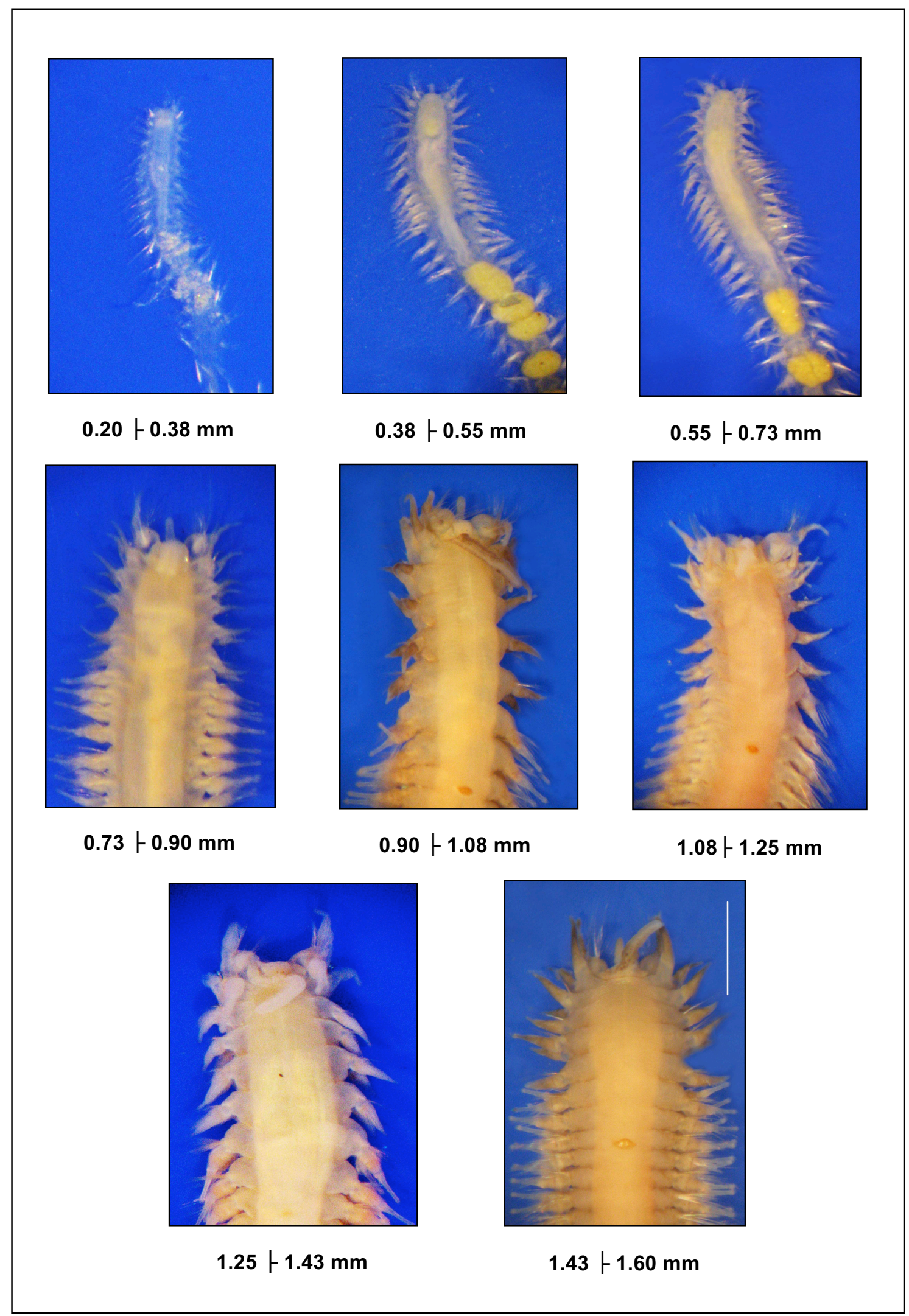

Figura 5.3. Fotografias digitais demonstrando as classes de tamanho de Poecilochaetus australis encontrados no sedimento. Nota: Escala: $1.0 \mathrm{~mm}$. 

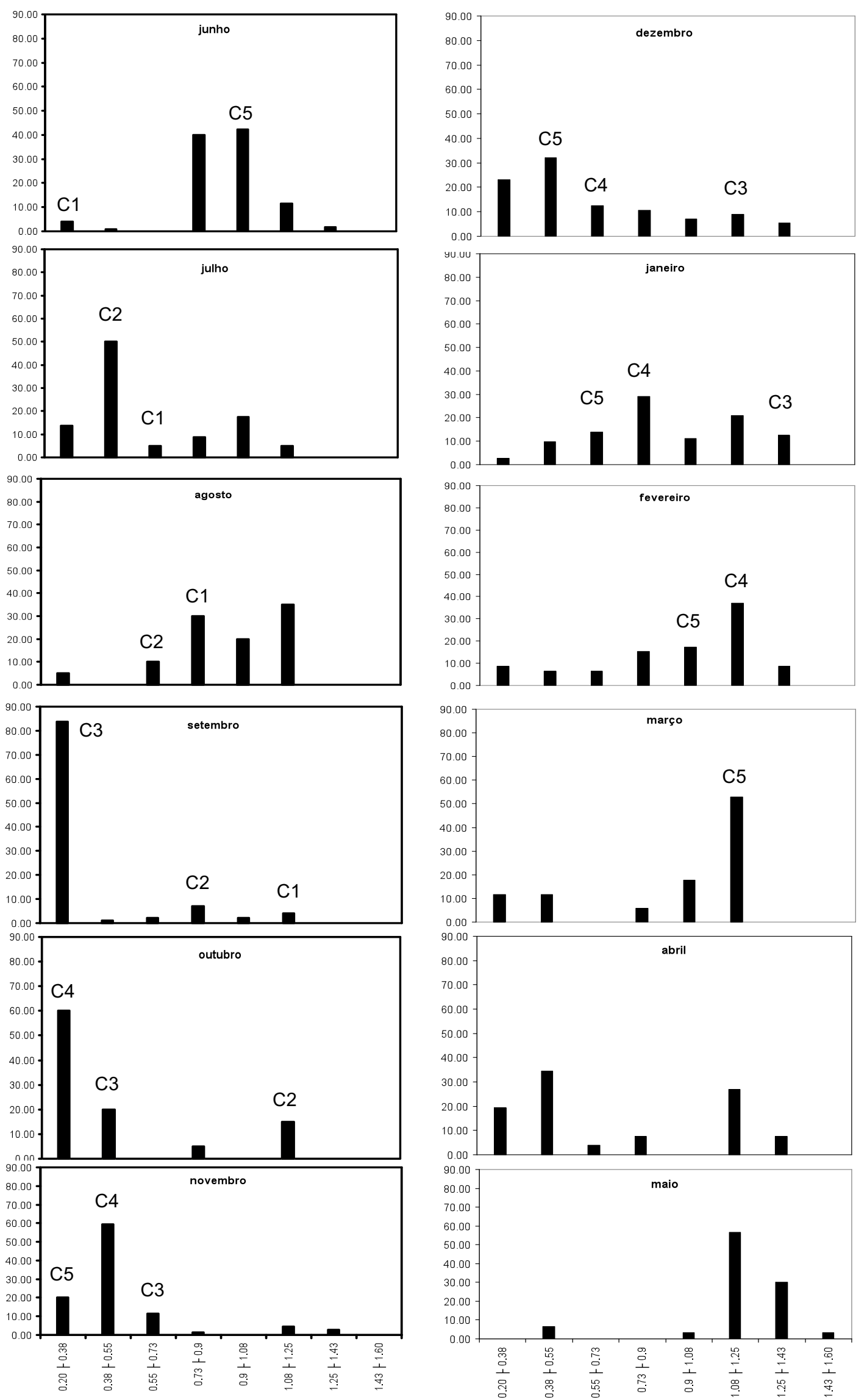

Figura 5.4. Distribuição relativa dos indivíduos de Poecilochaetus australis em classes de tamanho (D 7) na Baía de Guanabara. Nota: eixo y = frequência (\%). C, coorte. 


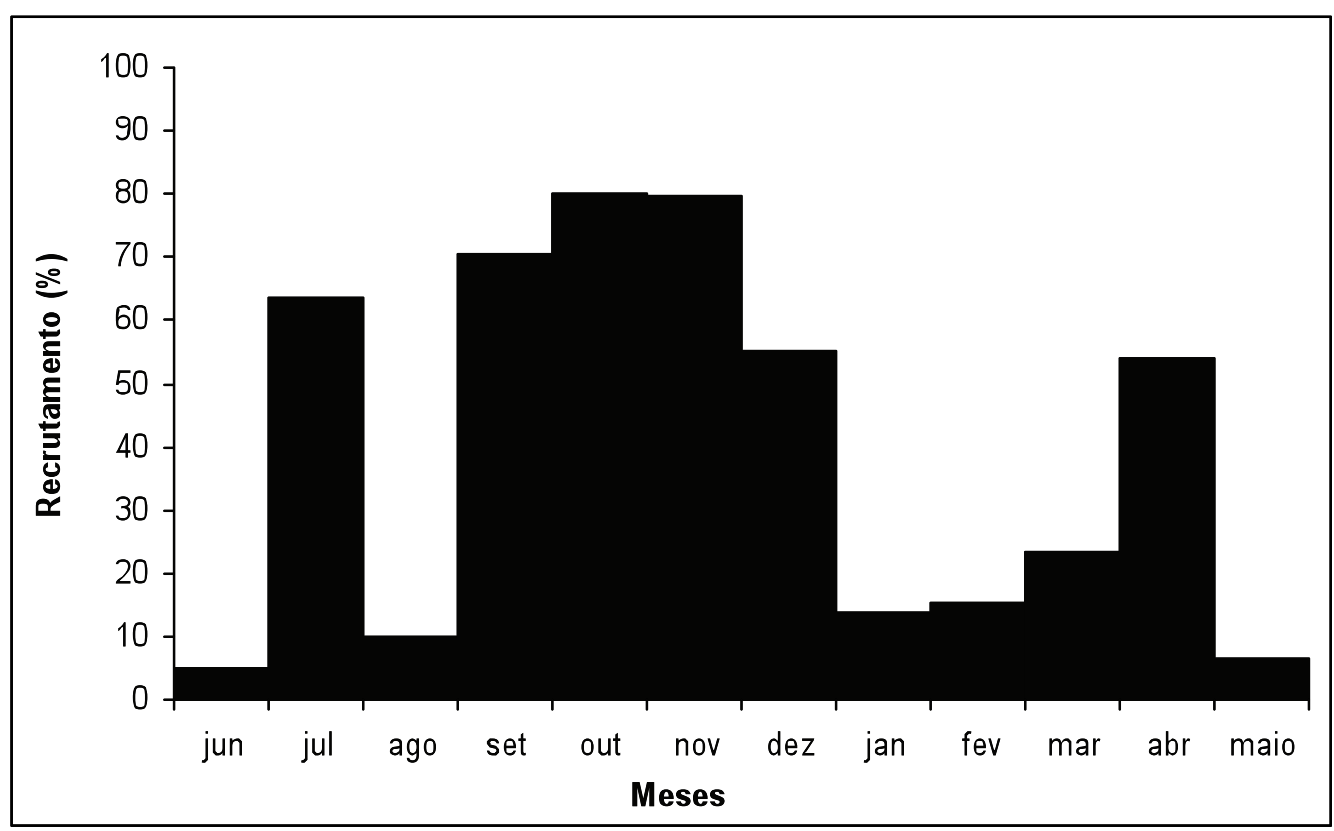

Figura 5.5. Padrão de recrutamento obtido através da curva de crescimento de Von Bertalanffy para Poecilochaetus australis entre junho de 2005 e maio de 2006.

\section{Discussão}

As características do ciclo de vida influenciam a estrutura da comunidade e as associações biológicas presentes no ambiente, determinando padrões de abundância de longo termo. Em um ambiente, qualquer que seja a escala, a distribuição e abundância dos invertebrados marinhos são mantidas por quatro principais fatores: recrutamento larval, que para a maioria das espécies é dependente; do assentamento larval e da metamorfose a qual está relacionada à disponibilidade de larvas competentes, assim como presença de condições propícias no sedimento (OLAFSON, 1994). Para algumas espécies com desenvolvimento direto, o recrutamento larval significa renovação in situ dos juvenis. A migração inclui a emigração e a imigração tanto de juvenis como a movimentação dos adultos. Organismos sésseis, uma vez fixados ao substrato, não são logicamente afetados pela migração. A mortalidade nos diferentes estágios do ciclo de vida pode ser causada por diversos fatores como: falha na fertilização, déficit nutricional (QIAN; CHIA, 1993), predação, competição por espaço e eventos isolados acidentais (e.g. poluição, hidrodinamismo). A reprodução assexuada, em algumas espécies, 
desempenha papel central no controle da abundância e distribuição das espécies bênticas (CHIA, 1989).

Uma aparente instabilidade de curto período pode geralmente resultar em estabilidade em longo prazo dependendo destas características. Algumas peculiaridades como a presença de estágios latentes do ciclo podem tamponar - decréscimo populacional em condições ambientais desfavoráveis (GIANGRANDE, 1994). É de consenso geral que as fases críticas do ciclo de vida de invertebrados marinhos são a ovogênese, o assentamento larval e recrutamento dos juvenis (ARNOUX et al. 1995).

Os resultados da dinâmica populacional de $P$. australis demonstraram que há estabilidade da população ao longo de todo período. Não foi possível identificar nenhuma alteração da abundância da população associada às variáveis ambientais analisadas. A única afirmativa segura que pode ser feita é que as contribuições orgânicas ao ecossistema bêntico no local amostrado na Baía de Guanabara parecem favorecer a reprodução, o desenvolvimento e o recrutamento contínuo das larvas e recrutas de $P$. australis, devido à grande oferta de matéria orgânica, sem que este input limite a sobrevivência da espécie. Apesar de terem sido observadas altas concentrações de matéria orgânica e clorofila a ao longo de todo o ano, as concentrações de oxigênio junto ao fundo foram consideradas normais. A estabilidade das condições ambientais (e.g. salinidade, oxigênio dissolvido) no local amostrado também pode ter facilitado a estratégia reprodutiva da espécie e dos processos de assentamento larval. Também é importante salientar que, apesar de não ter sido mensurado diretamente, o local amostrado é caracteristicamente de baixa energia hidrodinâmica, revelada pela predominância de frações de silte e argila com grãos pobremente selecionados (capítulo 1). Devido ao hábito tubícola, a matriz sedimentar (silte/argila com frações de areia fina), a qual a população está inserida, é totalmente favorável a construção de galerias e tubos pela espécie (NONATO, 1963). As interações biológicas parecem ser mais relevantes do que a influência de fatores físicos na determinação do sucesso da população neste local.

Sabe-se também que adultos residentes influenciam o sucesso dos colonizadores determinados por muitos fatores, dentre eles: modo de alimentação, modificação do sedimento (ALLER; YINGST, 1985) e 
hidrodinamismo (ECKMAN, 1996). A densidade pode ser especialmente determinante no que concerne a influência das espécies como inibidoras ou facilitadoras na colonização das demais espécies (WHITLATCH et al, 1998). Os adultos em princípio atuam como agentes facilitadores em áreas impactadas quando as densidades são baixas e os recursos básicos (i.e. alimento) não são escassos (THRUSH, 1992). A relação adulto-recruta é altamente complexa, regida essencialmente por marcadores bioquímicos que fornecem "pistas" que facilitam aos recrutas identificarem o local mais apto ao desenvolvimento e crescimento da espécie (QIAN; DAHMS, 2006). No caso da população estudada, parece que esta interação está relacionada com a alta densidade desta espécie e a conseqüente manutenção da população no ambiente.

Em relação à disponibilidade de larvas na coluna d'água e sua conseqüência na dinâmica populacional de $P$. australis não foi possível estabelecer correlações confiáveis com os resultados apresentados. A oferta de larvas e recrutas de $P$. australis não pode ser diretamente relacionada, já que existem muitas lacunas dos estudos sobre mortalidade das larvas, recrutas e juvenis, e qual a influência da manutenção da população em longo prazo. A dinâmica populacional da maioria das espécies bênticas é controlada pelo sucesso diferencial dos recrutas, variável extremamente difícil de ser mensurada (GIANGRANDE, 1994; LEVIN, 2006). Muito embora as maiores larvas coletadas na coluna d' água tenham sido do mesmo tamanho (D7) dos recrutas encontrados no sedimento, não é possível afirmar que as maiores contribuições de recrutas estão associadas às maiores densidades de larva na coluna d' água. Durante muito tempo acreditou-se que a larva planctotrófica não recrutaria na população de origem (retroalimentação), mas simplesmente seria exportada para outras populações, aumentando a capacidade de dispersão da espécie (THORSON, 1950). BHAUD (1988) e PECHENICK (1990) em suas revisões apontaram que este paradigma pode ser falso em função do pequeno número de estudos realizados até então, sugerindo que as afirmações são em grande parte especulativas. LEVIN \& BRIDGES (1995) compilaram informações da espécie poecilogônica Streblosppio benedicti e concluíram não haver diferença entre populações com modos planctotróficos e lecitotróficos de desenvolvimento na estabilidade da população. No caso de 
espécies que apresentam somente um modo de desenvolvimento, como no caso de $P$. australis, essa análise fica limitada à interpretação comparativa entre populações isoladas geograficamente.

A presença de larvas planctônicas e a freqüência constante de recrutas no sedimento indicam que o recrutamento é constante e que o controle da densidade populacional possa estar mais ligado à mortalidade pósassentamento do que pelo insucesso na fase de recrutamento. NONATO (1963) apontou que larvas de $P$. australis em estágios mais avançados (estágio nectosoma de Hannerz) são freqüentes na coluna d'água, mas raros no sedimento. Na Baía de Guanabara o resultado encontrado foi diferente, já que os estágios de desenvolvimento mais avançados foram encontrados tanto na coluna d'água, mas principalmente no sedimento, evidenciado pela presença constante de recrutas ao longo de todo ano. CHA \& BHAUD (1992) verificaram que o recrutamento da espécie Eupolymnia nebulosa ocorria após um reconhecimento passivo das características do substrato pela larva planctônica, seguida por uma reorganização ativa da distribuição larval. BHAUD \& GRÉMARE (1988) verificaram que a competência da larva permitia o uso de partículas sedimentares suficientemente finas para serem manipuladas e organizadas dentro da estrutura do tubo. Estes indícios podem apontar para a possibilidade das larvas de Poecilochaetus adiantarem seu desenvolvimento ainda na coluna d'água, otimizando as chances de recrutamento pelo desenvolvimento de estruturas corporais capazes de auxiliarem a construção dos tubos já nos estágios iniciais de vida no sedimento.

Poucos estudos identificaram a disponibilidade larval nos estratos da coluna d'água, principalmente na interface água-sedimento, e sua conseqüência no recrutamento das larvas (QIAN; DAHMS, 2006). O fluxo laminar exerce papel importante no sucesso de assentamento das larvas de espécies bênticas em locais propícios ao desenvolvimento (BUTMAN, 1987). NOZAIS et al. (1997) verificaram que Poecilochaetus serpens é capaz de efetuar deslocamentos relativamente expressivos na coluna d'água, sugerindo que a espécie é capaz de controlar seu deslocamento a fim de adaptar-se às condições mais vantajosas, tanto do ponto de vista da dispersão como do recrutamento, no local mais apropriado para a espécie. Devido à metodologia de coleta de larvas empregada ser pontual, vertical e ter sido realizadas a partir 
de cerca de 1 metro da camada superficial do sedimento, os dados encontrados são incapazes de apontar relação direta da disponibilidade larval com o sucesso dos recrutas no sedimento. Não é possível afirmar, inclusive, que as larvas planctônicas são de origem da própria população estudada na Baía de Guanabara. Esta observação encontra suporte devido à dois fatores combinados: larva teleplânica e carência de informação taxonômica das larvas.

Ainda é difícil demonstrar a correlação entre a ecologia larval, o modo reprodutivo e a dinâmica populacional dos adultos, diminuindo a possibilidade de previsibilidade da tendência da comunidade de introdução de larvas da coluna d'água e da abundância de juvenis recém-assentados (FELLER et al., 1992; BHAUD, 2000; QIAN; DAHMS, 2006; LEVIN, 2006). Em particular, a importância relativa entre os eventos pré e pós-assentamento na dinâmica populacional está ainda em debate. Mais especificamente os processos de pós-assentamento têm sido amplamente discutidos no intuito de explicar as flutuações das espécies e a estrutura espacial da fauna sublitoral.

A estratégia reprodutiva e o padrão da dinâmica populacional encontrado na população estudada da Baía de Guanabara apontam que o ciclo de vida da espécie é bastante eficiente, capaz de manter a população estável por um longo período. Não foi encontrado nenhum resultado que apontasse ciclo de vida do tipo oportunista para a espécie $P$. australis, pelo contrário. Conforme visto no capítulo 4, a população estudada parece investir em poucas fêmeas maduras ao longo do ano, porém com estágio de maturação avançado. Esta estratégia de investimento energético na reprodução pode ser considerada bem sucedida, já que a oscilação das classes de tamanho durante os 12 meses estudados indicam que a população consegue manter indivíduos aptos a se reproduzirem e liberarem gametas na coluna d'água ao mesmo tempo em que não excluem a possibilidade de entrada de novos recrutas. Em mares temperados geralmente é observado um padrão diferente. As variações sazonais são mais marcantes na estratégia do ciclo de vida de invertebrados com larvas planctotróficas em regiões temperadas (GIANGRANDE, 1994; BLAKE, 2006: ECKELBARGER, 2006). LACALLI (1981) já havia verificado que estas espécies podem desenvolver-se com sucesso somente quando há aumento da quantidade de diatomáceas durante a primavera, aumentando os riscos da perda do investimento reprodutivo em caso de falha no recrutamento 
dos juvenis e um possível declínio crítico da população. No caso da população de $P$. australis na Baía de Guanabara não houve grandes oscilações das variáveis ambientais mensuradas, principalmente aquelas que são determinantes para o desenvolvimento larval planctotrófico e o crescimento dos recrutas recém-assentados (e.g. clorofila-a sedimentar e matéria orgânica). Em grande parte do período estudado houve contribuição expressiva de recrutas na abundância de indivíduos, sem que as classes de tamanho maiores fossem excluídas. Tal estratégia torna-se extremamente interessante, já que a população é capaz de manter adultos no ambiente com potencial reprodutivo, ao mesmo tempo em que a espécie otimiza a estabilidade da população através da alta disponibilidade de larvas e recrutas em ambiente propício ao desenvolvimento, crescimento e reprodução. 


\section{Referências bibliográficas:}

ALLER R. C.; YINGST J. Y. Effects of the marine deposit-feeders Heteromastus filiformis (Polychaeta), Macoma balthica (Bivalvia), and Tellina texana (Bivalvia) on averaged sedimentary solute transport, reaction rates, and microbial distributions. J. Mar. Res., v. 43, n. 3, p. 615-645, 1985.

ARNOUX, S.; BHAUD, M.; CAZAUX, C.; CHA, J. H.; DUCHÊNE, J. C.; FRAUNIÉ, P.; MARCANO, G.; MARTIN, D.; NATTERO, M. J. 1995. , NOZAIS, C.; PINEDO, S.; SARDÁ, R. Recruitment in the light of biological physical intercations in coastal Waters: results of PNDR action at the Arago Laboratory in 1994-1995. Vie et Milieu, v. 45, p. 85-105, 1995.

BHAUD, M.; GRÉMARE, A. Larval development of the Terebellid Polychaeta Eupolymnia nebulosa, (Montagu), in the Mediterranean Sea, Zool. Scripta, v. 17, p. 347-356, 1988.

BHAUD; M.; CHA, J. H. Sources de fluctuation et de stabilité dans le cycle de vie d'eupolymnia nebulosa (Polychète) en Méditerranée, Ann. Inst. Océanogr. Paris, v. 68, p. 25-35, 1992.

BHAUD, M. R. The spreading potential of polychaete larvae does not predict adult distributions; consequences for conditions of recruitment. Hydrobiologia, v. $375 / 376$, p. $35-47,1988$.

BHAUD, M. R. Some examples of the contribution of planktonic larval stages to the biology and ecology of polychaetes. Bull. Mar. Sci., v. 67, n. 1, p. 345-358, 2000.

BLAKE, J. A. Spionida. In, Reproductive biology and phylogeny of Annelida. ROUSE, G.; PLEIJEL, F. (Eds.). Chapter 13, Enfeld, NH, USA: Science Publishers. 688p., 2006. 
BUTMAN, C. A. Larval settlement of soft-sediment invertebrates: the spatial scale of pattern explained selection and the emerging role of hydrodynamical. Oceanogr Mar Biol Ann Rev, v. 25, p. 13-165, 1987.

CHIA, F. S. Differential larval settlement of benthic marine invertebrates. Pp. 312. In, Ryland J. S. and Tyler, P. A. (Eds.). Reproduction, Genetics and Distributions of Marine Organisms, Olsen and Olsen, Fredensborg, Denmark. 1989.

ECKMAN, J. E. Closing the larval loop: linking larval ecology to the population dynamics of marine benthic invertebrates, J. Exp. Mar. Biol. and Ecol., v. 200, 207-237, 1996.

ECKELBARGER, K. J. Oogenesis. In, Reproductive biology and phylogeny of Annelida. ROUSE, G.; PLEIJEL, F. (Eds.). Chapter 2, Enfeld, NH, USA: Science Publishers. 688p., 2006.

FELLER, R. J.; STANCYK, S. E.; COULL, B. C.; EDWARDS, D. G. Recruitment of polychaetes and bivalves: long-term assessment of predictability in a softbottom habitat. Mar. Ecol. Prog. Ser., v. 87, p. 227-238, 1992.

GAYANILLO, F. C.; PAULY, DFAO-ICLAR Stock assessment tools (FISAT). Reference Manual. FAO Computerized Information Series (Fisheries), $n^{\circ} .8$. Rome, FAO, 1997.

GIANGRANDE, A. Polychaete reproductive patterns, life cycles and life histories: an overview. Ocean. Mar. Biol. an anual. Rev., v. 35, p. 323-386, 1994.

GRAY, J. S. Animal-sediment relationships. Oceanogr. Mar. Biol. Annu. Rev., v. 12, p. 223-261, 1974. 
GRAY, J. S., WU, R. S.; OR, Y. Y. Effects of hypoxia and organic enrichment on the coastal marine environment. Mar. Ecol. Prog. Ser., v. 238, p. 249-279, 2002.

JONES, G. P.; KALY, U. L. Criteria for selecting marine organisms in biomonitoring studies. In, Scmitt, R. J. \& Osenberg, C. W. (eds.). Detecting Ecological Impacts - Concepts and Apllications in Coastal Habitats: 29-45. Academic Press. San Diego, California, 1996.

LACALLI, T. Annual spawning cycles and planktonic larvae of benthic invertebrates from Passamaquoddy Bay, New Brunswick. Can. J. Zool., v. 59, p. $433440,1981$.

LEVIN, L. A.; BRIDGES, T. S. Pattern and diversity in reproduction and development. Pp. 1-48. In, MCEDWARD, L. (Ed.). Ecology of Marine Invertebrate Larvae CRC Press, Boca Raton, New York, London, Tokyo. p. 1464, 1995.

LEVIN, L. A. 2006. Recent Progress in Understanding Larval Dispersal: New Directions and Digressions. Integ. Comp. Biol., v. 46, p. 282-297, 2006.

MACCORD, F. S. Dinâmica populacional e biologia reprodutiva de duas espécies de Scolelepis (Spionidae) e de Laeonereis acuta (Nereididae) (Annelida: Polychaeta). Tese de doutorado. Instituto de Biociências da Universidade de São Paulo. Departamento de Zoologia. 130p. 2005.

MACCORD, F. S.; AMARAL, A. C. Z. Morphometric analysis of two species of Scolelepsis (Polychaeta: Spionidae). J. Mar. Biol. Assoc. U.K., 84: 769-784, 2005.

NONATO, E. F. Poecilochaetus australis sp. nov. (Annelida, Polychaeta). Neotropica, v. 9, n. 28, p. 17-26, 1963. 
THORSON, G. Reproductive and larval ecology of marine bottom invertebrates. Biol. Rev., v. 25, p. 1-45, 1950.

THRUSH, S. F.; PRIDMORE, R. D.; HEWITT, J. E.; CUMMINGS, V. J. Adult infauna as facilitators of colonization on intertidal sandflats. J. Exp. Mar. Biol. Ecol., v. 159, p. 253-265, 1992.

WHITLATCH; R. B., LOHRER, A. M.; THRUSH, S. F., PRIDMORE, R. D.; HEWITT, J. E.; CUMMINGS, V. J.; ZAJAC, R. N., Scale-dependent benthic recolonization dynamics: life stage-based dispersal and demographic consequences. Hydrobiologia, v. 375/376, p. 217-226, 1998. 
NOZAIS, C.; DUCHÊNE, J-C; BHAUD, M. Control of position in the water column by the larvae of Poecilochaetus serpens, (Polychaeta): the importance of mucus secretion. J. Exp. Mar. Biol. and Ecol., v. 210, p. 91-106, 1997.

OLAFFSON, E. B, PETERSON, C. H, AMBROSE, W. G. Does recruitment limitation structure populations and communities of macroinvertebrates in marine soft sediments? The relative significance of pre and post settlement processes. Oceanogr Mar Biol Ann Rev, v. 32, p. 65-109, 1994.

OMENA E. P.; AMARAL, A. C. Z. Population dynamics and secondary production of Laeonereis acuta (Treadwell, 1923) (Nereididae: Polychaeta). Bull. Mar. Sci., v. 67, n. 1, p. 421-431, 2000.

OMENA, E. P.; AMARAL, A. C. Z. Population dynamics and secondary production of Laeonereis acuta (Treadwell, 1923) (Nereididae: Polychaeta). Bull. Mar. Sci., v. 67, p. 421-431, 2000.

PAULY, D.; GASCHUTZ, G. A simple method for fitting oscillating length growth data, with a program for pocket calculators. International Council Exploration of the Sea, Council Meeting. G:24, Demersal Fish Cttee. 26 p., 1979.

PAULY, D.; GASCHUTZ, G. A simple method for fitting oscillating length growth data, with a program for pocket calculators. International Council Exploration of the Sea, Council Meeting. G:24, Demersal Fish Cttee. 26 p., 1979..

PECHENICK, J. A. On the advantages and disadvantages of larval stages in benthic marine invertebrate life cycles. Mar. Ecol. Prog. Ser., v. 177, p. 269$297,1999$.

QIAN, P. Y.; CHIA, F. S. Larval growth and development as influenced by food limitation in two polychaetes: Capitella sp. and Polydora ligni. J. of Exp. Mar. Biol. and Ecol., v. 166, p. 93-105, 1993. 
QIAN, P-Y; DAHMS, H-U. Larval ecology of the Annelida In, Reproductive biology and phylogeny of Annelida. ROUSE, G.; PLEIJEL, F. (Eds.). Chapter 7, Enfeld, NH, USA: Science Publishers. 688p., 2006.

SANTOS, P. J. P. Morphodynamical in£uence of a temporary freshwater stream on the population dynamics of Scolelepis gaucha (Polychaeta: Spionidae) on a sandy beach in southern Brazil. Bull. Mar. Sci., v. 48, 657-664, $1991 .$.

SANTOS, P. J. P. Population dynamics and production of Scolelepis gaucha (Polychaeta: Spionidae) on the sandy beaches of southern Brazil. Mar. Ecol. Prog. Ser., v. 110, p. 159-165, 1994.

SHIMIZU, R. M. Ecologia populacional de Scolelepis squamata (Muller, 1806) (Polychaeta: Spionidae) e Callichurus major (Say, 1818) (Crustacea: Decapoda: Thalassinidae) da Praia de Barequeçaba (São Sebatião, SP). Tese de doutorado, Departamento de Ecologia Geral, Insituto de Biociências, Universidade de São Paulo, 49pp., 1997.

SANTOS, P. J. P. Morphodynamical influence of a temporary freshwater stream on the population dynamic of Scolelepsis gaucha (Polychaeta: Spionidae) on a sandy beach in Southern Brazil. Bull. Mar. Sci., v. 48, p. 657-664., 1991.

SANTOS, P. J. P. Population dynamic and production of Scolelepis gaucha (Polychaeta: Spionidae) on the sandy beaches of Southern Brazil. Mar. Ecol. Prog. Ser., v. 110, p. 159-165, 1994.

SHIMIZU, R. M. Ecologia populacional de Scolelepis squamata (Muller, 1806) (Polychaeta: Spionidae) e Callichurus major (Say, 1818) (Crustacea: Decapoda: Thalassinidae) da Praia de Barequeçaba (São Sebatião, SP). Tese de doutorado, Departamento de Ecologia Geral, Insituto de Biociências, Universidade de São Paulo, 49pp., 1997.

SNELGROVE, P. V. R. Getting to the Bottom of Marine Biodiversity: Sedimentary Habitats. Bioscience, v. 49, n. 2, p. 129-138, 1999. 


\section{Considerações finais:}

A Baía de Guanabara é considerada um dos ecossistemas costeiros mais poluídos do mundo. A comunidade sublitoral estudada está inserida em uma área da baía com forte influência de esgotos de origem urbana sem tratamento adequado. Entretanto, foi verificado, através da dinâmica temporal da macroinfauna bêntica que, no local estudado, o efeito direto do incremento orgânico não pôde ser considerado crítico na estabilidade da comunidade. As oscilações mensais das variáveis ambientais analisadas foram relativamente pequenas e não resultaram em grandes modificações no padrão estrutural tanto da macroinfauna bêntica como na dinâmica populacional de Poecilochaetus australis. Os processos biológicos parecem ter assumido papel mais relevante nesta estruturação do que os processos físicos e até mesmo da influência dos aportes orgânicos. Apesar das interações inter e intraespecíficas da macroinfauna bêntica sublitoral serem determinantes no entendimento da dinâmica espaço-temporal, o tema ainda recebe poucos esforços de pesquisa na costa brasileira.

O mesmo ponto de vista pode ser dito a respeito da importância dos estudos taxonômicos. A carência de especialistas em grupos zoológicos-chave pode induzir a erros comparativos determinantes na interpretação dos resultados. No caso do presente trabalho, uma correta análise da identidade taxonômica do gênero Poecilochaetus foi fundamental ao direcionamento da estratégia amostral. Um pequeno esforço na correta identificação taxonômica foi suficientemente capaz de identificar duas espécies distintas em regiões consideradas próximas geograficamente e semelhantes do ponto de vista taxonômico.

A ovogênese contínua de $P$. australis no local amostrado demonstra que a espécie não sofre interrupção do período reprodutivo, muito provavelmente devido à ausência de limitações energéticas (i.e. disponibilidade alimentar). Estudos histológicos são necessários para aprofundar o conhecimento da ovogênese. A metodologia empregada também não foi capaz de esclarecer em qual região do corpo do animal se inicia a produção dos ovos. Seria interessante investigar o ciclo gametogênico da espécie, a fim de verificar o investimento reprodutivo com maior precisão e se existem estímulos, 
não mensurados no presente trabalho, que possam indicar a relação de algum composto orgânico com o início da ovogênese. Estudos recentes apontam que o ciclo gametogênico pode estar relacionado com a presença de substâncias orgânicas específicas presentes no sedimento.

A dinâmica populacional de $P$. australis na Baía de Guanabara revelou que a estratégia reprodutiva da espécie favorece a manutenção da população. A população foi capaz de manter simultaneamente adultos com potencial reprodutivo e alta disponibilidade de larvas e recrutas em ambiente propício ao desenvolvimento, crescimento e reprodução da espécie. As respostas da fauna bêntica ao aporte orgânico ainda são pouco conhecidas. As informações obtidas no presente trabalho apontam que, ao contrário de regiões temperadas, não foi encontrada nenhuma variável capaz de direcionar o investimento reprodutivo e o pico de recrutamento para uma determinada época do ano, provavelmente devido à falta de flutuações ambientais marcantes. Entretanto, pesquisas recentes verificaram que o estímulo ao assentamento e recrutamento das espécies está ligado não somente aos teores de matéria orgânica, mas também de enxofre e às concentrações de certos íons que podem induzir o assentamento, afetando o potencial elétrico através da membrana celular. Seria bastante interessante desenvolver estudos experimentais direcionados a responder as preferências da espécie aos estímulos ambientais que refletem no sucesso reprodutivo e no recrutamento da espécie no ambiente. A análise de marcadores lipídicos, proteínas e aminoácidos no sedimento pode fornecer respostas bastante promissoras no entendimento da dinâmica populacional das espécies bênticas e sua influência por estímulos exógenos. 
ANEXOS 
Anexo 1 - Planilha dos táxons identificados dos meses de Junho de 2005 a maio de 2006.

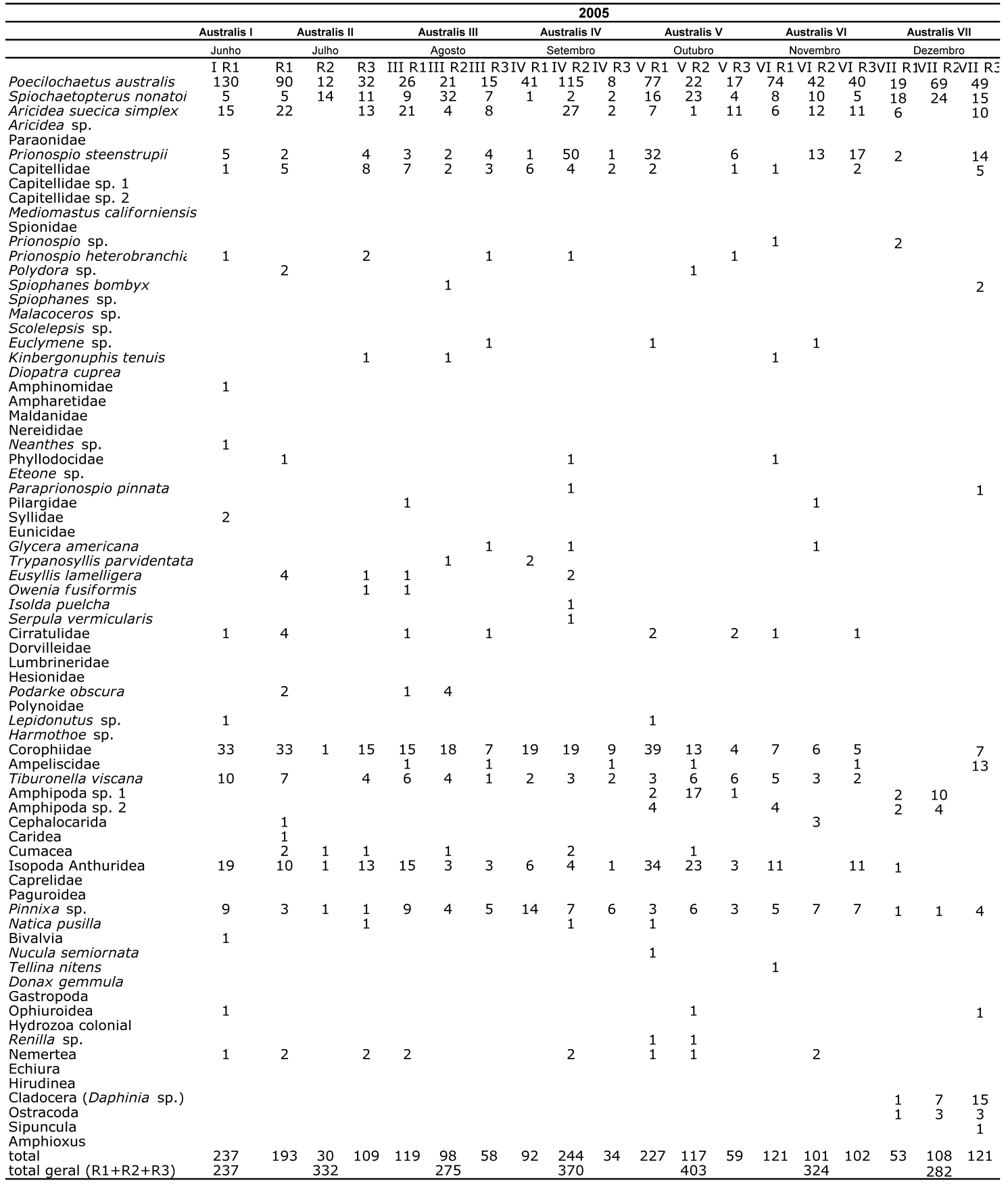


Anexo 1 - Planilha dos táxons identificados dos meses de Junho de 2005 a maio de 2006 (continuação).

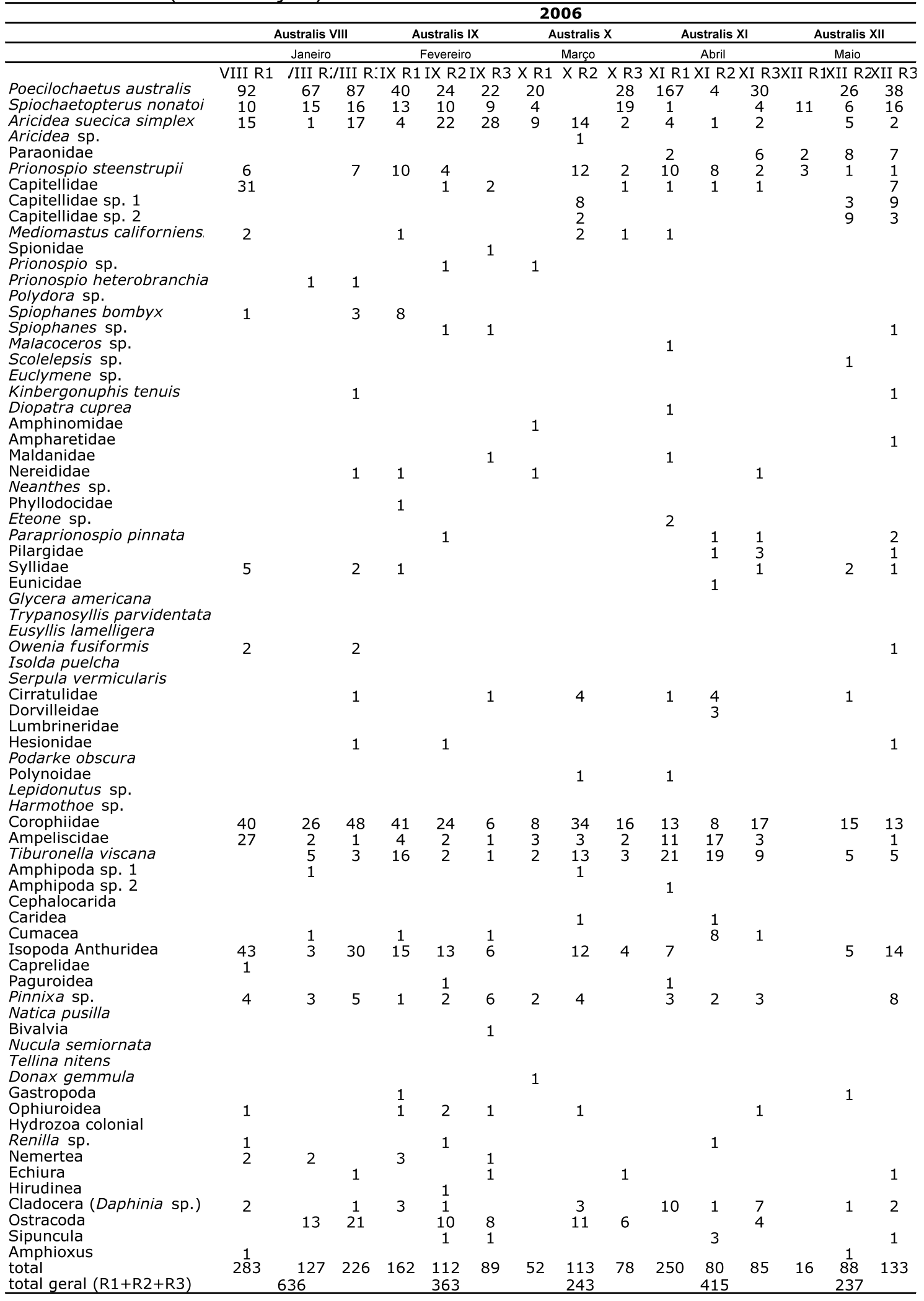


ANEXO 2 - Lista das espécies da macroinfauna bêntica encontradas na Baía de Guanabara durante o período estudado.

\section{Cnidaria}

Hydrozoa

Anthozoa

Octocorallia

Pennatulacea

Renilla sp.

Nemertea

Sipuncula

\section{Echiura}

Annelida

Polychaeta

Scolecida

Capitellidae

Capitellidae sp. 1

Capitellidae sp. 2

Mediomastus californiensis

Maldanidae

Euclymene sp.

Orbiniidae

Paraonidae

Aricidea suecica simplex

Aricidea sp.

Palpata

Aciculata

Eunicida sensu stricto

Dorvilleidae

Eunicidae

Lumbrineridae

Onuphidae

Kinbergonuphis tenuis

Diopatra cuprea

Amphinomida

Amphinomidae

Phyllodocida

Glyceridae

Glycera americana

Goniadidae

Hesionidae

Podarke obscura

Nereididae

Neanthes sp.

Phyllodocidae

Eteone sp.

Pilargidae

Polynoidae

Lepidonutus sp.

Harmothoe sp. 
ANEXO 2 - Lista das espécies da macroinfauna bêntica encontradas na Baía de Guanabara durante o período estudado (continuação).

Syllidae

Trypanosyllis parvidentata

Eusyllis lamelligera

Canalipalpata

Sabellida

Oweniidae

Owenia fusiformis

Serpulidae

Serpula vermicularis

Spionidae

Chaetopteridae

Spiochaetopterus nonatoi

Poecilochaetidae

Poecilochaetus australis

Poecilochaetus perequensis

Spionidae

Polydora sp.

Malacoceros sp.

Scolelepsis sp.

Paraprionospio pinnata

Spiophanes bombyx

Spiophanes sp.

Prionospio steenstrupii

Prionospio heterobranchia

Prionospio sp.

Terebellida

Ampharetidae

Isolda puelcha

Cirratulidae

Hirudinoidea

Arthropoda

Crustacea

Cephalocarida

Branchiopoda

Cladocera

Daphinia sp.

Malacostraca

Eumalacostraca

Eucarida

Decapoda

Caridea

Brachyura

Pinnixa sp.

Anomura

Paguroidea

Peracarida

Cumacea 
ANEXO 2 - Lista das espécies da macroinfauna bêntica encontradas na Baía de Guanabara durante o período estudado (continuação).

Isopoda

Anthuridae

Amphipoda

Corophiidae

Ampeliscidae

Tiburonella viscana

Caprellidae

Amphipoda sp. 1

Amphipoda sp. 2

Maxillipoda

Ostracoda

Mollusca

Gastropoda

Naticidae

Natica pusilla

Bivalvia

Nuculidae

Nucula semiornata

Tellinidae

Tellina nitens

Donacidae

Donax gemmula

Echinodermata

Ophiuroidea

Chordata

Cephalochordata

Amphioxus 